Manuel Antonio Rodríguez-Guitián · Javier Amigo

Vázquez · Íñigo Pulgar Sañudo

\title{
Revisión del encuadre biogeográfico del Parque Natural do Invernadeiro (Ourense, Galicia) a partir de nuevos datos sobre su cubierta vegetal
}

Recibido: 8 xaneiro 2020 / Aceptado: 18 marzo 2020

(C) IBADER- Universidade de Santiago de Compostela 2020

\begin{abstract}
Resumen En este trabajo se realiza una actualización y, en su caso, una reinterpretación de las principales comunidades vegetales presentes dentro de los límites del Parque Natural Invernadeiro (Ourense, NW España). Esta información se utiliza para discutir las afinidades biogeográficas de este espacio natural protegido y el macizo montañoso en el que se integra con respecto a las montañas Galaico-Portuguesas y Galaico-ZamoranoLeonesas, concluyendo que se trata de un territorio "puente" entre ambas áreas montañosas pero que muestra una mayor afinidad por estas últimas. Finalmente, a través de la correlación de las comunidades vegetales identificadas con los tipos de hábitat del Anexo I de CD 92/43/CEE, se evalúa el interés de este Espacio Natural Protegido en el contexto de la Red Europea Natura 2000.
\end{abstract}

Palabras clave vegetación, Macizo Central ourensano, biogeografía.

Reassesment of the biogeographic framework of the Invernadeiro Natural Park (Ourense, Galicia) based on new data on its vegetation cover.

Manuel Antonio Rodríguez-Guitián

Dpto. de Produción Vexetal e Enxeñaría de Proxectos. Escola Politécnica Superior de Enxeñaría. Campus Terra, 27002-Lugo (España).

Tel: 982823103 - Fax: 982823001.

E-mail: manuelantonio.rodriguez@usc.es

Javier Amigo Vázquez

Dpto. de Botánica. Facultade de Farmacia. Campus Vida. 15705-

Santiago de Compostela (A Coruña, España).

Íñigo Pulgar Sañudo

Área de Botánica, Dpto. de Biología Molecular e Ingeniería Bioquímica, Facultad de Ciencias Experimentales, Universidad Pablo de Olavide, Carretera de Utrera, km 1. 41013-Sevilla (España).

https://doi.org/10.15304/rr.id6975
Abstract In this work, an update is made and, where appropriate, a reinterpretation of the main plant communities present within the limits of the Invernadeiro Natural Park (Ourense, NW Spain). This information is used to discuss the biogeographic affinities of this Protected Area, and the mountainous massif in which it is integrated, with respect to the Galician-Portuguese and Galician-Zamorane-Leonese mountains, concluding that it is a "bridge" territory between the two mountainous areas but with greater affinity for the latter. Finally, through the correlation of the plant communities identified with the habitat types listed in Annex I of CD 92/43/EEC, the interest of this Protected Area in the context of the European Natura 2000 Network is evaluated.

Key words plant communities, Macizo Central ourensano, biogeography.

\section{Introducción}

Los estudios sobre vegetación en Galicia, especialmente los que aplican el sistema fitosociológico como método para describir, nombrar y organizar jerárquicamente las comunidades vegetales, se remontan a 1945, año en la que el profesor Bellot se incorporó a la cátedra de Botánica de la USC. Desde entonces hasta el presente, se han llevado a cabo diversos estudios de detalle en territorios concretos, enmarcados en la elaboración de tesis doctorales específicas, a partir de los que se ha publicado una variada serie de trabajos; se puede ver una recopilación y una síntesis de lo conocido de la vegetación gallega hasta finales del pasado siglo en Izco et al. (1999, 2001). Entrados en el siglo XXI, los avances en los estudios de vegetación han sido notables, motivados, en buena medida, por la necesidad de identificación de los hábitats incluidos en el Anexo I de la Directiva Comunitaria 92/43/CEE ("Directiva Hábitats"), puesto que una parte importante de estos, particularmente en el medio terrestre, han sido denominados y definidos siguiendo propuestas emanadas de trabajos fitosociológicos. El conocimiento de su variabilidad y distribución a lo largo de los territorios de los diferentes países miembros de la Unión Europea ha sido 
uno de los pilares sobre los que se ha diseñado e ido desarrollando la Red Natura 2000 a lo largo de más de 25 años.

Una parte de los esfuerzos realizados a raíz de esta iniciativa han culminado con revisiones fitosociológicas a diferentes niveles, tanto europeo (Mucina et al. 2016) como ibérico (Rivas-Martínez 2011, Costa et al. 2012). Sin embargo, a nivel regional, Galicia no se ha visto beneficiada en la misma medida, siendo el número de trabajos fitosociológicos publicados desde la aprobación de dicha Directiva comparativamente menos numeroso y ceñidos, tanto en su temática como en lo geográfico, a ámbitos mucho más concretos (algunos tipos de vegetación litoral: Izco \& Sánchez 1996, 2002; determinadas comunidades de medios especializados: Izco \& al. 2006; Pulgar \& Izco 2007). Dentro de esta tendencia general, se ha registrado un incremento sustancial en la información generada sobre la diversidad fitocenótica de los bosques tanto de Galicia estricta, como del territorio cantábrico occidental (Amigo et al. 2009, Rodríguez-Guitián 2011; Rodríguez-Guitián et al. 2001, 2003, 2005, 2007, 2014, 2017), pudiendo tomarse como ejemplo el extenso trabajo monográfico sobre los hayedos coordinado por Rodríguez-Guitián \& Rigueiro (2011), a pesar de que la superficie ocupada por Fagus sylvatica en Galicia es sensiblemente inferior a la que alcanza en el resto de los territorios pirenaico-cantábricos.

Como acontece en áreas similares en otras partes del Mundo, las áreas de montaña de Galicia, particularmente las de su mitad oriental, mantienen una elevada biodiversidad fitocenótica. Por un lado, sus mayores desniveles altitudinales propician una mayor variedad de ambientes de un neto carácter "montano" frente a las áreas occidentales y septentrionales, más oceánicas y térmicas y por otro, su continuidad ambiental actual y pretérita con el amplio conjunto montañoso cántabro-pirenaico ha propiciado una historia paleoambiental común, responsable de la diferenciación de un conjunto de taxones endémicos de carácter orófilo que imprime un carácter florístico particular a todo este amplio conjunto montañoso. Por estas causas, se escogieron en su momento los macizos de $\mathrm{O}$ Courel (Amigo 1984, Guitián 1984), Trevinca (Ortiz 1986), Ancares (Silva-Pando 1990) y, más tarde, el Xurés (Pulgar 1999) y el conjunto montañoso galaico-asturiano (Rodríguez-Guitián 2004), como escenarios de realización de respectivas tesis doctorales.

A diferencia de los casos indicados, el Macizo Central Ourensano ha permanecido hasta nuestros días como uno de los territorios gallegos con un conocimiento más deficiente acerca de su vegetación, a pesar de tener zonas de notable interés, como las que en el año 1997 fueron incluidas dentro del Parque Natural do Invernadeiro. La escasez de inventarios fitosociológicos que reflejaran detalladamente la composición de sus comunidades vegetales ha sido un vacío de información notable a la hora de recopilar una síntesis de la sintaxonomía de Galicia (Izco et al. 1999, 2001). Aunque existían descripciones de carácter general de la cubierta vegetal de estas montañas (Merino 1902, Iglesias 1929, Rodríguez Bouzo 1929), el primer estudio fitoecológico de cierto detalle realizado en este ámbito montañoso fue el publicado por Castroviejo
(1977) sobre la Sierra de Invernadeiro. Este autor describió una serie de unidades de vegetación mediante listados de especies presentes (en ciertos casos con añadido de unos valores no numéricos de frecuencia). Siendo esa información muy valiosa, no alcanza el nivel de la que proporcionan los inventarios individuales, que sí permiten una comparación con los obtenidos en otros territorios y la valoración de sus relaciones biogeográficas.

Con posterioridad al trabajo de Castroviejo (op. cit.) se desarrolló un estudio de ecología vegetal centrado en el la mitad septentrional del Macizo de Manzaneda-Queixa (Morla 1983), trabajo que no utilizó el método fitosociológico y excluyó los Montes do Invernadeiro. Sin embargo, gran parte de la información contenida en ese trabajo fue aprovechada para la publicación de una revisión del origen y configuración del paisaje vegetal del Macizo Central Ourensano en su conjunto realizada por el autor mencionado (Morla 1985), dentro de la que figura una extensa relación fisionómica de comunidades vegetales con indicación de sus especies características. Poco más tarde, este mismo autor intervino en un trabajo colectivo (CostaTenorio et al. 1990) centrado en la descripción de los abedulares de la Serra de San Mamede, situada a unos 10 $\mathrm{km}$ al NW de O Invernadeiro y con la que comparte grandes afinidades en términos de flora y vegetación. En tiempos más recientes, tan sólo se puede reseñar la breve descripción del conjunto de la vegetación existente en el Parque Natural que se aporta como apartado introductorio en la Guía de la Flora publicada por la Xunta de Galicia, de la que es autor Pulgar (2004).

Teniendo en cuenta los notables avances que en los últimos años se han producido en el conocimiento de la vegetación natural de diversas áreas de montaña del oriente y sur de Galicia (Silva-Pando 1990, Ortiz et al. 1997, Pulgar 1999, Rodríguez Guitián 2004, 2005; Rodríguez Guitián et al. 2005, 2009, 2013, 2014, 2017) y en otras próximas de Asturias (Fernández-Prieto \& Bueno 1996, Díaz González \& Fernández Prieto 1994), SW León (González de Paz 2012) y N de Portugal (Aguiar 2000, Honrado 2003), nos hemos planteado la realización del presente trabajo, que tiene como principal objetivo el aportar nueva información fitosociológica sobre la cubierta vegetal del Parque Natural de Invernadeiro con la intención de reevaluar sus características y determinar sus relaciones biogeográficas con los territorios montañosos de su entorno.

\section{Área de estudio}

El Parque Natural do Invernadeiro fue declarado en 1997 por la Xunta de Galicia (Xunta 1997) y comprende un espacio de 5.722 ha situado al SE de la Comunidad Autónoma de Galicia, en la vertiente meridional del Macizo Central ourensano, perteneciente al ayuntamiento de Vilariño de Conso (Figura 1). Este espacio se articula en torno a dos cuencas fluviales delimitadas por sendos cordales montañosos principales alineados en dirección NW-SE. El pico Seixo (1.706 m), situado fuera de los límites del Parque, es la cumbre de la que derivan estos dos cordales cuyas divisorias se mantienen durante largos 
tramos por encima de los $1.300 \mathrm{~m}$, la Serra da Pena hacia el E-SE y la Serra do Fial das Corzas, que describe un amplio arco, en dirección S-SE. Entre medias de ambas líneas de cumbres se dispone una tercera que, partiendo de las proximidades del Pico Cazcallal $(1.550 \mathrm{~m})$ separa las cuencas de los ríos Ribeira Grande, hacia el NE, y Ribeira Pequena, hacia el SW. Originariamente, estos dos ríos desembocaban en el Río Camba por su margen izquierda, aguas abajo de la localidad de Campobecerros. No obstante, la inauguración en 1974 del Embalse de As Portas distorsionó esta configuración hidrológica de manera que, durante una gran parte del año, ambos ríos vierten sus aguas directamente al volumen de agua estancada de dicho embalse.

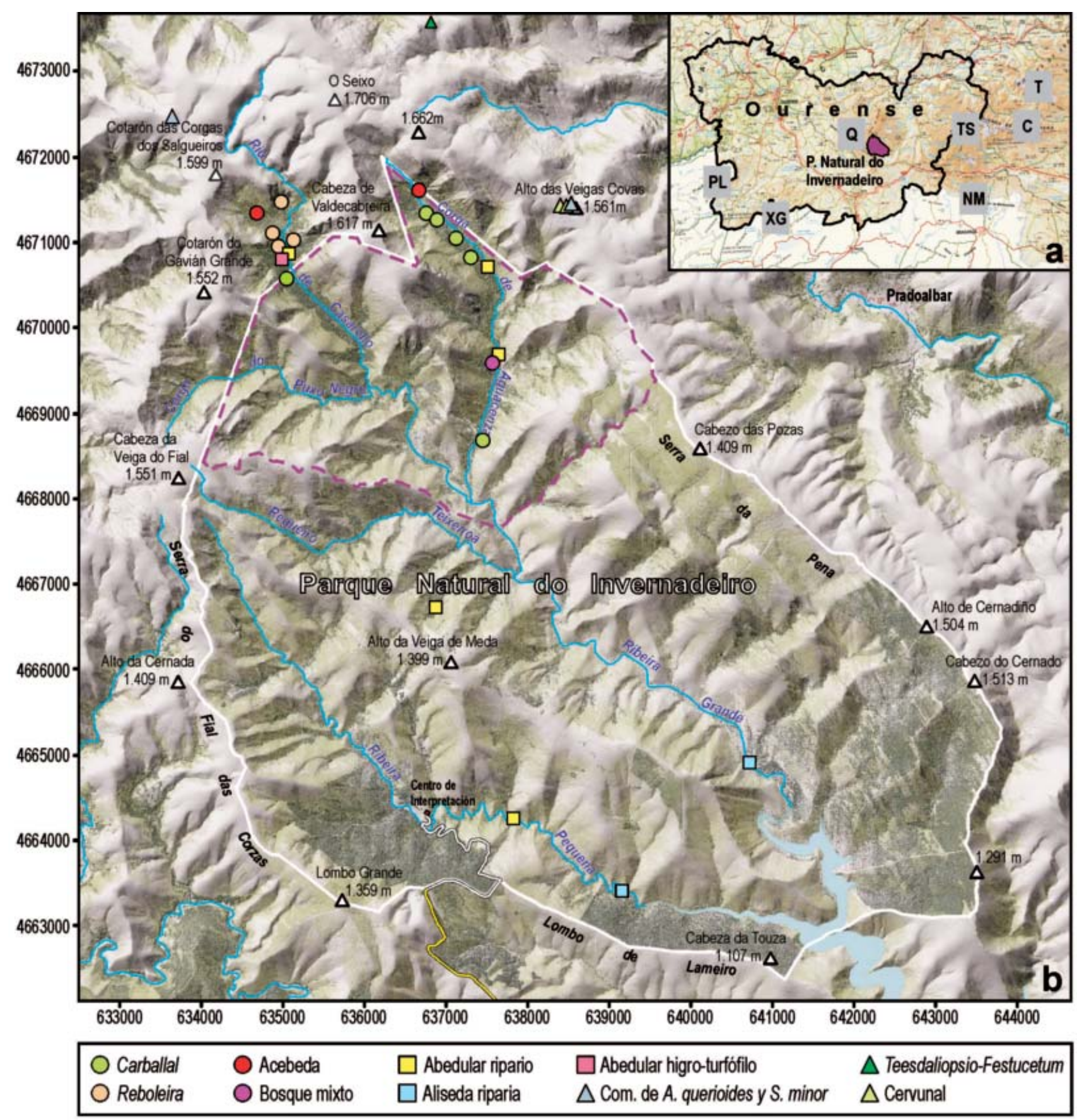

Figura 1.- a: localización del Parque Natural do Invernadeiro. b: delimitación del perímetro del Parque (línea blanca) y de la Zona de reserva (línea morada discontinua), con indicación de los topónimos utilizados en el texto y la situación de los inventarios florísticos incluidos en el Anexo I. Los acrónimos de la figura a, se corresponden con los macizos montañosos indicados en la Tabla 1. Elaboración propia a partir del PORN del parque (XUNTA 2019) y el MDT proporcionado por el visor lberpix (IGN). Datum Coordenadas UTM: ETRS89 
El relieve de este espacio se caracteriza por las formas alomadas de las cumbres y una fuerte impronta del glaciarismo cuaternario en las cabeceras de los valles (Figura 2), más marcada en el sector de nacimiento de los arroyos Puxo Negro, Casarello y Figueiro, en la parte alta de la cuenca de la Ribeira Grande. Las laderas de estas cabeceras muestran unas pendientes elevadas y grandes superficies ocupadas por afloramientos y paredes rocosas, manteniendo las vertientes de umbría manchas de bosques de cierta entidad que constituyen uno de los principales valores de la zona de Reserva del Parque. La cota más baja se encuentra ligeramente por debajo de los $900 \mathrm{~m}$ y coincide con el punto de unión de ambas Ribeiras.
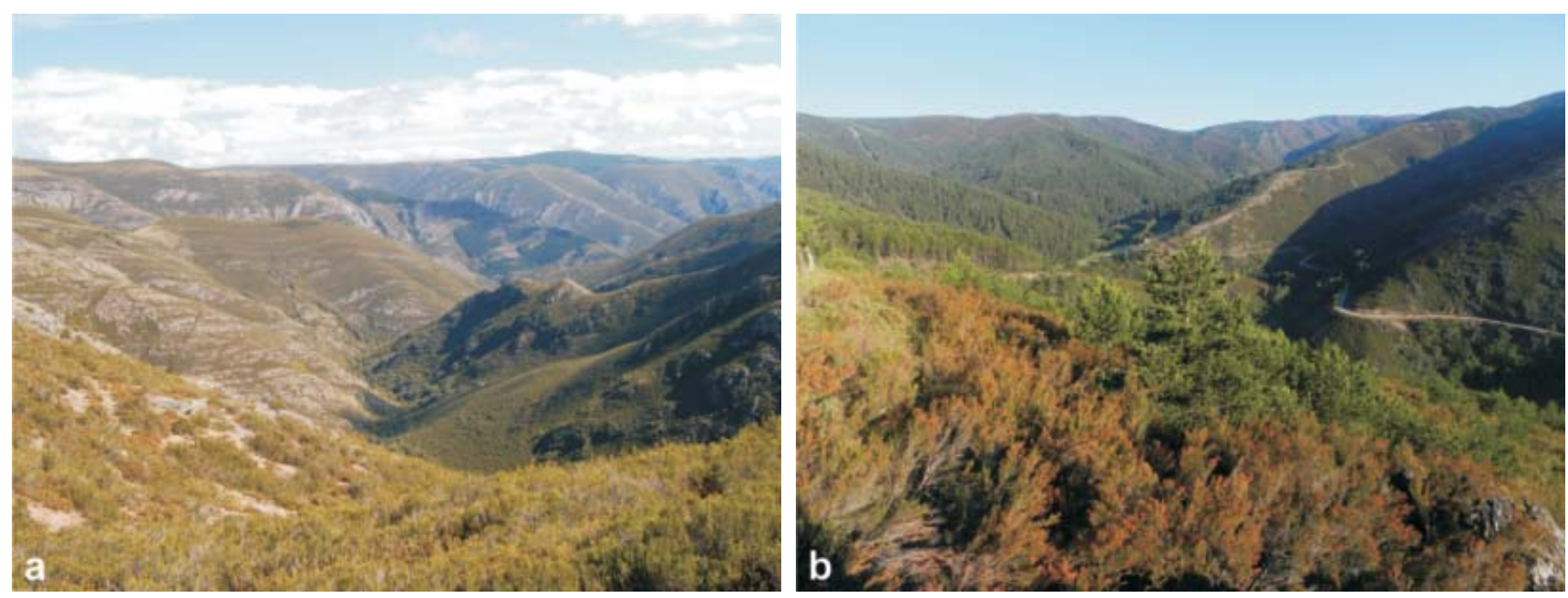

Figura 2.- Vistas generales del Parque Natural de Invernadeiro desde (a) la cabecera de Os Fornallos y (b) el mirador de Lombo da Ribeira Pequena

Los materiales litológicos dominantes son rocas metamórficas silíceas de edad paleozoica (período Ordovícico inferior: 495-425 m.a.). Hacia el sector SW del Parque afloran pizarras, filitas y micacitas del Grupo Nogueira y de las denominadas Pizarras de Luarca, que son reemplazados en el sector central y NE por cuarcitas (cuarcita Armoricana), más resistentes a la erosión (IGME 2019); debido a la composición química de estos tipos de rocas, los suelos presentan un $\mathrm{pH}$ ácido (Castroviejo 1977) y favorecen la instalación de vegetación de carácter netamente acidófilo. En las áreas más escarpadas y que se han visto sometidas de una manera reiterada al fuego, su espesor y grado de evolución son marcadamente inferiores en relación a lo que se observa en las umbrías más protegidas, partes bajas de las vertientes o en rellanos a media ladera y en los fondos de valle.

Desde el punto de vista bioclimático, analizando los escasos registros meteorológicos de que disponía entonces, Castroviejo (1977) concluyó que los Montes do Invernadeiro se encuadrarían dentro de la Región Mediterránea, al presentar un verano caluroso y seco, con déficit de precipitación de 2 meses; sin embargo, ya resaltaba una importante influencia atlántica-oceánica, que otorgaba al territorio una interesante ambigüedad evidenciada en la condición transicional de su cubierta vegetal. Algo más de 4 décadas después, la aplicación de la clasificación bioclimática de Rivas-Martínez (2007) a las estaciones de "Invernadeiro" y "Cabeza de Manzaneda" (Figura 3) revela que la primera de ellas, presentaría, por muy poco desde el punto de vista matemático, un mes estival de sequía, mientras que la segunda carecería de ellos. Por esta razón, habría que admitir que el Parque tendría condiciones bioclimáticas de submediterraneaidad en su zona inferior, por debajo de los $1.050 \mathrm{~m}$ de altitud aproximadamente, mientras que el resto, su mayor parte, se encuadraría dentro del macroclima templado típico. Esta situación concuerda con la cartografía de tipos de macroclimas publicada por Rodríguez-Guitián \& RamilRego (2007: Figura 15). No obstante, hay que recordar el papel que se atribuye al suelo, en tanto que reservorio de agua para las plantas, en la clasificación bioclimática comentada a la hora de establecer el grado de sequía estival que puede experimentarse en una localidad determinada. En este sentido, territorios caracterizados por un escaso desarrollo edáfico podrían, en el plano teórico, no mostrar sequía o ser esta lo suficientemente corta como para no alcanzar las condiciones de mediterraneidad y, sin embargo, en la práctica, estar su vegetación sometida a un estrés hídrico estival más o menos considerable. La presencia de determinadas especies y comunidades vegetales en este parque natural parecen indicar que esta última situación acontece, al menos, en sus niveles inferiores, por lo que habría de considerarse que sus cotas bajas presentan condiciones de submediterraneidad a efectos de su vegetación. De todas maneras, un macroclima típicamente mediterráneo no se presenta en esta parte de Galicia hasta alcanzar el fondo de valle del Támega, aguas abajo de la población de Verín. 

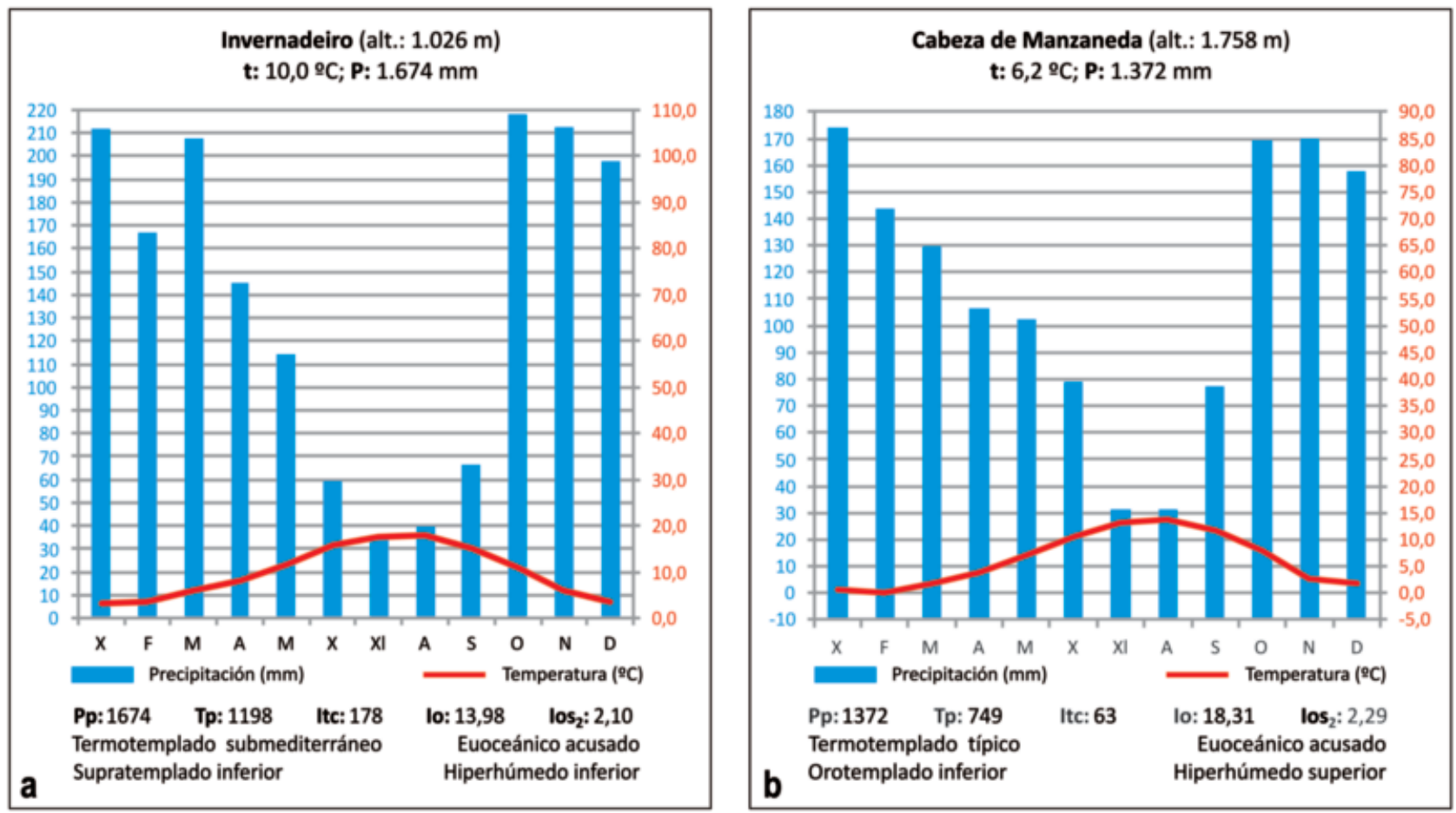

Figura 3.- Diagramas ombrotérmicos y diagnosis bioclimática según la clasificación de Rivas-Martínez (2007) de las estaciones de Invernadeiro y Cabeza de Manzaneda. Fuente: elaboración propia a partir de datos suministrados por Meteogalicia (https://www.meteogalicia.gal [acceso: octubre 2019])

Desde el punto de vista termotípico, la práctica totalidad del territorio del Parque se debe adscribir al piso bioclimático supratemplado, aunque a lo largo de las cumbres principales se puedan presentar puntualmente comunidades cuyo óptimo se encuentra en el piso orotemplado (orotemplado topográfico) congruentes con la existencia de fenómenos de crioturbación asociados al frío invernal y la innivación. La ausencia de un piso bioclimático mesotemplado está avalada, además de por la información climática disponible, por la escasa significación que alcanza en el territorio la flora de carácter termófilo (Rodríguez Guitián \& Ramil-Rego 2007). Los valores obtenidos para el índice ombrotérmico en las dos estaciones utilizadas arrojan valores dentro de tipo hiperhúmedo, en su horizonte inferior en el caso de la estación de Invernadeiro y en el superior para la de Cabeza de Manzaneda.

Más controvertida ha sido la asignación biogeográfica de este enclave, precisamente por ese carácter ambiguo, que podemos simplificar, siguiendo a Castroviejo (1977), en "atlántico y mediterráneo a la vez". A lo largo de las diferentes aproximaciones corológicas que se han propuesto para la Península Ibérica, el área montañosa comprendida dentro del Parque fue adscrita a diferentes unidades: al sector Orensano-Sanabriense, Región Mediterránea (Rivas-Martínez 1979), al sector JuresianoQueixense, Región Eurosiberiana (Rivas-Martínez et al. 1984), al sector Juresiano, Región Eurosiberiana (RivasMartínez et al. 2002), al sector Queixense, Región Eurosiberiana (Rodríguez-Guitián \& Ramil-Rego (2008) o, más recientemente, al sector Bierzo-Sanabria, Región
Mediterránea (Rivas-Martínez et al. 2017). Estos sucesivos cambios nomenclaturales y de adscripción a regiones biogeográficas evidenciarían, en parte, la ambigüedad florística y vegetacional del territorio, pero también responderían a la falta de información detallada sobre la que afianzar una tipología biogeográfica de aceptación general. Independientemente de la opción que se pueda escoger (en este trabajo, la propuesta por RodríguezGuitián \& Ramil-Rego 2008), parece claro que se trata de un territorio transicional en el que es posible encontrar flora y comunidades vegetales que representan las dos principales unidades biogeográficas a nivel de Región en las que se reparte la Península Ibérica.

\section{Metodología}

El trabajo se ha basado en la recogida de inventarios representativos de diversos ambientes, particularmente de los existentes en los valles de cabecera de su red fluvial, que constituyen la Zona de Reserva de este Espacio Natural Protegido, habiéndose prestado especial interés en las masas de bosque, puesto que recogen las etapas más maduras del dinamismo de la vegetación y suelen ser las más relevantes para aportar información biogeográfica de un territorio. Además de ellos, hemos estudiado o confirmado la presencia de otros tipos de comunidades, leñosas o herbáceas, que consideramos relevantes para comprender la diversidad fitocenótica de este Parque Natural. Por las razones apuntadas al expresar el objetivo del presente trabajo, se han dejado fuera de este estudio las 
superficies forestales cubiertas por las repoblaciones de coníferas. Los trabajos de campo fueron realizados previa obtención del correspondiente permiso de investigación expedido por el Servizo de Patrimonio Natural de Ourense (Consellería de Medio Ambiente, Territorio e Vivenda, Xunta de Galicia).

Los inventarios de vegetación han sido elaborados con la metodología fitosociológica sigmatista (Braun-Blanquet 1979) y se presentan en el Anexo I figura al final del trabajo. La nomenclatura de las especies vegetales ha seguido principalmente los criterios de Flora iberica (Castroviejo 1986-2018); hacen excepción las Poaceae, no incluidas aún en esta obra y para las que hemos seguido la propuesta por Romero Zarco (2015), y Genista florida subsp. polygaliphylla, para la que hemos seguido a Costa et al. (2012). Así mismo, hemos asimilado a los taxones Hedera hibernica (G. Kirchn.) Bean y Lonicera periclymenum subsp. hispanica (Boiss. \& Reut.) Nyman las referencias a Hedera helix L. y Lonicera periclymenum L. realizadas por diversos autores. Para cada una de las unidades identificadas, se describe su composición florística, las características ecológicas de los biotopos donde crecen y se asigna una categoría sintaxonómica. Los inventarios fitosociológicos fueron utilizados para hacer comparaciones con la información disponible (publicada o inédita) en territorios vecinos y sustentan los resultados expuestos en el presente estudio.

\section{Resultados y discusión}

En la Figura 1 se muestra la localización de los inventarios de vegetación realizados durante los trabajos de campo efectuados dentro del área de trabajo. Comentaremos a continuación las principales comunidades identificadas, presentando sus principales características ecológicas y, en su caso, las asignaciones fitosociológicas propuestas.

\section{Vegetación arbórea}

Empezamos por los robledales, ya que según las reconstrucciones paleoambientales disponibles para el conjunto montañoso dentro del que se inscribe el Parque Natural (Maldonado 1994, Santos et al. 2000, Santos 2004), debieron de constituir el tipo principal de bosque con anterioridad a la generalización de la actividad humana en la mayor parte de este territorio, aunque el papel que pudiera haber correspondido a cada una de las dos especies de robles mayoritarias (Quercus robur y $Q$. pyrenaica) es todavía una incógnita. En todo caso, su extensión en el momento actual es sumamente reducida en relación a la potencialidad que se les puede atribuir $y$, aunque la historia paleoambiental de $O$ Invernadeiro se conoce de manera parcial, no parece discutible que las actividades humanas deforestadoras hayan sido la principal causa de esta situación. Su antigüedad e intensidad ya fue advertida por diversos autores (Merino 1902, Iglesias 1929, Rodríguez Bouzo 1929), incluido el mismo Castroviejo (1977). Por suerte, las plantaciones forestales realizadas por la empresa Papelera Española S.A., última propietaria de los Montes do Invernadeiro antes de su adquisición por la Administración Autonómica (Paül Carril 2011), no llegaron a afectar a las laderas más abruptas y sombrías, en las que subsistieron importantes masas de arbolado nativo.

\section{Bosques de roble común (Quercus robur)}

Los bosques dominados por Quercus robur fueron considerados conjuntamente con los abedulares por Castroviejo (1977). En nuestro trabajo de campo hemos podido estudiar robledales de cierta extensión, algunos con características estructurales próximas a un teórico estado de madurez, aunque con evidencias de antiguos aprovechamientos madereros (tocones). En todo caso, llama la atención la presencia de amplios rodales dominados por ejemplares de Quercus robur con tallas superiores a los $20 \mathrm{~m}$ de altura y diámetros normales de más de $1,5 \mathrm{~m}$, dimensiones que raramente se encuentran en otros lugares de Galicia con condiciones ambientales similares (Figura 4a). En ellos destaca, aparte del dominio claro del carballo en el dosel, la presencia constante del escornabois (Sorbus aucuparia) en el nivel arbóreo y de la arandeira (Vaccinium myrtillus), junto a diversas plantas acidófilas, como Luzula sylvatica, Teucrium scorodonia, Avenella flexuosa, Galium rotundifolium o Melampyrum pratense, en el sotobosque; tampoco suelen faltar otras especies leñosas, como Betula pubescens, Erica arborea, Corylus avellana o Genista polygaliphylla, y lianas, como Hedera hibernica y Lonicera hispanica (Anexo I: Tabla 1).

La elevada proporción de acebo presente en algunos de los inventarios de robledales recogidos (Anexo I: Tabla 1, inv. 3 y 5) es consecuencia, muy posiblemente, de las entresacas y cortas selectivas que padecieron estos bosques hace más de medio siglo. La extracción de los ejemplares maderables (robles principalmente) habría permitido la proliferación de los pies de llex aquifolium preexistentes en el sotobosque, de los que hoy día se pueden ver individuos de altura considerable, pero siempre menor que la de los carballos dominantes (árboles "emergentes"). En otros casos, los robledales presentan un crecimiento mucho más uniforme, sin diferencias de edad apreciables (Figura 4b) y, en ocasiones, colonizan vertientes cubiertas por canchales, presentando en estos casos una estructura más abierta y una mayor luminosidad, que afectan a la composición florística tanto de su nivel superior, por la entrada de pies de Quercus pyrenaica o de sus híbridos con Q. robur, como de su sotobosque (Anexo I: Tabla 1, inv. 7), en el que se observa la penetración de taxones de carácter heliófilo, como Ceratocapnos claviculata, Lamium maculatum o Sedum hirsutum, aunque se mantiene la flora de carácter nemoral (Avenella flexuosa, Hyacinthoides non-scripta, Stellaria holostea, Vaccinium myrtillus).

Un detalle relevante en la composición del estrato arbóreo de los robledales es que los ejemplares estudiados se identificaron como Quercus robur y, en algunos casos, se encontraron ejemplares de $Q$. x andegavensis (híbrido de $Q$. robur y $Q$. pyrenaica); no fue visto ningún ejemplar de $Q$. petraea, especie que fue citada como de aparición esporádica por Castroviejo (op. cit.), lo cual no debe interpretarse más que como que su existencia sigue esperando confirmación. Tampoco ha sido detectada la 

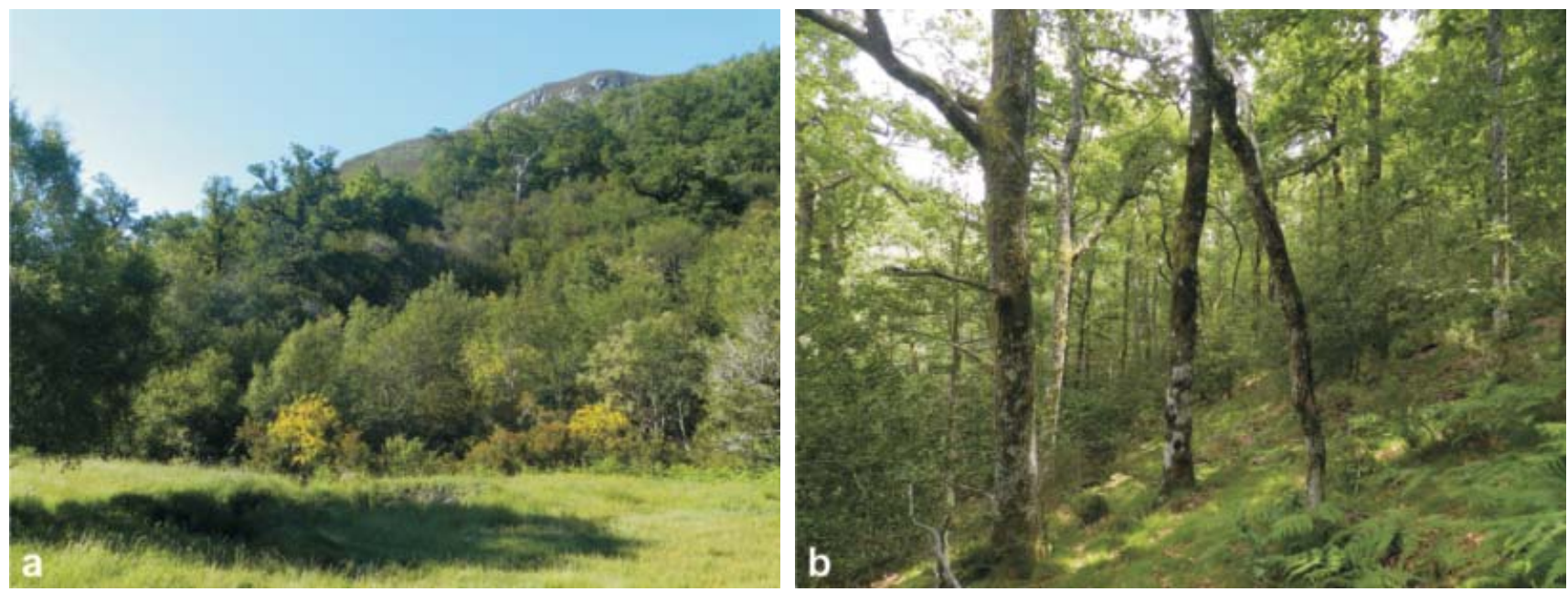

Figura 4.- Aspecto exterior de un robledal de Quercus robur en O Figueiro (a) y vista interior de otro situado en la Mallada dos Castiñeiros (b)

presencia de Quercus orocantabrica, cuya existencia en Galicia parece restringirse a ejemplares achaparrados en pedreras y áreas rocosas marginales del piso orotemplado o niveles superiores del supratemplado (Rodríguez Guitián et al. 2013, 2014); con ese hábito alcanzaría su límite occidental en la Serra de Queixa (Díaz González \& Vázquez 2004).

Castroviejo (1977: pág. 67) dio a entender en su publicación que este tipo de bosques formaba en Invernadeiro un mosaico con abedulares conformando una suerte de "bosque mixto" como consecuencia de "la alteración del estado natural [...] y el carácter fuertemente oceánico del clima". Según nuestras apreciaciones, algunas masas de robledal existentes en $\mathrm{O}$ Invernadeiro están coronadas por una cintura más o menos desarrollada de bosques secundarios ricos en abedul, pero, en contra de lo expresado por Castroviejo (op. cit.), no es habitual que estos dos tipos de bosque se encuentren mezclados. De esta afirmación se exceptúan los bosques higro-turfófilos de abedul que se describirán más adelante.

La catalogación fitosociológica de estos bosques no está exenta de debate, pero con la información manejada, consideramos como única alternativa su adscripción a la Vaccinio myrtilli-Quercetum roboris, la misma asignación que realizó Castroviejo (op. cit.), aunque en aquel momento había menos datos para contrastar; también es la opción que manejaron Morla $(1983,1985)$ y Pulgar (2004), aunque ninguno de estos autores llegó publicar inventarios de estos bosques. Posteriormente, Rivas-Martínez (2011) propuso una interpretación restrictiva de la Vaccinio-Quercetum roboris, reservando su ámbito geográfico a las porciones elevadas de las sierras de Peneda y Gerês, limítrofes entre Portugal y Galicia (territorio "Juresiano"). Siguiendo esa misma lógica, las propuestas de Díaz \& Penas (2017) incluyeron el Macizo Central ourensano dentro de un "sector Bierzo-Sanabria", integrado en una Provincia Mediterránea Ibérica Occidental y, por tanto, en la Región Mediterránea, sin ofrecer ninguna alternativa sintaxonómica para los bosques de Quercus robur que se puedan encontrar en esta unidad biogeográfica, contradiciendo las evidencias ya apuntadas por Castroviejo (1977) y corroboradas en este trabajo; solamente hacen mención a una asociación dominada por Quercus orocantabrica, de la que no han sido publicados inventarios fitosociológicos.

A la vista de los inventarios que se muestran en la Tabla 1 (Anexo I), creemos que la Vaccinio myrtilli-Quercetum roboris, descrita originalmente por Pinto da Silva et al. (1950) de la Serra do Gerês, es una asociación más extendida por el territorio gallego de lo que atribuyeron Rivas-Martínez (2011) y Díaz \& Penas (2017) y probablemente los robledales del Parque Natural do Invernadeiro sean unas de sus más orientales y mejores muestras.

\section{Bosques de rebolo (Quercus pyrenaica)}

Las reboleiras o melojares son un tipo de bosque menos sombrío y húmedo que los robledales porque su árbol característico presenta una foliación más tardía y tienden a ocupar orientaciones más insoladas y, consecuentemente, secas, en laderas de solana o posiciones edafoxerófilas. Castroviejo (1977) resaltó, al hablar del dinamismo de la vegetación de O Invernadeiro, que Quercus pyrenaica mostraba mayor pujanza que el carballo, situación que justificaba como consecuencia de la presión antrópica y, especialmente, de los incendios, que favorecerían la regeneración y expansión del primero a expensas del segundo. Nuestro análisis de la dinámica actual de la vegetación no resulta tan rotundo por dos causas. En primer lugar, es evidente que $Q$. robur no se restringe únicamente a las laderas umbrosas, sino que se integra en otros tipos de bosques, entre los que se encuentran los propios bosques helio-xerófilos dominados por Q. pyrenaica que muestran un cierto grado de madurez (Anexo I: Tabla 1, inv. 9-10); en segundo, si bien se puede admitir que la especie arbórea que recoloniza las vertientes de solana es mayoritariamente $Q$. pyrenaica, muchas laderas umbrías deforestadas que mantienen una cierta profundidad edáfica 

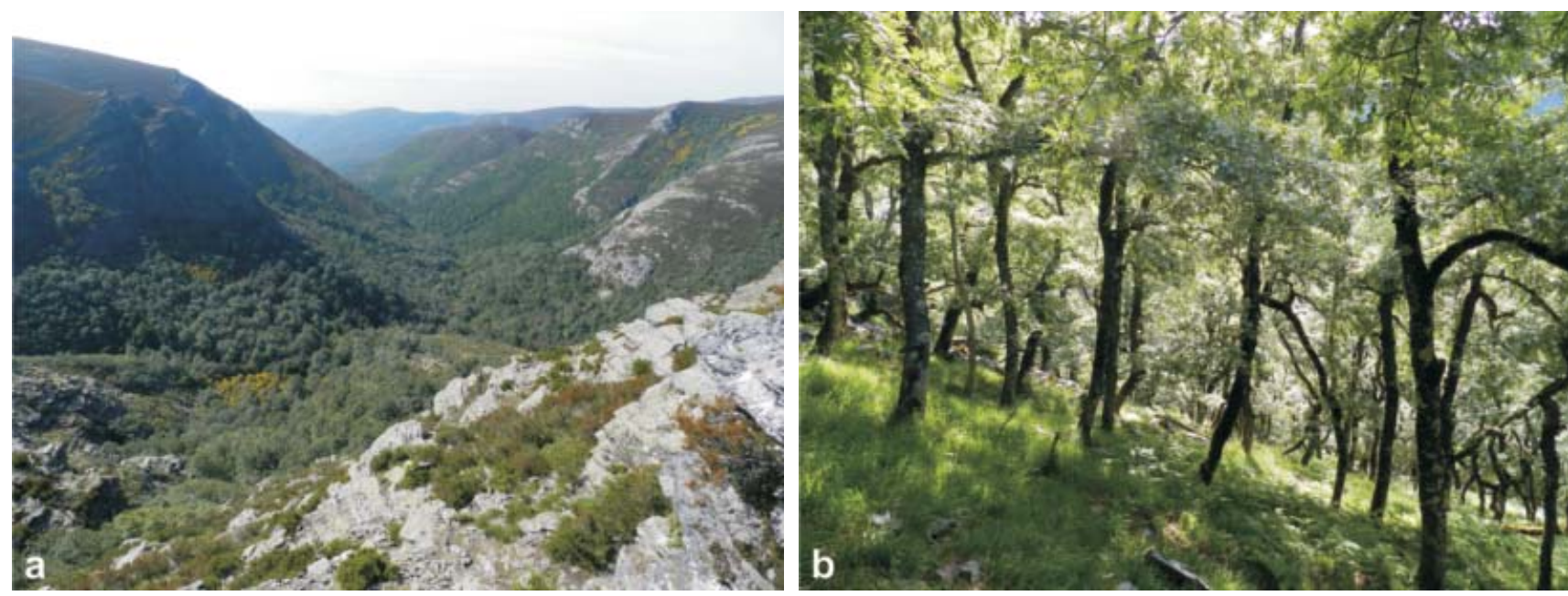

Figura 5.- Vista de la cabecera del Río Casarello (a), mostrando extensas manchas de reboleiras que dan paso, valle abajo, a bosques de carballo (color verde más intenso al fondo) y aspecto interior de una reboleira en este mismo lugar (b)

y llevan un tiempo sin verse afectadas por los incendios, se encuentran en un proceso de progresiva colonización por especies arbóreas entre las que Betula pubescens, Sorbus aucuparia y el propio carballo son las más frecuentes, evidenciando que no existe una única dinámica de recuperación de la cubierta arbolada en estas montañas. Pulgar (2004) coincide, de manera implícita, en esta apreciación al concebir su esquema sintético de la vegetación del Parque.

Hemos reunido en la Tabla 1 del Anexo I varios inventarios tomados en las cabeceras de los valles visitados para reflejar la composición de estas reboleiras a los que hemos unido otros tomados en localidades próximas (valles de Pradoalbar y Chaguazoso), pero ya fuera de los límites de este Espacio Natural Protegido. Dejando a un lado la peculiaridad de la elevada participación del acebo en una de estas muestras, la flora de estos bosques está caracterizada por una constancia elevada de taxones como Holcus mollis, Lonicera hispanica, Pteridium aquilinum, Stellaria holostea, Teucrium scorodonia o Viola riviniana. Como principal diferencia florística de estos bosques frente a los robledales de Quercus robur se puede destacar la ausencia de determinadas especies nemorales (Avenella flexuosa, Blechnum spicant, Dryopteris affinis subsp. borreri, D. dilatata, Luzula sylvatica, Oxalis acetosella, Saxifraga spathularis) y la relativa abundancia de Agrostis capillaris, Dactylis glomerata subsp. izcoi, Galium papillosum, Festuca elegans subsp. merinoi, etc.), que no han sido observadas en aquellos.

Tampoco es fácil una asignación fitosociológica de estos melojares dado que, al igual que se comentó para los robledales, están enclavados en un territorio biogeográficamente ambiguo y la ausencia de estudios detallados en los territorios inmediatos ha propiciado que se aportasen opiniones cambiantes a lo largo de la literatura sintaxonómica de las últimas décadas. Cuando estudió estos bosques, Castroviejo (op. cit.) resolvió llevarlos a la asociación Holco mollis-Quercetum pyrenaicae, una comunidad descrita del centro-norte de Portugal cuyo concepto fue aplicado a numerosas formaciones con dominio del rebolo en el interior de la provincia de Ourense (Morla 1983, 1985) y en las sierras del límite entre Galicia, León y Zamora (Amigo 1984, Ortiz 1986) y el NE de Portugal (Aguiar 2000). Más tarde, fue descrita otra asociación en el occidente leonés (Penas \& Díaz 1985), que recibió el nombre de Genisto falcatae-Quercetum pyrenaicae y que se utilizó para incluir en ella a los melojares del interior orensano en altitudes bajas, mientras que los situados por encima de los $1.100 \mathrm{~m}$ se mantenían como Holco mollis-Quercetum pyrenaicae (Ortiz et al. 1997).

Ha habido propuestas posteriores, como la defendida por Díaz \& Penas (2017), que plantean la alternativa de incluir dentro de la Genisto falcatae-Quercetum pyrenaicae todos los melojares del sector Bierzo-Sanabria y considerar la Holco mollis-Quercetum pyrenaicae solamente portuguesa y, más precisamente, exclusiva de la Serra da Estrela. Sin embargo, con los datos del presente trabajo y otros derivados de cierto conocimiento de los territorios situados entre Galicia-Zamora-Norte de Portugal, pensamos que la opción Holco mollis-Quercetum pyrenaicae puede ser una buena alternativa para resaltar el carácter de mayor influencia atlántica que presentan estos bosques del piso supratemplado submediterráneo, al menos en una parte significativa del territorio interior ourensano y su transición hacia el Este (Zamora) y el Sur (Tras-Os-Montes); en esta última zona también lo reconocen Aguiar \& Vila-Viçosa (2017). La posición ecológica y piso bioclimático en que hemos muestreado este tipo de bosque son coherentes con esa interpretación.

\section{Bosques mixtos sobre coluviones de ladera}

Castroviejo (1977) no advierte la existencia de este tipo de bosques en su trabajo, ni se puede deducir de sus comentarios que pudieran haber sido incluidos dentro de otras comunidades arboladas que sí describe. No obstante, 
las características dasométricas (altura y grosor) de los pies que dominan los fragmentos de arbolado de este tipo que hemos tenido oportunidad de estudiar (Anexo I: Tabla 2), permiten afirmar que ya existían como tales en la época en la que este autor visitó estas montañas.

Se trata de bosques desarrollados en partes bajas de laderas, sobre depósitos coluviales de grandes piedras y bloques rocosos, con frecuencia inestables, que suelen contactar por su extremo superior o lateralmente con robledales, con bosques higroturbosos dominados por el abedul en sentido lateral y bosques de ribera (abedulares riparios) por su límite inferior (Figura 6). El dosel presenta una cobertura elevada, próxima al $100 \%$, estructurada en dos niveles, uno superior formado por individuos muy corpulentos de Acer pseudoplatanus y Fraxinus excelsior, y en menor medida Betula pubescens y Quercus robur, por debajo de este nivel, un piso casi continuo de Corylus avellana, entre el que aparecen otras especies arbóreas, como Ulmus glabra o Prunus avium. En un nivel arbustivo se encuentra Corylus avellana abundantemente representado. La cobertura del nivel inferior es baja, debido a la elevada pedregosidad, y se caracteriza por el dominio de Polystichum setiferum, Primula acaulis y Geranium robertianum, encontrándose especies típicas de bosques desarrollados sobre suelos humíferos ricos en nutrientes, como Melica uniflora, Mycelis muralis o Sanicula europea.
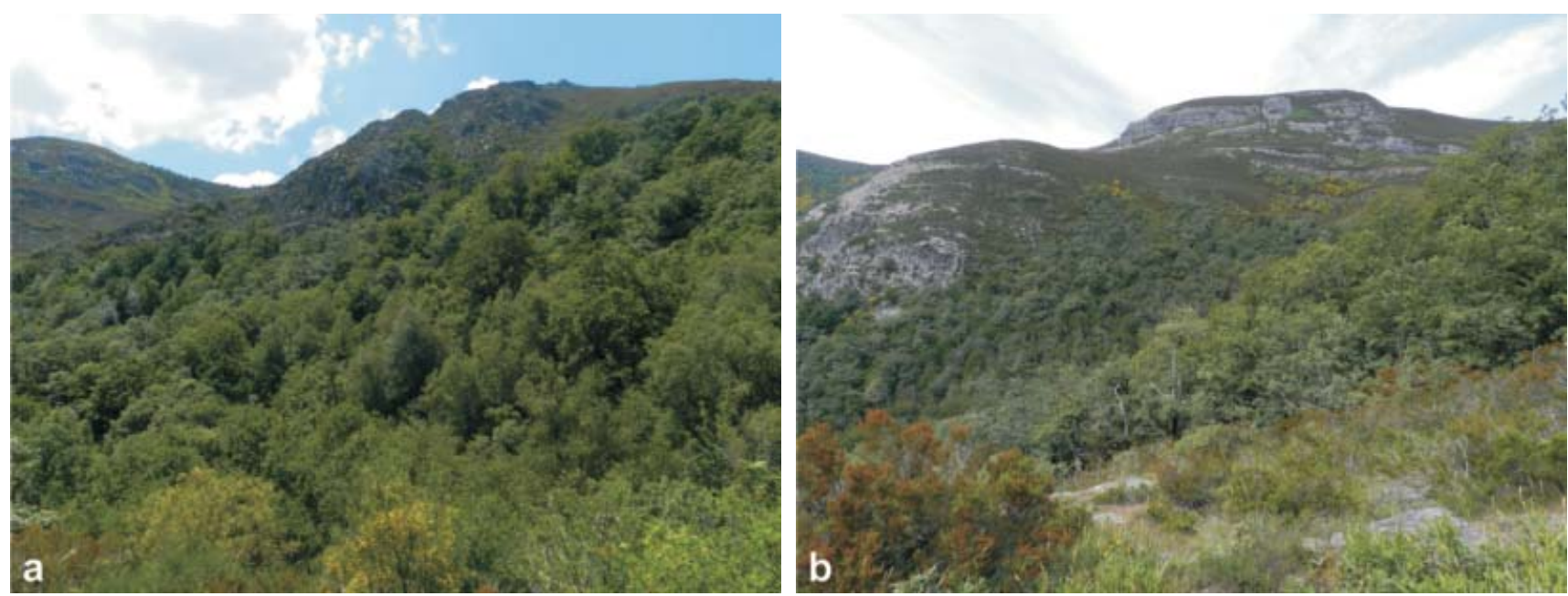

Figura 6.- Aspecto exterior de bosque mixto en el valle de la Corga de Aguacenza (a) y mosaico de robledal-acebeda (ladera en segundo plano, al fondo) en la cabecera del Río de Casarello (b)

La escasez de información existente acerca de este tipo de bosques en el Macizo Central ourensano dificulta enormemente su interpretación fitosociológica. En un principio, dada su localización biogeográfica y ecología, podría admitirse que se trata de representaciones occidentales de bosques silicícolas de la asociación Luzulo henriquesii-Aceretum pseudoplatani (Díaz \& FernándezPrieto 1994, Fernández-Prieto \& Bueno 1996, RodríguezGuitián et al. 2013, 2014), descrita del occidente de la Cordillera Cantábrica. Sin embargo, estos bosques carecen de Quercus petraea y Quercus × rosacea, habituales en la asociación anteriormente citada, que aquí son sustituidos por $Q$. robur.

Fuera de las montañas orocantábricas, en los territorios sublitorales cantábricos occidentales Rodríguez-Guitián et al. $(2004,2005,2012)$ han identificado otro tipo de bosque mixto de laderas y lugares abarrancados sobre sustratos igualmente silíceos, que han denominado "Bosques mixtos oligotrofos cántabricos occidentales" y que podría guardar relación con los aquí tratados, al ser Quercus robur una de las especies arbóreas con presencia más constante, si bien nunca dominante. Más próxima desde el punto de vista geográfico, ha sido descrita del NW portugués otra asociación de bosques polifitos con participación de Quercus robur, denominada Hyperico androsaemiQuercetum roboris (Honrado et al. 2002). Sin embargo, en ambos casos se trata de bosques con un acusado carácter termófilo, en los que son habituales especies como Arbutus unedo, Asplenium onopteris, Castanea sativa, Osmunda regalis, Phyllitis scolopendrium o Ruscus aculeatus, que no se han visto en los bosques mixtos estudiados en el Parque; tampoco aparece en ellos Fraxinus angustifolia, habitual en los bosques de la asociación lusitana comentada.

Por todo ello, como en el caso de otros tipos de bosques comentados, la interpretación fitosociológica de estos bosques necesita del acopio de más información a lo largo del cuadrante NW Ibérico. No obstante, con independencia de la filiación fitosociológica a nivel de asociación que finalmente se establezca para ellos, parece claro que las especies arbóreas dominantes y su ecología coinciden con la de los bosques que, dentro del ámbito centro-occidental europeo, se han venido incluyendo dentro de la alianza Tilio-Acerion (Rivas-Martínez 2011). 


\section{Acebedas}

Bosques de mediana talla (12-24 m), densos y umbrosos, situados en partes bajas de laderas en las áreas de cabecera del Río de Casarello y la Corga do Figueiro (Figura 6). El carácter perennifolio de la especie dominante y la densidad de su follaje proporcionan un ambiente umbroso a su sotobosque, que se caracteriza por presentar una cobertura baja de especies herbáceas, mayoritariamente de carácter nemoral, entre las que se encuentran taxones oliogotrofos (Vaccinium myrtillus, Galium rotundifolium, Luzula sylvatica, etc.) junto a otras de preferencias eutrofas (Melica uniflora, Primula acaulis, Sanicula europea,) y otras indiferentes (Hedera hibernica, Lonicera hispanica, Oxalis acetosella). Aunque no han sido visitados, bosques similares a estos sobreviven en las cabeceras de diversos valles de la cabecera del Río da Edreira que lindan por el NW con el Parque y en la Serra de San Mamede (Costa-Tenorio et al. 1990), distante unos 10 $\mathrm{km}$ en línea recta del mismo hacia el $\mathrm{N}$. Desde el punto de vista florístico, salvo por la presencia de Quercus robur, la composición de las acebedas existentes en el Macizo Central ourensano es similar a la que se conoce de todo el amplio conjunto de las montañas silíceas del extremo occidental de la Cordillera Cantábrica (Fernández-Prieto \& Bueno 1996, Silva-Pando 2009, Rodríguez Guitián et al. 2014).

Son varias las soluciones sintaxonómicas manejadas para este tipo de formaciones, en gran medida relacionadas con la interpretación dinámica que se ha hecho de ellas. Para algunos autores, las acebedas deben vincularse al aprovechamiento humano (talas, pastoreo) de las áreas de montaña en las que están presentes, opción que defendemos debe de aplicarse en este caso. Su conformación habría sido favorecida por la corta de otras especies arbóreas en beneficio del acebo, árbol de copa perenne que proporciona cobijo contra el frío al ganado en invierno y da frescor durante el verano. Esta explicación ha sido aplicada por, entre otros, el mismo Castroviejo (1977) para el área de estudio, Rodríguez Guitián (2004) en las montañas septentrionales de Galicia y el NW asturiano, Fernández-Prieto \& Bueno (1996) en las montañas de Muniellos, o Silva-Pando (2009) y Rodríguez Guitián et al. (2014) en la Sierra de Ancares. La mayor parte de estos autores han optado por interpretar estas formaciones como facies de los tipos de bosques entre los que se insertan, excepto en el caso de Silva-Pando (op. cit.), quien los ha vinculado con los abedulares climácicos del territorio por medio de una subasociación particular (Luzulo henriquesiiBetuletum celtibericae subas. ilicetosum aquifoliae), solución que no parece la más acertada, toda vez que las acebedas ancaresas se localizan mayoritariamente dentro del piso altitudinal ocupado por los hayedos y robledales albares. Otros autores, partiendo de la consideración de que las acebedas presentan diferencias ecológicas, florísticas y estructurales que justifican su tratamiento independiente frente a los bosques con los que se relacionan dinámicamente (Rodríguez-Guitián 2004, Rodríguez-Guitián et al. 2012) son partidarios de reconocer varias comunidades de acebedas de carácter serial en el territorio de Galicia, aunque sin realizar una propuesta en firme desde el punto de vista fitosociológico. Las aquí comentadas serían incluibles dentro del tipo "acebales silicícolas orocantábricos".

En otros casos, se ha propuesto su posible carácter de bosque en equilibrio con las condiciones ambientales, lo que equivaldría a atribuirles la consideración de vegetación climácica en biotopos favorables. Tal opinión fue expresada ya hace unos decenios por Costa-Tenorio et al. (1990) a propósito de las acebedas existentes en la vecina Serra de San Mamede, aunque sin llegar a proponer una unidad sintaxonómica concreta. Más recientemente, RivasMartínez (2011), basándose en los datos proporcionados por García-Baquero (2005), ha propuesto la asociación Saniculo europaeae-Ilicetum aquifoliae, para incluir en ella a las acebedas que se encuentran en el Sistema Ibérico y la Cordillera Cantábrica, otorgándoles la condición de etapa madura de una serie de vegetación. Este mismo criterio ha sido seguido por Díaz (2014) en su publicación sobre las series de vegetación de Asturias. Como puede verse, no existe unanimidad en la interpretación del origen y estatus fitosociológico a aplicar para este tipo de bosques dentro de las diferentes áreas del $\mathrm{N}$ de la Península Ibérica en las que han sido estudiados.

\section{Bosques higrófilos}

El trabajo de Castroviejo (1977) resulta particularmente ambiguo en lo que a la descripción de los bosques de ribera se refiere, puesto que las denominaciones y las tipologías que reconoce no se ajustan a los diagramas que adjunta (Castroviejo op. cit:: Figs. 3 y 7). Según este autor, se distinguirían dos tipos de bosques ribereños: "alisedas, en las zonas bajas, y las avellanedas en las altas", por encima de los $1.400 \mathrm{~m}$ de altitud. En nuestra opinión, la observación de la cubierta vegetal actual del Parque demuestra que este planteamiento es incongruente, puesto que, si bien efectivamente las alisedas no superan los 1.000 de altitud, entre esta cota y los $1.400 \mathrm{~m}$ se extiende un amplio intervalo altitudinal dentro del que Castroviejo (op. cit.) no contempla la existencia de ningún tipo de bosque de ribera. Por si esto fuera poco, la longitud de los cauces que tienen asociados bosques de ribera por encima de los $1.400 \mathrm{~m}$ de altitud dentro de estas montañas es extraordinariamente reducida $y$, seguramente, era menor en la época en la que Castroviejo realizó sus trabajos de campo.

El esquema que manejamos sobre la tipología y distribución de los bosques de ribera, amparado en los inventarios que se presentan en la Tabla 4 (Anexo I) y referencias previas (Rodríguez-Guitián et al. 2017), reconoce, en el sentido de avance de las aguas corrientes, dos tipos de bosque de ribera: abedulares y alisedas. Además de bosques asociados a los cauces fluviales, hemos observado otro tipo de bosque higrófilo asentado sobre suelos pesados, muy orgánicos y rezumantes, semejantes a los "abedulares higro-turfófilos" descritos por Rodríguez-Guitián et al. (2012) en diferentes ámbitos montañosos del extremo NW ibérico.

\section{Abedulares riparios}

Se trata de un tipo de bosque asociado a las cabeceras fluviales, en tramos rápidos y con cauces pedregosos (a menudo con abundancia de grandes bloques) en los que se 
evidencian signos erosivos durante las épocas de crecida (Figura 7). Debido a su posición en la parte alta de las redes fluviales, las oscilaciones de caudal son importantes y este suele reducirse de manera acusada durante la época estival. Sin lugar a dudas, es el tipo de bosque ripario más extendido dentro del territorio estudiado, en consonancia con lo descrito para el conjunto de los territorios supratemplados del Macizo Central ourensano (RodríguezGuitián et al. 2017).

Son bosques de talla irregular $(10-20 \mathrm{~m})$ dominados por el abedul y con participación prácticamente constante de Sorbus aucuparia, Salix atrocinerea, Quercus robur, Ilex aquifolium y Acer pseudoplatanus. Otras especies arbóreas y grandes arbustos presentes son Corylus avellana, Erica arborea, Genista polygaliphylla, Frangula alnus, Fraxinus excelsior, Salix caprea y Sambucus nigra. El plantel de especies herbáceas es amplio e incluye taxones típicos de bordes de río, como Aquilegia vulgaris, Athyrium filixfemina, Blechnum spicant, Carex reuteriana, Polystichum setiferum, Ranunculus ficaria, Ranunculus repens y plantas frecuentes en bosques no riparios, como Crepis lampsanoides, Euphorbia dulcis, Euphorbia hyberna, Luzula sylvatica, Oxalis acetosella, Poa nemoralis, Primula acaulis, Sanicula europea, Saxifraga spathularis, Teucrium scorodonia, Vaccinium myrtillus, Veronica montana o Viola riviniana. Las especies lianoides están representadas por Hedera hibernica, Lonicera hispanica y Rubus Iucensis.

A pesar de que estos abedulares cubren la mayor parte del intervalo altitudinal dentro del que se distribuyen los bosques de ribera en este parque natural, llegando de manera puntual a superar los $1.450 \mathrm{~m}$ de altitud en las cabeceras de los arroyos de Os Fornallos, Teixeiroá, Gavián Grande y Corga da Ramallosa, su composición y fisionomía tiene un encaje difícil con la establecida por Castroviejo (1977) para sus "avellanedas ribereñas". Esta dificultad radica en la ausencia en éstas de un conjunto de especies con claras preferencias por los suelos húmedos de los bordes de los cauces fluviales, como Athyrium filix-femina, Salix atrocinerea, Frangula alnus, Carex reuteriana, Galium broterianum o Silene dioica, entre otros taxones presentes en los abedulares aquí tratados. En sentido inverso, resulta sorprendente la inclusión de Fraxinus x oxycarpa en el listado de especies presentes en sus avellanedas, por cuanto, en nuestra opinión, de existir poblaciones de especies del género Fraxinus por encima de los 1.400 en este territorio, han de ser de Fraxinus excelsior, y no de su híbrido con F. angustifolia.

Si nos atenemos al listado de taxones proporcionado por Castroviejo (op. cit.), sus "avellanedas ribereñas" sin especies de ribera podrían representar bosques de carácter serial, dominados por especies heliófilas (Betula pubescens, Sorbus aucuparia, Salix caprea), aunque con presencia de árboles habituales en el sotobosque de robledales y hayedos (Corylus avellana, Ilex aquifolium), desarrollados sobre suelos frescos o en la proximidad de nacientes y manantiales. Esta interpretación encontraría correspondencia con las avellanedas de sustitución ricas en acebo descritas por Amigo (1984) en la Serra do Courel y por Silva-Pando (1990) en las montañas de Ancares, o con algunas variantes de los bosques coureliano-ancareses pertenecientes a la asociación Sorbo aucupariae-Salicetum capreae (Rodríguez-Guitián et al. 2005, 2013, 2014). Otra posibilidad, menos plausible en nuestra opinión, es que Castroviejo hubiera observado un tipo de comunidad de la que, transcurridos más de 40 años, no queden testigos a consecuencia del proceso de sucesión vegetal. En todo caso, la ausencia de datos propios que puedan corroborar estas posibilidades limita nuestra capacidad de interpretación de las descripciones hechas por Castroviejo.

La comparación de la composición florística de los abedulares riparios muestreados por nosotros con la descrita para formaciones semejantes en el ámbito de las montañas noroccidentales ibéricas (Anexo I: Tabla 4) permite considerarlos como representaciones de la asociación Valeriano officinalis-Betuletum pubescentis (Rodríguez-Guitián et al. 2017). La presencia en estos bosques de taxones como Aquilegia dichroa, Galium broterianum o Rosa corymbifera, diferenciales de esta asociación frente al resto de abedulares riparios descritos en las montañas del extremo NW Ibérico, y de Poa nemoralis, diferencial frente a la asociación galaicoportuguesa y atlántico-orolusitana Carici reuterianaeBetuletum celtibericae, descrita por Honrado et al. (2003), justifica esta adscripción fitosociológica.

\section{Alisedas riparias}

Tal y como describió Castroviejo (1977) en su trabajo, las alisedas riparias están presentes únicamente en los tramos más bajos de los dos principales ríos del Parque. En el caso de la Ribeira Grande, ascienden desde el límite superior del embalse de As Portas hasta una cota de $950 \mathrm{~m}$, valle arriba del canal de captura de peces existente en este río; en la Ribeira Pequena, remontan hasta un poco más arriba de su confluencia con el Corgo das Rubias, hasta unos $925 \mathrm{~m}$ (Figura 7).

Se trata de bosques dominados por el aliso (Alnus glutinosa), con presencia habitual de sauce común (Salix atrocinerea), abedul (Betula pubescens) y serbal de cazadores (Sorbus aucuparia) en el estrato superior (Anexo I: Tabla 3). Otros árboles de menor talla, como avellano (Corylus avellana) y arraclán (Frangula alnus), y arbustos grandes (Erica arborea, Genista polygaliphylla) conforman un subpiso por debajo de los anteriores. El estrato herbáceo es exuberante y muy diverso, resaltando la abundancia de Luzula sylvatica, Brachypodium pinnatum subsp. rupestre, Brachypodium sylvaticum, Euphorbia dulcis, Galium broterianum, Carex elata subsp. reuteriana, Anemone nemorosa, Anemone trifolia subsp. albida, etc., así como diversas megaforbias (Allium victorialis, Angelica laevis, Heracleum sphondylium, Ranunculus platanifolius). En el caso de la Ribeira Grande, Calamagrostis arundinacea alcanza localmente una notable cobertura. Es interesante resaltar que las únicas poblaciones de Fraxinus angustifolia encontradas dentro de los límites del área de estudio han aparecido integradas en este tipo de bosque de ribera.

Con la composición florística comentada, las alisedas presentes en el área de estudio serían incluibles en la asociación Galio broteriani-Alnetum glutinosae, descrita originalmente de territorios centro-ibéricos, pero que ha sido reconocida en diferentes áreas montañosas del NW Ibérico 
(Navarro-Andrés et al. 1986, Díaz et al. 1987, Aguiar 2000, González de Paz 2012), incluida la vertiente meridional de las montañas portuguesas de Peneda-Gerês (Honrado 2003). Dentro de esta asociación, las alisedas estudiadas se encuadrarían en la subasociación típica, pues en ellas a lo largo del ámbito de estudio no se ha encontrado ninguno de los taxones que permiten diferenciar las otras tres subasociaciones que han sido descritas (paradiseetosum Iusitanicae, scrophularietosum scorodoniae y fraxinetosum excelsioris).

\section{Abedulares higro-turfófilos}

Bosques asentados sobre suelos siempre húmedos, ricos en materia orgánica, localizados en rellanos situados en la parte baja de las vertientes, en coincidencia con el afloramiento de niveles freáticos próximos a la superficie. Pueden alcanzar los $20 \mathrm{~m}$ de altura de copas e integrar diversas especies arbóreas (Sorbus aucuparia, Salix atrocinerea, Quercus robur, Ilex aquifolium), además del abedul dominante (Anexo I: Tabla 3). A su sombra crecen, además de numerosas especies nemorales, otras marcadamente higrófilas (Athyrium filix-femina, Carex echinata, C. remota, C. laevigata, Chrysosplenium oppositifolium, Dactylorhiza maculata, Juncus effusus, Pyrola minor, Ranunculus repens); también están presentes diversos taxones escio-nitrófilos (Geranium robertianum, Omphalodes nitida, Prunella vulgaris), favorecidos por la visita periódica de fauna silvestre a estos ambientes para utilizarlos como bañaderos.

La interpretación fitosociológica de este tipo de bosques está pendiente de la recopilación de información detallada acerca de su composición florística y distribución. Por el momento, se ha citado la existencia de formaciones arboladas semejantes a estas, desde el punto de vista ecológico y por la dominancia del abedul, en diversas áreas montañosas del noroccidente ibérico, como la Serra dos Ancares (Rodríguez-Guitián et al. 2014), el macizo de Trevinca-Sanabria (Ortiz 1986, Rodríguez-Guitián \& Bariego 2009), las montañas septentrionales lucenses (RodríguezGuitián et al. 2009) y, posiblemente, en el extremo oriental de la Serra do Gerês (Honrado 2003). En el caso de las sierras del norte lucense y en Os Ancares, algunos de estos abedulares se asientan sobre antiguas turberas y han sido interpretados como turberas arboladas (Rodríguez-Guitián et al. 2012, 2014).
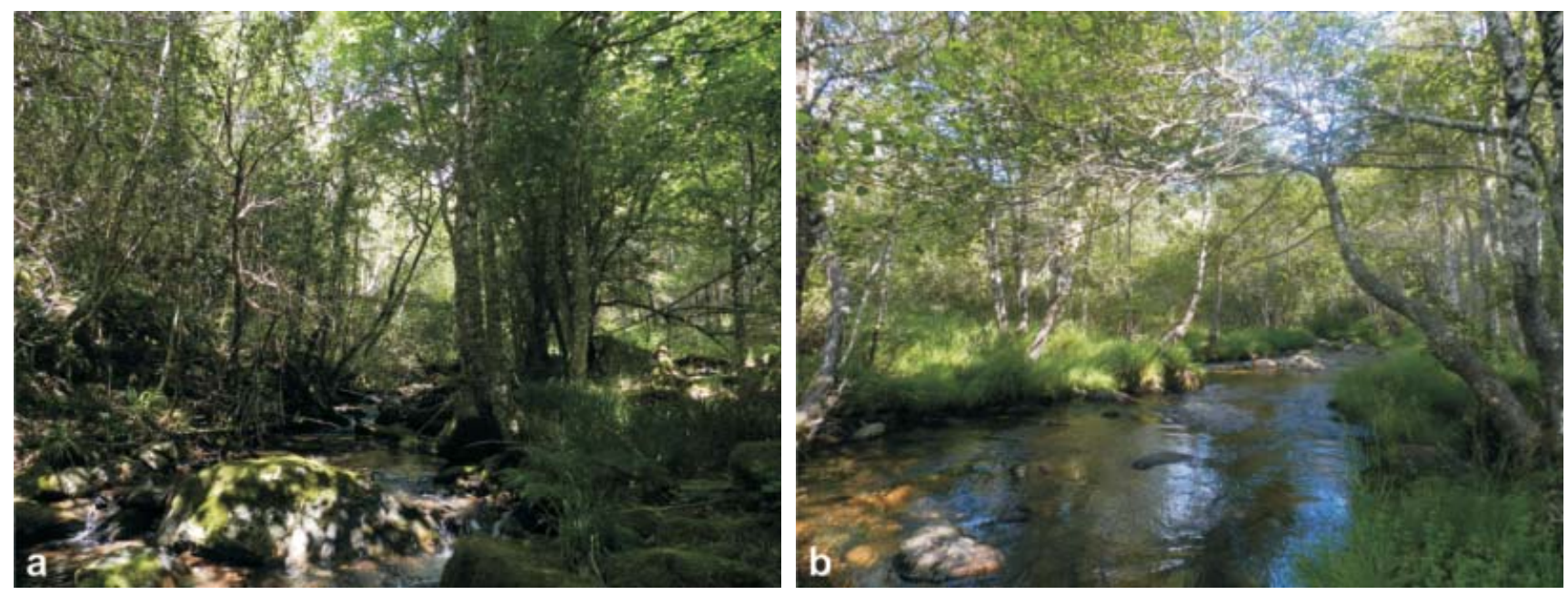

Figura 7.- Aspecto de un abedular ripario en la Corga de Aguacenza (a) y de una aliseda riparia en el tramo final de la Ribeira Grande (b)

Sea como fuere, en el esquema sintaxonómico de RivasMartínez (2011) no se considera ninguna categoría de rango superior (alianza, orden) que comprenda abedulares que crezcan en las condiciones comentadas. En cambio, en la propuesta de Mucina et al. (2016), se contempla una alianza de bosques acidófilos húmedos de distribución euroasiática dominados por el abedul pubescente que colonizan turberas mesotrofas (Betulion pubescentis Lohmeyer et Tx. ex Oberd. 1957), perteneciente al orden SphagnoBetuletalia pubescentis Scamoni et Passarge 1959 que, a su vez, pertenece a la clase Alnetea glutinosae Br.-BI. et Tx. ex Westhoff et al. 1946. La presencia en los bosques comentados de especies características de esta clase de vegetación, como Carex laevigata o Potentilla erecta, podría avalar su inclusión en la alianza comentada, posición que defendemos aquí mientras no exista un estudio más en profundidad.

\section{Vegetación arbustiva}

Describiremos aquí las principales formaciones dominadas por especies leñosas pero con tallas más modestas que las de los bosques. En conjunto, estas formaciones son las que mayor superficie ocupan dentro del Parque Natural do Invernadeiro, a semejanza de lo que se puede observar en la mayor parte de las montañas orientales gallegas; en síntesis, la presión deforestadora debida a la presencia 
humana ha reducido considerablemente la superficie cubierta por los bosques climácicos y, en su lugar, se han instalado comunidades vegetales arbustivas como etapas de sustitución.

\section{Matorrales de leguminosas}

De entre los matorrales derivados de la destrucción de los bosques destacan sobre todos los piornales, por ser los más cercanos al bosque maduro en el dinamismo vegetal de recuperación de la situación forestal tras tala o incendio. La instalación de piorno (Genista polygaliphylla) en claros del bosque o en sus bordes exteriores, indica que la calidad y profundidad edáficas todavía son suficientemente buenas como para que se recupere el arbolado del bosque si cesan las presiones deforestadoras. Esta función dinámica, bien conocida en el caso de los matorrales dominados por leguminosas Genisteae, ya fue observada por Castroviejo (1977) al describir la vegetación del que acabaría siendo Parque Natural. Aunque no hemos recogido inventarios de estos piornales, la abundancia con la que aparecen Cytisus scoparius y Genista polygaliphylla indica que se deben interpretar como formaciones de la asociación Cytiso scoparii-Genistetum polygaliphyllae, claramente dominante como orla de los bosques supratemplados desde el extremo occidental de la provincia Orocantábrica hasta las montañas del mismo piso bioclimático del norte de Portugal (Figura 8).
Además, en algunas laderas soleadas de tramos altitudinales inferiores (por debajo de los $1.200 \mathrm{~m}$ ) hemos apreciado formaciones densas de Cytisus multiflorus, la xesta branca, para las que caben tres posibles interpretaciones: 1) una variante de la asociación del piornal con un significado de cierta influencia mediterránea (como la Cytiso scoparii-Genistetum polygaliphyllae subas. cytisetosum multiflori, reconocida con abundante presencia en las montañas del occidente de la Cordillera Cantábrica); 2) representaciones en una posición altitudinal extrema de una asociación de escobonal (Lavandulo sampaioanaeCytisetum multiflori) de significado más acusadamente meso-supramediterráneo y que alcanzaría este macizo asociado a las condiciones más marcadas de un bioclima templado submediterráneo, ó 3) constituir formaciones de una asociación propia del ambiente meso-supratemplado de carácter submediterráneo, extendida por los macizos de la Galicia meridional; tal asociación fue descrita por Pulgar (1999) de la Serra do Xurés bajo el nombre de Halimio alyssoidis-Cytisetum multiflori, pero no alcanzó a ver su publicación efectiva por lo que continúa siendo un nomen nudum según las normas del CINF. Sin embargo, tanto florística, como bioclimática y sinfitosociológicamente, podría ser la interpretación idónea para estos escobonales de xesta branca presentes en parque natural estudiado.
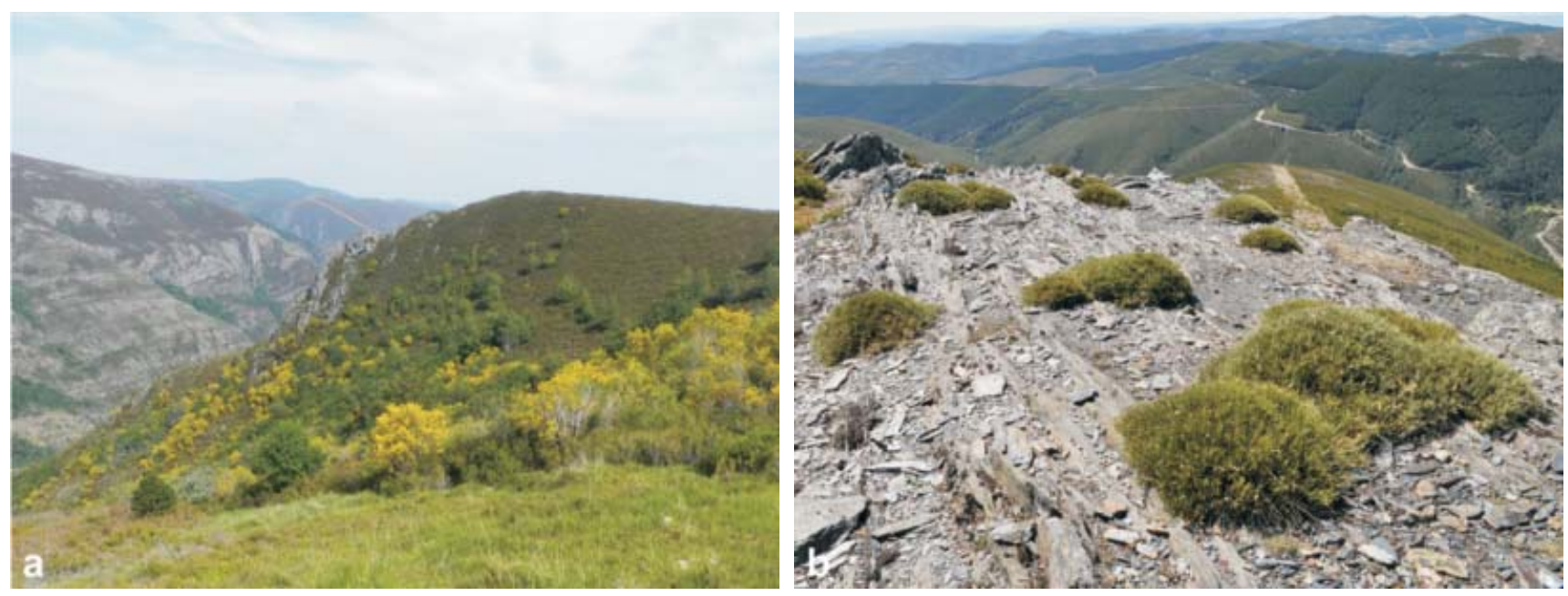

Figura 8.- Aspecto estival de piornales en plena floración en la cabecera del valle del Río de Casarello (a) y de un cambrional en los Altos da Veiga de Meda (b)

Por último, dentro de este grupo de matorrales hay que mencionar los piornales orófilos presididos por Genista obtusiramea, una Genisteae endémica de los macizos montañosos silíceos del NW ibérico. Castroviejo (op. cit.) citó estos matorrales localizándolos en el rango altitudinal de los 1500-1600 m s.n.m., a lo largo del límite superior de los bosques y soportando condiciones de elevada innivación, detalle que explica su fisonomía menos erguida y más decumbente, y que los diferencia de los dominados por G. polygaliphylla. En una publicación posterior
(Castroviejo 1982) afirmaba tratarse de una especie abundante en el macizo Invernadeiro-Queixa-Manzaneda.

Según Castroviejo (1977), la composición florística de estas formaciones arbustivas sería incluible dentro de la asociación Genistetum obtusirameo-polygaliphyllae. Sin embargo, las diferentes jornadas de trabajos de campo realizadas en los últimos 10 años a lo largo del perímetro superior del Parque Natural do Invernadeiro, en buena medida por encima de los $1.500 \mathrm{~m}$, no encontramos un solo ejemplar de G. obtusiramea, por lo que, en nuestra opinión, 
la persistencia de piornales de esta especie dentro del territorio estricto del Parque necesitaría confirmación. Formaciones extensas de este tipo de piornal en el Macizo Central Ourensano, cada vez más afectadas por el acondicionamiento mecánico de áreas de pastoreo en zonas de cumbres, se localizan más al norte, en el entorno de la Cabeza de Manzaneda; hacia el W, en la Serra de San Mamede, se encuentran las poblaciones más occidentales de este endemismo en territorio gallego que, junto a las existentes en algunos macizos montañosos del NW de Portugal (Domingues de Almeida 2000) son de gran interés por su carácter finícola occidental.

Otra comunidad de matorral, mucho más minoritaria en el territorio del Parque, pero de cierto interés biogeográfico, es la constituida por las formaciones de "erizón" o "cambrión" (Echinospartum ibericum). Se trata de una Genisteae de bajo porte, pulvinular (esto es, de aspecto hemisférico), muy ramoso y pinchudo (Figura 8b). Esta especie aparece en formaciones abiertas de cobertura incompleta, asociadas a fisuras de rocas, o claros de los brezales, donde asoman rocas ácidas (granitos, gneises, cuarcitas) dentro del piso supratemplado, llegando incluso al orotemplado. En concreto las que alcanzan este parque natural se deben relacionar con la asociación Festuco graniticolaeEchinospartetum pulviniformis, descrita por Costa-Tenorio et al. (1993) y cuyo nombre integra una subespecie de $E$. ibericum (E. ibericum subsp. pulviniformis) que Flora Iberica no reconoce como diferente de la subespecie típica (Talavera 1999); por otro lado, la otra componente del nombre es una gramínea, Festuca graniticola, descrita hace más de tres décadas (Kerguélen \& Morla 1985) como un endemismo exclusivo del Macizo Central Ourensano, pero que estudios posteriores (Devesa et al. 2013, Romero Zarco 2015) han puesto en evidencia que no es diferenciable de otro taxón endémico del occidente peninsular pero de distribución claramente más amplia: Festuca summilusitana. Independientemente de la entidad taxonómica de la Festuca, los cambrionales de esta asociación son un tipo de vegetación restringido a zonas elevadas y frías del conjunto de montañas silíceas del límite León-Zamora-Ourense, alcanzando más puntualmente el Macizo Central Ourensano. Estas comunidades están relacionadas florísticamente con las más occidentales de la Serra do Xurés y del N de Portugal (Pulgar 1999, Honrado 2003), por lo que en su conjunto esta asociación reuniría a los cambronales más occidentales del NW Ibérico.

\section{Brezales}

Los brezales son otro tipo de comunidades muy extendidos por las áreas montañosas, como resultado de la secular deforestación, y presentan una alta diversificación en el NW peninsular. Por ello, se pueden emplear para evaluar la posición biogeográfica de numerosas áreas de las que han desaparecido sus comunidades vegetales más maduras (sus bosques). Castroviejo (1977) distinguió tres tipos de matorrales dominados por brezos que se diferenciaban por cambios en su composición florística en relación a la profundidad del suelo orgánico que necesitan para desarrollarse; los resumió en una "fase de Erica umbellata", otra "fase de Erica australis" y finalmente en "otros tipos" en los que describía unos brezales de mayor talla y carácter preforestal dominados por Erica arborea.

Aunque no hemos realizado inventarios en este tipo de formaciones vegetales, sí se han determinado las especies principales que las conforman, lo que permite su determinación fitosociológica. El brezal mayoritario en el Parque Natural do Invernadeiro, especialmente en las cumbres y en las laderas donde los fuegos y talas han erosionado y adelgazado sus suelos de manera más intensa, se corresponde con lo que Castroviejo (op. cit.) etiquetó como Pterosparto-Ericetum aragonensis; el nombre deriva del hecho de que numerosos autores reconocen que el brezo rojo que se extiende por el norte y noroeste ibérico sobre sustratos silíceos es Erica australis subsp. aragonensis, aunque ese rango subespecífico no es compartido por el monógrafo del género para la Flora Iberica (Bayer 1996).
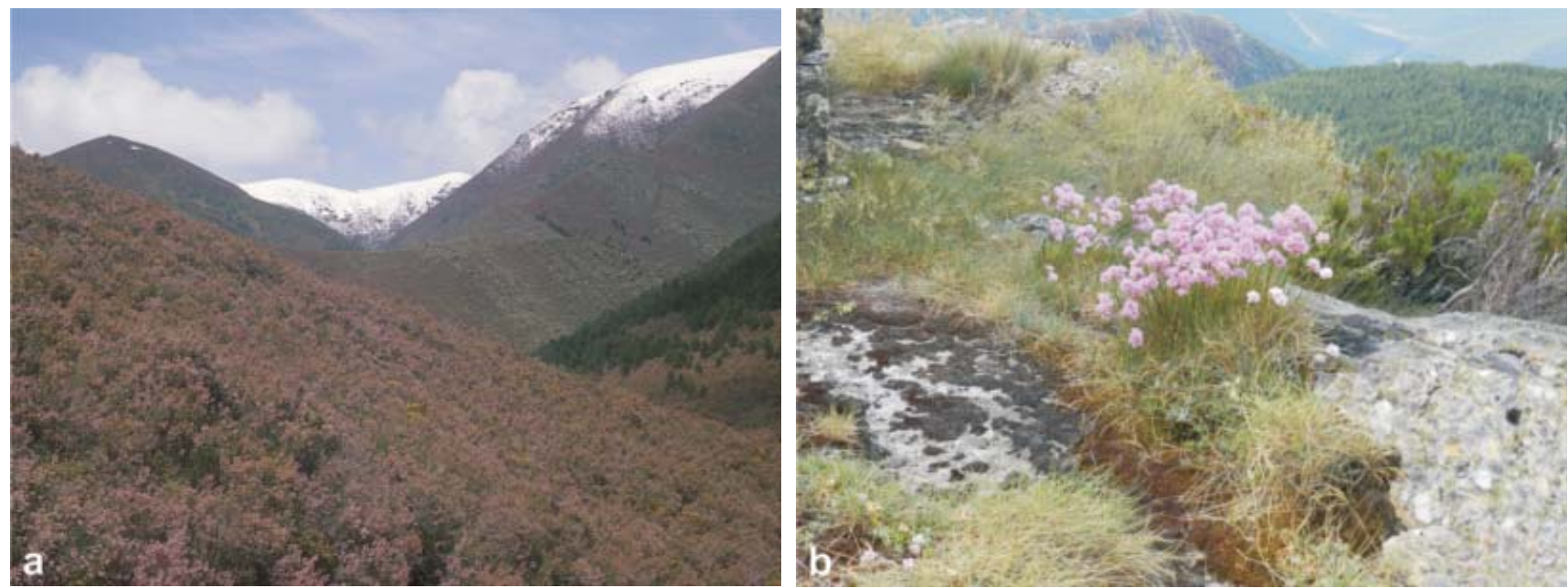

Figura 9.- Vista de extensos brezales secos dominados por Erica aragonensis enfrente a O Rocín (a) y detalle de la asociación Armerio ciliatae-Festucetum summilusitanae en los crestones pizarrosos de la Serra da Pena (b) 
Numerosos estudios posteriores han establecido que dentro del ámbito geográfico de presencia de este sintaxón están representadas realmente dos asociaciones que comparten un conjunto de especies dominantes en lo fisionómico pero que difieren, además de en otros aspectos florísticos, por la subespecie de Pterospartum tridentatum presente: una Pterosparto cantabrici-Ericetum aragonensis mesosupratemplada de distribución orocantábrica y cántabro atlántica, y una Pterosparto lasianthi-Ericetum aragonensis supramediterránea y supratemplada submediterránea de distribución noroccidental galaico-duriense (Figura 9a). En la primera de ellas es frecuente y hasta constante la presencia de una serie de especies de carácter atlántico, entre las que destacan Daboecia cantabrica y Pterospartum tridentatum subsp. cantabricum como las más emblemáticas $\mathrm{y}$, tal vez, también Ulex gallii s.l.; en la segunda destaca la ausencia de Daboecia, la sustitución del taxón asignable a la carqueixa, que en este caso es Pterospartum tridentatum subsp. lasianthum, y en menor medida, la posible presencia de Ulex minor, taxón ausente del Parque. Tal como resaltó Pulgar (2004), en este parque están presentes las dos subespecies de Pterospartum tridentatum; no obstante, nuestras observaciones nos llevan a rechazar la distribución restringida a las altitudes inferiores que este autor otorgó a $P$. tridentatum subsp. lasianthum, pues su presencia alcanza de manera generalizada los brezales que se extienden a lo largo de las pistas perimetrales del Parque.

Por su parte, entendemos que, la llamada "fase de Erica umbellata" por Castroviejo (1977), no es más que una variante de mayor degradación edáfica derivada del brezal mayoritario de la Pterosparto lasianthi-Ericetum aragonensis. Se trata de una comunidad muy frecuente a lo largo de los montes galaico-zamorano-portugueses que ocupa zonas concretas (a veces de gran superficie) tras erosión edáfica intensa y descarnamiento del suelo por reiteración del fuego, entre enormes extensiones de brezal de Erica australis subsp. aragonensis. En estas situaciones, el matoral se empobrece en especies humícolas y aparece dominado por los brezos de talla más modesta (Erica cinerea, E. umbellata), cuya menor cobertura favorece la presencia de especies herbáceas perennes como Tuberaria globulariifolia o Simethis mattiazzi, que fácilmente desaparecen cuando se pasa a un brezal más desarrollado, dominado por el brezo rojo.

En una casuística un tanto opuesta a la anterior se encuentran las formaciones que Castroviejo (op. cit.) distinguió como "brezales de Erica arborea". No ocupan grandes extensiones pero claramente se desarrollan sobre suelos más frescos y profundos que los que sustentan otros brezales, por lo que su presencia se puede interpretar como situaciones de orla forestal, con un significado similar al establecido para la asociación Avenello flexuosae-Ericetum arboreae por Rodríguez Guitián et al. (2003) o incluso de matorrales altos de preferencia edafohigrófila. El propio Castroviejo (op. cit.) resaltó dos especies de entre la lista de acompañantes del brezo blanco: Frangula alnus y Salix atrocinerea; ambas contribuyen a resaltar el matiz de humedad edáfica y la posición mayoritaria "en los bordes de los ríos de montaña ocupando suelos pedregosos y abruptos". En el trabajo de campo no se tomaron datos de las formaciones (comunidades) de este brezo, pero se considera válido y vigente el comentario de Castroviejo (op. cit.) Faltaría confirmar, en base a un estudio florístico detallado, si estas formaciones corresponden o no a la asociación anteriormente indicada.

\section{Vegetación herbácea}

Trataremos en este apartado algunas comunidades vegetales de diferentes características ecológicas pero siempre presididas por especies herbáceas y que normalmente ocupan biotopos de extensión limitada, a veces muy puntual, pero que pueden ser fácilmente identificables por la particular flora, adaptada a condiciones específicas, que a menudo las caracteriza. En la mayor parte de los casos no hemos recogido inventarios detallados de todas estas formaciones, pero su mera identificación fisionómica en el campo nos permite dar cuenta de la existencia de cierta diversidad fitocenótica que no había sido identificada previamente en este Parque Natural.

\section{Comunidades herbáceas orófilas}

En primer lugar, comentaremos un grupo de comunidades que reunimos bajo la denominación de "vegetación orófila", término con el que habitualmente se alude a tipos de vegetación propios de hábitats de montaña, esto es, comunidades especializadas que se desarrollan en los ambientes de mayor rigor climático sometidas, según los casos, a los efectos de a una mayor pluviosidad, temperaturas medias anuales más bajas, prolongada innivación, extenso período de heladas, crioturbación edáfica, efecto desecante del viento, etc. Las adaptaciones que muchas especies vegetales presentan a vivir en estos medios selectivos justifican que este tipo de vegetación sea rica en especies endémicas o de distribución geográfica restringida $y$, por esa misma razón, con frecuencia amenazadas de extinción. Aunque el territorio estricto del Parque tiene unas altitudes modestas, sus áreas más elevadas forman parte del sector culminante del Macizo de Queixa y presentan condiciones bioclimáticas próximas a las del piso bioclimático orotemplado (equivalente al concepto "subalpino" de clasificaciones más tradicionales) que, en sentido estricto solamente se alcanzaría en el sector de Cabeza de Manzaneda; sin embargo, se pueden encontrar algunas comunidades vegetales que tienen su óptimo en tal piso y por tanto su presencia aquí, aunque sea de forma esporádica o discontinua, tiene una cierta relevancia biogeográfica.

\section{Pastizales psicro-xerófilos}

Quizás, uno de los ambientes más estresantes para la mayor parte de la flora presente en el Parque sean las áreas dominadas por afloramientos rocosos o suelos incipientes de las cumbres montañosas afectadas por períodos prolongados de heladas, que en las partes más elevadas se pueden extender desde el mes de octubre hasta inicios de junio. En estas situaciones crecen comunidades vegetales psicroxerófilas, es decir, adaptadas a vivir en ambientes 
más secos de lo habitual en su entorno, debido a la escasez de suelo, y más fríos, porque se sitúan en espolones y roquedos aflorantes, desprotegidos frente a los vientos intensos y desprovistos de nieve rápidamente tras las nevadas.

En el área meridional europea y sobre todo en el Mediterráneo occidental hay una clase de vegetación que recoge una gran diversidad de comunidades de este tipo: la clase Festucetea indigestae; sus comunidades se localizan por todos los macizos montañosos silíceos de la Península Ibérica donde se den condiciones del piso orotemplado (o bien del oromediterráneo), pero pueden descender a niveles inferiores (supratemplados o supramediterráneos) en condiciones edafo-topográficas favorables. En las montañas orientales de los límites de Galicia se han reconocido hasta tres asociaciones de entre las comunidades más marcadamente orófilas de esta clase; una de ellas (Armerio ciliatae-Festucetum summilusitanae) fue estudiada y descrita ya en el siglo XXI como una asociación restringida a las cumbres silíceas de Galicia y como mucho hasta montes contiguos de León o de Zamora (Pulgar \& Izco 2007). Esta suele reconocerse por la dominancia de Festuca summilusitana, un endemismo de las montañas de la mitad occidental peninsular, y de Armeria ciliata, endemismo más restringido aún, ya que se encuentra solamente en montañas elevadas de LugoOurense-León-Zamora. Se presenta como comunidades herbáceas discontinuas, de baja cobertura y conformada por pocas especies, siempre perennes y entre las que los céspedes de $F$. summilusitana resultan los mejores bioindicadores. En la publicación de la descripción de esta asociación se incluyeron un par de inventarios levantados en el Fial das Corzas y otros dos localizados en "Vilariño de Conso, Invernadeiro". Además, en nuestro recorrido por el borde perimetral del Parque hemos podido observar algún individuo de esta asociación a lo largo de la Serra da Pena, con la participación de F. summilusitana, Armeria ciliata, Dianthus langeanus, Sedum brevifolium y Phalacrocarpum oppositifolium, a lo largo de la ruta que pasa por el Pico da Ortiga en dirección NW, a una altitud aproximada de 1.500 m (Figura 9).

Merece la pena destacar que en este espacio natural protegido se pueden encontrar poblaciones de Armeria ciliata en posiciones pioneras similares pero en altitudes inferiores, en las que el efecto de la crioturbación edáfica puede ser nulo; en esos casos esta especie endémica ya no está formando parte de la asociación inicial (deja también de aparecer Festuca summilusitana) y hay que considerarla integrante de otro tipo de comunidad, que pertenece a la misma clase (Festucetea indigestae) pero que se agrupa con otras asociaciones menos orófilas en la llamada alianza Hieracio castellani-Plantaginion radicatae. En esta otra comunidad, aún no suficientemente estudiada, por lo que carece de nombre fitosociológico, se aprecia otra diferencia florística, como es la participación del endemismo galaicoleonés Dianthus laricifolius subsp. merinoi.

Con una distribución espacial parecida a la Armerio ciliataeFestucetum summilusitanae, pero ocupando topografías llanas o de muy ligera inclinación y formando mosaico entre afloramientos rocosos y brezales de estructura abierta, crece otro tipo diferente de vegetación. Se trata de comunidades de baja cobertura dominadas por hemicriptófitos de pequeño tamaño, postrados, que se instalan sobre suelos muy escasamente desarrollados, con abundantes fragmentos rocosos sin apenas cohesión procedentes de la alteración física de pizarras y filitas y que se ven afectados por ciclos reiterados de hielo-deshielo a lo largo del invierno y primavera (suelos crioturbados)(Figura 10). Esta comunidad tiene un carácter pauciespecífico (compuesta por pocas especies), ocupa pequeñas superficies y presenta una baja cobertura, pero en ella aparecen algunas especies interesantes, como se refleja en la Tabla 5 (Anexo I). La posición topográfica en la que tiende a aparecer, claramente quionófoba, la relaciona con la misma clase Festucetea indigestae, de la que ya hemos comentado una asociación de fisonomía más graminoide; de hecho, tanto Arenaria querioides como Jurinea humilis son especies consideradas como características de dicha clase.

Costa et al. (2012) describieron de las áreas supratempladas culminantes de diversos macizos montañosos del NW de Portugal una comunidad desarrollada en un ambiente similar, a la que denominaron Arenario querioidis-Sedetum brevifolii. Las especies que conforman esta comunidad en el único inventario publicado por sus autores son, como características, Arenaria querioides, Sedum brevifolium y Agrostis truncatula (=A. durieui), y como compañeras, Tulipa australis, Thymus caespititius y Helictochloa marginata. Aunque dos de las especies más relevantes de esta comunidad se encuentran en la identificada en O Invernadeiro, existen diferencias florísticas evidentes, como la ausencia de Thymus caespititius, que no está pesente en el Parque. Además, hay un matiz peculiar que aporta Sesamoides minor $(=S$. pygmaea) a la comunidad de los Montes de Invernadeiro; esta especie es un endemismo de las montañas silíceas del noroeste ibérico, del que se conoce su presencia en el Macizo de Pena Trevinca colonizando pedreras formadas por pequeñas lajas esquisto-pizarrosas originadas por los ciclos de hielo/deshielo invernales que tienen lugar en los niveles orotemplados (Figura 10). Esa capacidad de colonizar depósitos de gelifractos es la principal característica de las comunidades de la clase Thlaspietea rotundifoliae, que también es conocida de los más altos sistemas montañosos de la Galicia Oriental; concretamente, de este macizo orensano-leonés se describió (Izco \& Ortiz 1987) una asociación denominada Sesamoido pygmeaeSilenetum gayanae, en la que participa flora típica de la clase Thlaspietea (Silene gayana, Linaria alpina, Rumex suffruticosus) y la especialista adaptada al pequeño tamaño de las lajas: Sesamoides minor.

A priori, la menor altitud del Macizo Central Ourensano y sus características geomorfológicas no parecen ser las más favorables para la formación de canchales de gelifractos similares a los existentes en el citado Macizo de Pena Trevinca, pero la presencia de Sesamoides minor en estas comunidades nos parece reveladora en cuanto a las condiciones ambientales que tienen las áreas supratempladas cumbreñas del Parque para albergar especies cuyo óptimo se encuentra en el piso orotemplado. 

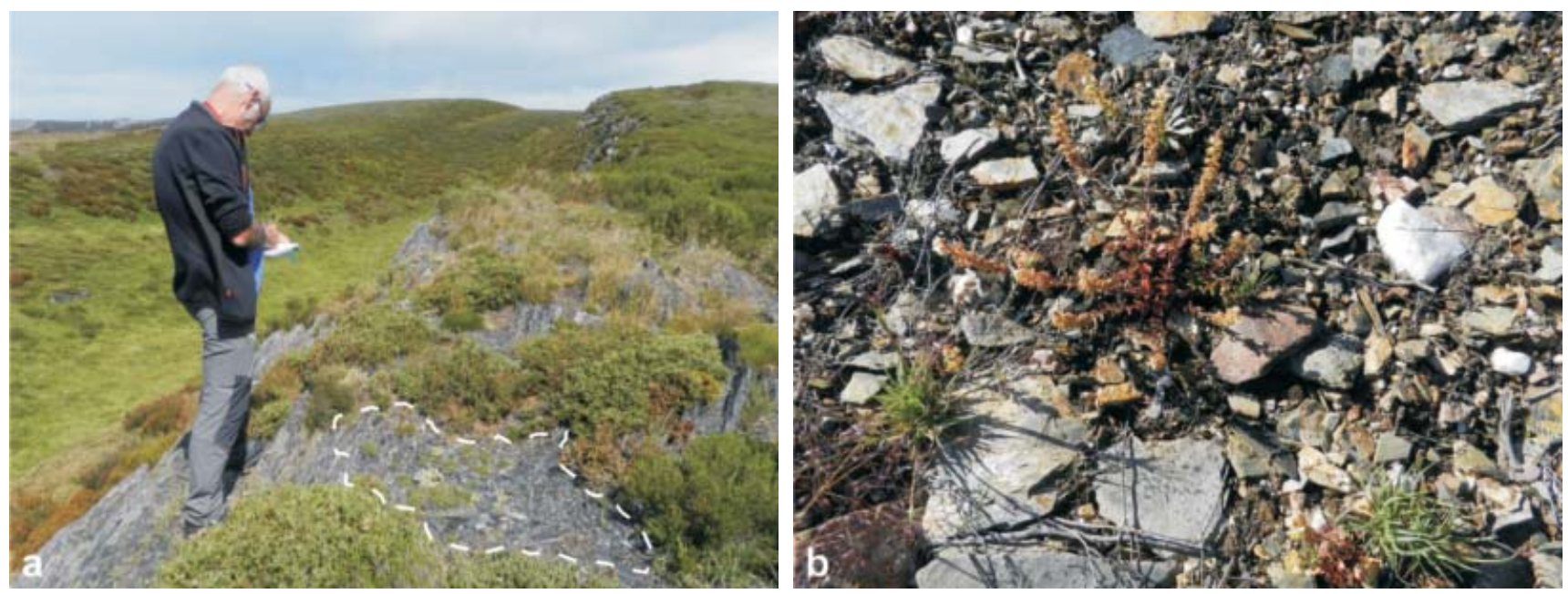

Figura 10.- Comunidad de Arenaria querioides y Sesamoides minor. Vista parcial de la Serra da Pena indicando la posición ecológica (línea discontínua) de esta comunidad (a) y detalle, mostrando un individuo de Sesamoides minor en el centro de la imagen, tomado en la cabecera del valle del Río do Casarello (b)

En espera de poder obtener más información para determinar si este tipo de vegetación pertenece o no a la asociación ourensano-sanabresa, la hemos denominado "comunidad de Arenaria querioides y Sesamoides minor".

En un ambiente ecológico similar, pero en situaciones topográficas más inclinadas, crece otra comunidad vegetal adaptada a la reptación ladera abajo, como consecuencia de los ciclos reiterados de hielo-deshielo, del sustrato sobre el que enraíza. Se trata de una comunidad vegetal que adopta una fisionomía escalonada y que se desarrolla, formando unas estructuras en guirnalda, en los frentes de reptación del sustrato. Esta comunidad vegetal recibe el nombre de Teesdaliopsio confertae-Festucetum summilusitanae y se extiende por las áreas orotempladas de las montañas silíceas del NW ibérico. Conocemos su presencia a escasos kilómetros del límite $\mathrm{N}$ del Parque, en los bordes superiores de los circos glaciares, a cotas superiores a los $1.500 \mathrm{~m}$, en donde se observan especies herbáceas como Teesdaliopsis conferta, Festuca summilusitana, Dianthus langeanus, Agrostis truncatula, Sedum brevifolium, Sedum anglicum, etc. (Anexo I: Tabla 6). Su presencia dentro de este espacio natural protegido en sentido estricto habrá de ser confirmado en futuros trabajos.

\section{Comunidades rupícolas orófilas}

Otro tipo de ambiente originado por la acción de los ciclos de hielo-deshielo son los depósitos de grandes fragmentos rocosos (canchales o pedrizas) que tapizan muchos laterales de los circos glaciares y las partes bajas de las vertientes en diversos sectores de las cabeceras de los valles de los arroyos de Casarello y Aguancenza (Figura 11). Aunque en su mayor parte se trata de depósitos estables, no es raro que reciban aportes esporádicos de clastos provenientes del desmantelamiento de paredes y vertientes rocosas situadas ladera arriba. Su vegetación es rala y de bajo porte, con predominio de líquenes, musgos y helechos adaptados a unas condiciones extremas, particularmente desecantes en los períodos en los que están desprovistos de cubierta nival. No hemos realizado un estudio particular de este tipo de ambiente, pero su apariencia es similar a la descrita en otras montañas silíceas del NW peninsular, en las que crece la comunidad denominada Cryptogrammo crispae-Dryoteridetum oreadis, que alcanza hacia el S la portuguesa Serra da Estrela (Rivas-Martínez 1981, Jansen 2011). En este sentido, tanto en las montañas de Xurés (Pulgar et al. 2001) como en el Macizo Central Ourensano (Redondo \& Horjales 1984) y en el propio Parque (Horjales et al. 2008), se ha citado la presencia del helecho Dryopteris oreades, una de las especies características de este tipo de biotopos y de la comunidad anteriormente comentada, que se incluye en la alianza Dryopteridion oreadis (orden Polystichetalia lonchitidis), perteneciente, igualmente, a la clase Thlaspietea rotundifolii.

Por último, dentro de este apartado dedicado a comunidades especializadas en colonizar sustratos rocosos escasamente edafizados, cabría comentar la existencia de una comunidad de baja cobertura dominada por gramíneas (Agrostis truncatula, Helictochloa marginata, Festuca summilusitana) y pequeñas plantas crasas del género Sedum (S. brevifolium), que coloniza las partes llanas o ligeramente inclinadas de roquedos (Figura 11b). Aunque no disponemos de inventarios concretos sobre los que sustentar una adscripción fitosociológica segura de esta comunidad, ampliamente repartida a lo largo de las áreas de cabecera del Parque, su composición florística presenta similitudes con la de la asociación Agrostio durieui-Sedetum pyrenaici, de muy amplia distribución en los territorios supratemplados y orotemplados inferiores de las montañas silíceas del cuadrante NW ibérico. Dicha comunidad pertenece a la clase Sedo albi-Scleranthetea biennis, que reúne comunidades herbáceas perennes especializadas en estos ambientes rupestres. No debe confundirse la comunidad aquí comentada con la cubierta vegetal 

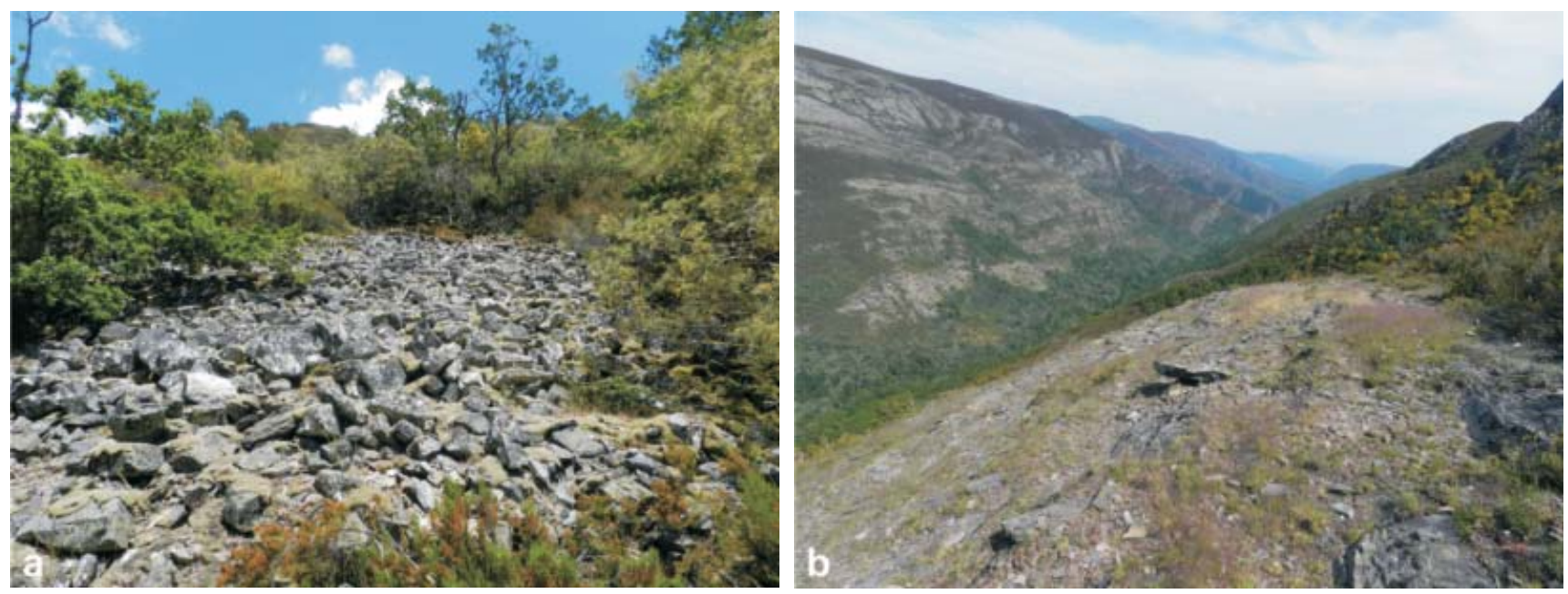

Figura 11.- Aspecto de un canchal en el tramo medio del valle de la Corga de Aguacenza (a) y de un pastizal pionero sobre roquedo pizarroso en la Cabecera del Río do Casarello (b)

dominada por Agrostis truncatula que se desarrolla profusamente a lo largo de los cortafuegos, tanto perimetrales como interiores, existentes en el Parque, cuya conformación, composición florística y persistencia se deben a la remoción periódica del sustrato que se realiza durante los trabajos de mantenimiento de estas infraestructuras forestales.

\section{Cervunales o nardetas}

En situaciones bien diferentes a las precedentes, se pueden encontrar unos pastizales perennes que se desarrollan preferentemente en áreas de montaña, en lugares que registran una prolongada innivación. Se trata de comunidades que crecen sobre suelos húmedos y ácidos, con cierta tendencia turbosa, lo que unido a la prolongada innivación que soportan, retrasa su óptimo fenológico hasta bien entrado el verano (Figura 12a). Por esta razón, son lugares aprovechados por la fauna silvestre $y$, en épocas (pre)históricas, el ganado doméstico, como fuente estival de pasto. Se identifican con la clase Nardetea strictae y en Galicia han sido reconocidas diversas asociaciones con un patrón de distribución parecido al de los pastos de Festucetea indigestae: los principales macizos montañosos de la Galicia oriental. Se reconocen más fácilmente en el piso orotemplado pero también se pueden presentar en el supratemplado, y en territorios hiperhúmedos, como en áreas de la Galicia próxima al litoral, también en el mesotemplado. En la bibliografía sobre vegetación, este tipo de comunidades herbáceas reciben el nombre de cervunales o nardetas, derivados, respectivamente, del nombre vulgar (cervuno) y científico (Nardus stricta) de la gramínea característica de estos ambientes.
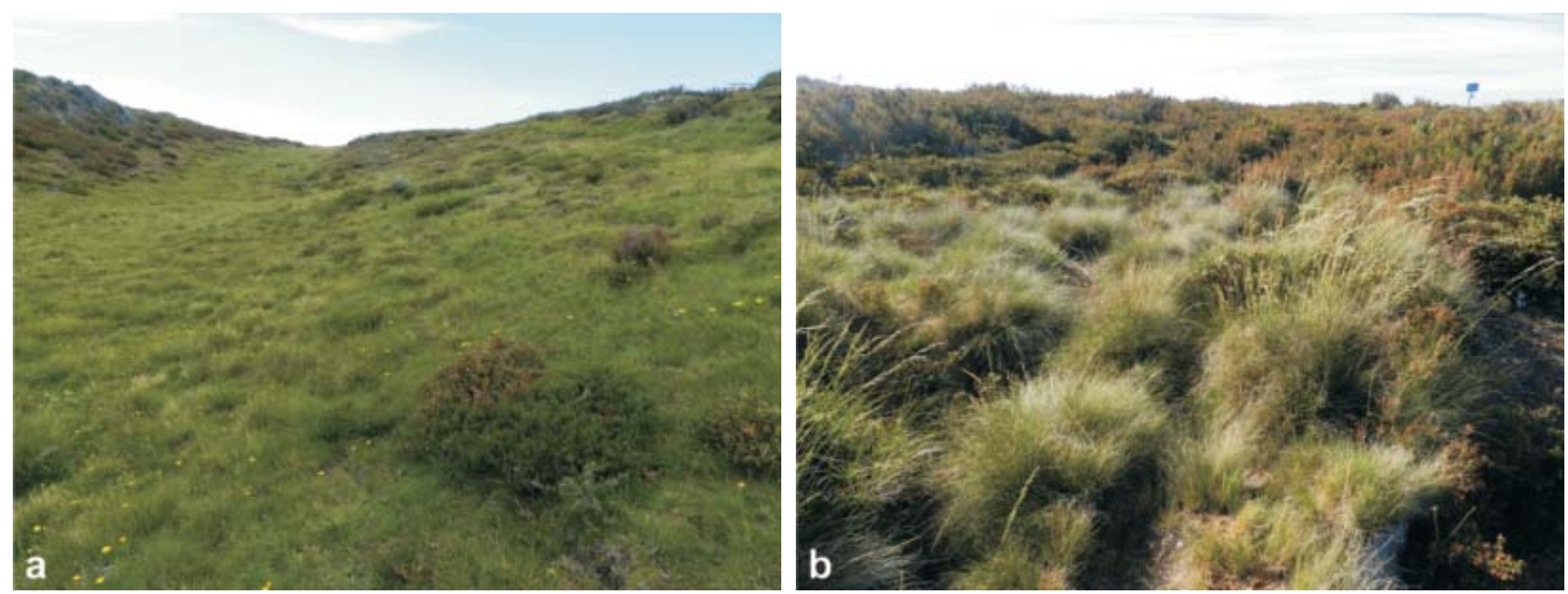

Figura 12.- Aspecto de un cervunal en el límite NE del parque (a) y de un herbazal de Festuca merinoi sobre suelos pizarrosos poco profundos no crioturbados en la Serra do Fial das Corzas (b) 
Debido a las características geomorfológicas y bioclimáticas de este Parque, no existen muchas áreas con condiciones favorables para el desarrollo de nardetas, que son algo más frecuentes en las áreas llanas culminantes que se extiende hacia el N del Macizo Central Ourensano. No obstante, ya Castroviejo (1977) describió la composición de algunas muestras y nosotros hemos tenido también la oportunidad de estudiar un par de localidades (Anexo I: Tabla 7), fácilmente reconocibles por su fisonomía de pradera herbácea homogénea y densa, asociada a una ligera depresión topográfica. Aunque su composición florística no se mostró demasiado rica, al menos presentaron unos cuantos componentes mínimos para su catalogación sintaxonómica dentro de la alianza Campanulo herminiiNardion strictae, que reúne distintas asociaciones de nardetas presentes a lo largo de las montañas silíceas comprendidas entre el Sistema Central y el occidente de la Cordillera Cantábrica; pero no tenemos elementos suficientes para asignarlos a alguna asociación concreta de entre las 4 que han sido reconocidas en Galicia. Como ocurre a menudo con comunidades que se presentan en situaciones desfavorables para sus requerimientos ecológicos, se observa un empobrecimiento en la composición florística que dificulta, como en este caso, la identificación de una asociación concreta.

\section{Comunidades herbáceas no orófilas}

Fuera de las áreas culminantes del Parque Natural do Invernadeiro se han identificado otros tipos de vegetación herbácea que ocupan ambientes ecológicos variados, cuyas características se detallan a continuación.

\section{Comunidades rupícolas}

Comenzando por los roquedos, es necesario advertir que la dificultad de acceso que presentan las zonas más escabrosas del Parque, particularmente las moles rocosas existentes en las cabeceras y tramos medios de los valles de Aguacenza y Casarelo así como el sector de Os Fornallos, ha impedido la realización, hasta el momento, de un estudio detallado de su flora y vegetación. La escasa información que se posee acerca de las comunidades rupícolas de las áreas media y baja del Parque Natural se ha obtenido en las inmediaciones de las vías rodadas que transitan por las partes bajas y la periferia de este espacio. Es el caso de una comunidad presidida por Silene acutifolia, cariofilácea endémica de Galicia, NE de León y Norte de Portugal (Guitián 1996) que hemos podido detectar en taludes inmediatos a la pista que discurre por el fondo de valle dirigiéndose a la Ribeira Grande. Se trata de un comófito que enraíza en grietas de roquedos silíceos que acumulan materia orgánica, en posición vertical o más o menos inclinada. Se han descrito varias asociaciones presidida por esta planta, correspondientes a distintas clases fitosociológicas.

Así, en el Parque Natural Baixa Limia-Xurés, Silene acutifolia acompaña a Festuca summilusitana en la asociación Minuartio recurvae-Silenetum acutifoliae, comunidad que se desarrolla sobre grietas con poca materia orgánica en las cumbres graníticas del Parque (Pulgar et al. 1996), pero que difiere sustancialmente de la que aquí comentamos. Sin embargo, se conoce otra asociación más claramente rupícola, endémica de los fondos de valle donde desemboca el río Sil en el Miño, en la que esta especie se posiciona en ambientes más térmicos y forma una comunidad que coloniza grietas de laderas y paredes de rocas silíceas; esta otra se denominó Holco gayani-Silenetum acutifoliae (Bellot 1951), en posición altitudinal menos montana que la de la Serra do Xurés. La Tabla 8 (Anexo I) muestra el único inventario que hemos recopilado de la comunidad presidida por $S$. acutifolia dentro de los límites del Parque, localizada en paredes casi verticales a unos $900 \mathrm{~m}$ de altitud. Aunque su composición florística resulta un tanto particular, nos inclinamos a considerarla como una comunidad más afín a esta segunda asociación, cuya posición sintaxonómica sigue siendo litigiosa por la escasez de datos publicados sobre ella. En la recopilación de la vegetación herbácea de Galicia publicada por Izco et al. (2001) las muestras que se conocían de Galicia fueron incluidas dentro de la clase Anomodonto-Polypodietea cambrici pero, posteriormente, autores portugueses (Costa et al. 2012) la consideraron perteneciente a la clase más estrictamente rupícola de Asplenietea trichomanis. La población de Invernadeiro deberá ser estudiada para aportar más datos que contribuyan a aclarar este dilema.

\section{Herbazales pioneros}

En ambientes con un mayor grado de evolución edáfica, pero en posiciones de cierta inclinación se han observado otras comunidades herbáceas silicícolas perennes que suelen aparecer ligadas a bosques dominados por Quercus perennifolios o marcescentes de óptimo mediterráneo (comunidades de la clase Stipo-Agrostietea), pero que pueden presentarse en posiciones xéricas dentro de territorios Cantabro-Atlánticos u Orocantábricos, preferentemente si el bioclima templado es de carácter submediterráneo. Aunque este tipo de pastizales no es demasiado rico en especies porque los sustratos sobre los que se desarrolla son de carácter oligotrófico, suelen albergar una apreciable proporción de flora endémica de la Península Ibérica. Dentro del territorio estudiado hemos reconocido la presencia de dos asociaciones. La primera, Sedo forsteriani-Agrostietum castellanae, se identifica por la abundancia del endemismo europeo occidental Sedum forsterianum ( $=S$. elegans), que destaca en época de floración fini-primaveral, al que acompaña un componente graminoide (Agrostis sp. pl., Periballia involucrata) más o menos esparcido. Sus formaciones suelen presentarse en pequeñas superficies, colonizando taludes y márgenes de caminos, principalmente si están en exposiciones soleadas y si esos taludes han quedado desprovistos de vegetación leñosa. Estas situaciones son relativamente comunes en los márgenes de las pistas que discurren por los fondos de valle, como la que une la entrada al Parque en la Ribeira Pequena hasta el Aula da Natureza. Castroviejo (1977) indicó la existencia de esta asociación en los Montes do Invernadeiro.

Phalacrocarpo oppositifolii-Festucetum merinoi es una comunidad de parecidas apetencias ecológicas a la anterior, por lo que en ocasiones se pueden ver retazos de una imbricándose en la otra. Pero esta asociación es más 
propensa a colonizar taludes anfractuosos, irregulares combinando asomos de rocas esquistoso-pizarrosas con escasa terrificación entre sus lajas (Figura 12b). Se encuentra preferentemente en los tramos inferiores de los valles y se hace más reconocible cuando proliferan las macollas de la gramínea que la preside: Festuca elegans subsp. merinoi; también es importante en esta comunidad, aunque su cobertura sea más escasa, la compuesta Phalacrocarpum oppositifolium. Esta asociación es endémica de los macizos montañosos silíceos del cuadrante noroeste ibérico y en $\mathrm{O}$ Invernadeiro tiene el valor añadido de que la compuesta participante se trata de $P h$. oppositifolium subsp. hoffmannsegi, un taxón de distribución aún más restringida, exclusiva del área ourensanozamorana.

\section{Herbazales de linderos y claros de bosque}

Otro tipo de vegetación diferente es la que comprende herbazales perennes que se asientan en linderos de bosque, sobre suelos profundos pero no nitrificados (clase Trifolio-Geranietea). Se caracterizan por estar constituidos por hierbas tiernas que pueden elevarse hasta $1 \mathrm{~m}$ o más del suelo, que no soportan el pisoteo y que tienen un carácter semiesciófilo, ya que aprovechan el ambiente umbroso proporcionado por las copas de los árboles y un cierto aumento de la luminosidad procedente de entornos próximos más despejados. Tampoco en esta ocasión conseguimos ningún inventario completo, pero sí hemos podido visualizar y certificar la existencia de algún individuo de asociación de la Omphalodo nitidae-Linarietum triornithophorae, una asociación de lindes de bosques acidófilos conocida en ambientes meso- y supratemplados de los territorios orocantábrico y cántabro-atlántico. La participación en ella de plantas como Linaria triornithophora, Hypericum pulchrum, Omphalodes nitida o Prunella grandiflora es suficiente para admitir la presencia de esta asociación en el Parque; el ejemplo mejor estructurado que pudimos encontrar se localizaba en las proximidades del tramo final de la Ribeira Grande, en los taludes herbosos que caen de la pista forestal hacia el bosque de ribera que se sitúa apenas a $10 \mathrm{~m}$ de la pista. Un componente que participaba de esta comunidad y que contribuye a darle un valor particular es la presencia de un endemismo galaicoportugués: Galium belizianum. Esta especie fue descrita a principios del presente siglo (Ortega-Olivencia et al. 2004) como un endemismo del extremo norte de Portugal, aunque poco más tarde se encontró en la parte gallega contigua que forma parte del Parque Natural Baixa Limia-Xurés (Pulgar 2006). Con su hallazgo en esta comunidad dentro del Parque Natural do Invernadeiro se amplía algo más su rango geográfico y se incrementa el catálogo florístico de este espacio con un endemismo que cumple muchos criterios para ser incluido dentro del Catálogo Galego de Especies Ameazadas.

\section{Comunidades higrófilas asociadas a aguas corrientes}

Asociada a paredes rezumantes sobre roquedos ácidos y márgenes de arroyos de aguas frías limpias se conforman comunidades herbáceas perennes dominadas por helófitos y con presencia más o menos destacada de briófitos (clase Montio-Cardaminetea). Aunque las formaciones más típicas y de mayor biomasa suelen ocurrir en arroyos juveniles con roquedos y pequeñas cascadas que propician salpicadura y nebulización de agua, más frecuentes en los pisos supra- y orotemplado (o supra- y oromediterráneo), también hay comunidades que se pueden presentar en pisos bioclimáticos inferiores. Es el caso de la asociación Saxifragetum lepismigenae caracterizada por el endemismo del noroeste ibérico Micranthes lepismigena (= Saxifraga lepismigena) con muy pocas compañeras vasculares, pero con pequeñas almohadillas de briófitos (Mnium sp., Bryum $\mathrm{sp}$.). Es una asociación que se presenta en paredes y taludes rezumantes, que se empapan de agua, con más facilidad (por menor competencia con otras plantas) si la pared es irregular, como ocurre a menudo en áreas de rocas esquisto-pizarrosas (Figura 13a). Tampoco hemos podido tomar inventarios de esta asociación pero la hemos detectado por la presencia de algunos tapices de Micranthes lepismigena en plena floración en taludes de los márgenes de la pista de entrada al Parque (fondo del valle de la Ribeira Pequena) y de la que recorre el valle de la Corga de Aguacenza, entre el desvío a O Rocín y el Prado do Figueiro.

\section{Vegetación de turberas}

Castroviejo (1977) hace mención en su trabajo de la existencia de una única turbera en los Montes de Invernadeiro, localiza bajo la cumbre del pico "Cabeza do Cernado", a unos 1.450 m de altitud, en exposición SSW y una inclinación de unos $15^{\circ}$, y sobre un depósito orgánico de $135 \mathrm{~cm}$ de espesor. Según el inventario que aporta, la vegetación presente en este lugar tendría un porte arbustivo y estaría dominada por Erica tetralix y Calluna vulgaris, entre las que se intercalarían musgos del género Sphagnum y diversas plantas herbáceas habituales en este tipo de medios, como Carex echinata, C. binervis, C. muricata, Dactylorhiza maculata, Drosera rotundifolia, Molinia caerulea, Genista micrantha, Juncus acutiflorus, J. effusus, J. squarrosus, Pedicularis sylvatica o Potentilla erecta.

La observación detallada de la ortoimagen disponible permite establecer que tal afirmación es demasiado taxativa, puesto que, dentro de los límites del Parque y en su entorno más próximo existen varios lugares en los que están presentes los ecosistemas turbosos, aunque es bien cierto que ocupan superficies de poca extensión. En uno de nuestros itinerarios de muestreo hemos tenido oportunidad de observar uno de estos ambientes desarrollado en una ladera enmarcada en un circo glaciar, entre los 1.465 y $1.485 \mathrm{~m}$ de altitud (Figura 13b), cuyo aspecto nos ha parecido muy similar al que se puede observar en turberas presentes en otros sectores culminantes del Macizo de Queixa.

Se trata de sistemas originados en puntos en los que el nivel freático de las laderas aflora en superficie, dando lugar, en combinación con las temperaturas medias anuales bajas que se registran en las cumbres de estas montañas, a un ambiente favorable para la acumulación de los restos orgánicos que anualmente produce su cubierta vegetal. Aunque no hemos realizado un estudio exhaustivo de su vegetación, hemos comprobado que está conformada por un mosaico de varias comunidades vegetales 

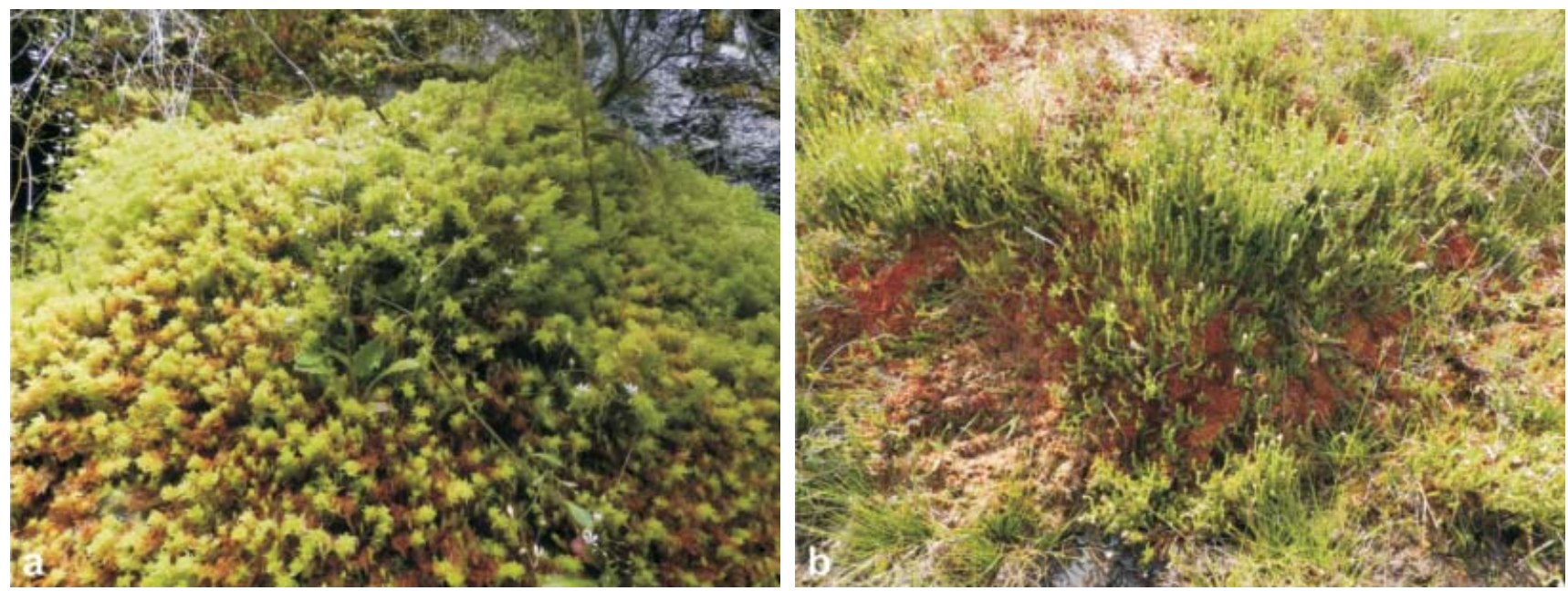

Figura 13.- Detalles de una comunidad de paredes rezumantes (Saxifragetum lepismigenae) (a) y de un abombamiento colonizado por Erica tetralix y esfagnos en una turbera ácida en el extremo $\mathrm{N}$ del Parque (b)

(abombamientos de esfagnos, comunidades herbáceas dominadas por ciperáceas y juncáceas, matorrales higroturfófilos, comunidades pioneras de calveros sobre turba), en función del grado de encharcamiento que registran y la alteración debida al tránsito de la fauna silvestre, particularmente cabras montesas, de manera que solamente una parte de este ambiente turboso vendría a corresponder por lo descrito por Castroviejo (1977). La descripción detallada de estos complejos de vegetación turfófila necesita de la recopilación de información específica.

Esquema de la cubierta vegetal del Parque Natural do Invernadeiro

Algunos trabajos previos han aportado representaciones gráficas en las que se pueden reconocer diversos aspectos de la cubierta vegetal de las Montañas do Invernadeiro. Luís Crespí realizó un esbozo, incluido en la publicación de Rodríguez Bouzo (1929), en el que se evidencia el elevado grado de deforestación que presentaban estas montañas hace casi un siglo, así como la persistencia del escaso arbolado a lo largo de los principales cauces fluviales (Figura 14a). Castroviejo (1977) aporta diversas ilustraciones de las etapas dinámicas que él establece para los brezales, la disposición de las comunidades a lo largo de los ejes fluviales y en los cervunales y un bloque-diagrama (Figura 14b) mostrando la disposición de las formaciones vegetales más ampliamente distribuidas por $\mathrm{O}$ Invernadeiro (brezales, abedulares, robledales, melojares y bosques de ribera). Más recientemente, Pulgar (2004) incluyó una catena idealizada de las comunidades vegetales que identificó dentro del Parque (Figura 14c), aunque algunas de ellas no son descritas en los textos de esa publicación.

Por nuestra parte, a partir de la información recopilada para este trabajo, hemos elaborado el modelo de distribución de las comunidades vegetales dentro del Parque que se muestra en la Figura 14d. Aunque parcial en cuanto a su contenido, por cuanto el trabajo realizado se considera incompleto debido a limitaciones temporales para su realización, la catena comentada presenta un aspecto abigarrado, acorde con la gran variedad de ambientes ecológicos que hemos reconocido dentro del Parque y que son claramente más numerosos que los descritos por Castroviejo (1977) o Pulgar (2004). Una elevada complejidad ambiental en estas montañas era esperable teniendo en cuenta algunos trabajos de detalle que han sido publicados en otros macizos montañosos del NW Ibérico, como la Reserva Integral de Muniellos (Fernández Prieto \& Bueno 1996), la Devesa da Rogueira (Rodríguez Guitián et al. 2013) o la Reserva de Biosfera de "Os Ancares Lucenses e Montes de Cervantes, Navia e Becerreá" (Rodríguez Guitián et al. 2014). Para ejemplificar la diversidad ecológica del área de estudio, presentamos en la Figura 15 una interpretación "realista" de la distribución de las comunidades vegetales con mayor representación a escala de paisaje que se pueden observar en uno de los escenarios más emblemáticos del PNI por su elevado valor de conservación: la cabecera del valle de la Corga de Aguacenza.

Afinidades biogeográficas del PNI con las montañas galaico-portuguesas y galaico-durienses

Desde el punto de vista geográfico, el PNI, junto con el resto de las montañas que conforman el Macizo Central ourensano, constituyen un puente entre las sierras de límite Galaico-Portugués. Como ya se comentó en una sección anterior, esta posición intermedia ha sido valorada en el plano biogeográfico de diferente manera por sucesivos autores, en gran medida, debido a la escasez de información botánica sobre toda esta gran área montañosa. Aunque este trabajo debe de considerarse como una modesta contribución dirigida a llenar ese vacío de información, nos permite precisar algo más en el conocimiento de las relaciones botánicas y biogeográficas 
existentes entre el PNI y otras áreas montañosas silíceas del extremo noroccidental ibérico (Tabla 1), ya sea hacia el SW (montañas de Larouco, Xurés-Gerês y Peneda-
Leboreiro), hacia el E (macizo de Trevinca-Sanabria, sierras de La Cabrera y del Teleno) o el SSE, en dirección a Portugal (sierras de Nogueira y Montezinho).
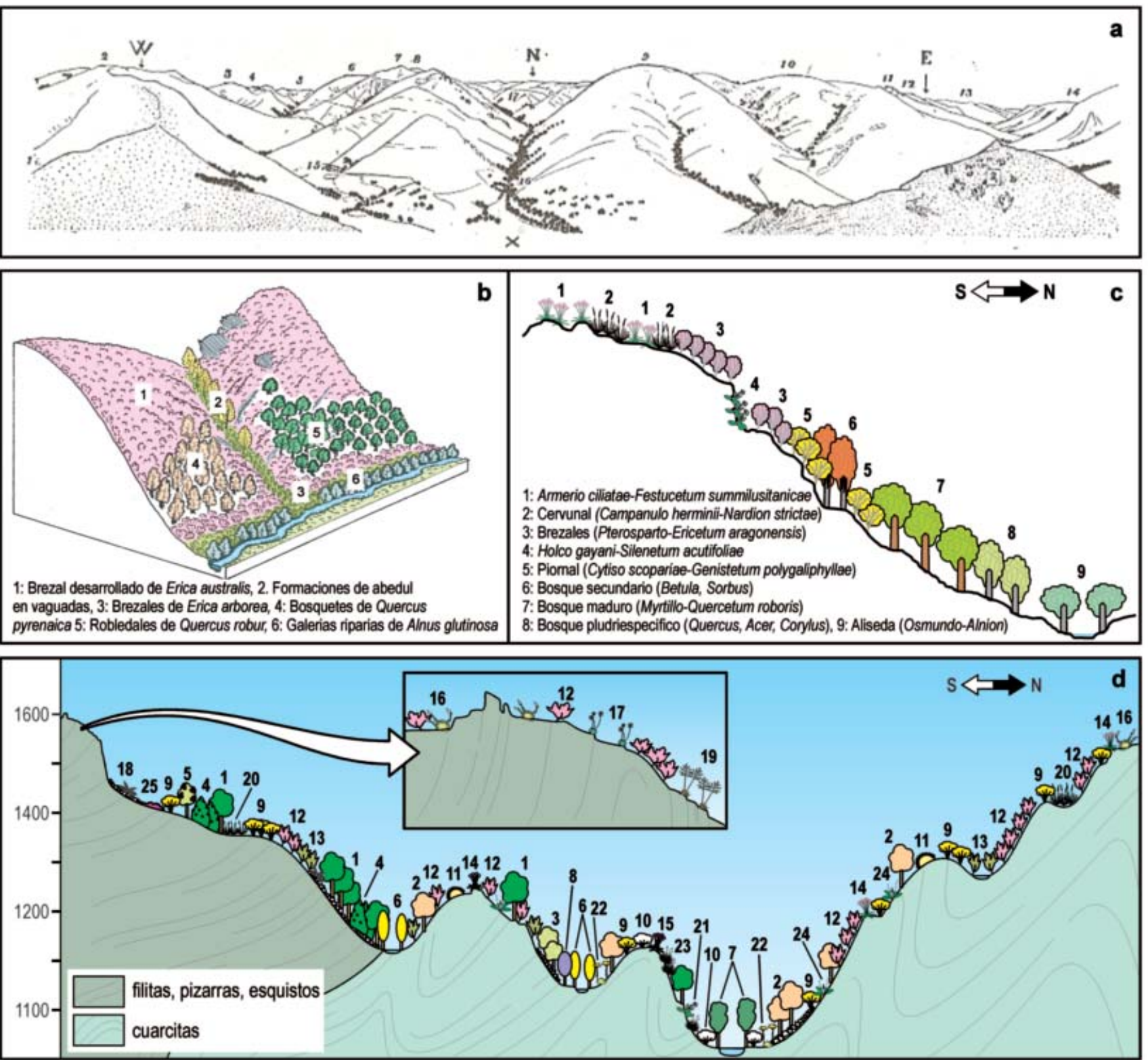

1: robledales (carballais) de Quercus robur 4 2: melojares (reboleiras) de Quercus pyrenaica $Q 9$ 3: bosques mixtos sobre coluviones 4: acebedas 9 5: bosques secundarios de abedul y escomabois $Q$ 6: abedulares riparios 9 7: alisedas riparias $Q 9$ 8: abedulares higro-turfófilos $\$$ 9: piornales de Genista polygaliphylla $\$$ 10: xesteiras de Cytisus multiflorus $P$ 11: cambrionales de Echinospartum ibericum 12: brezales de Erica aragonensis $\quad$ 13: com. de Armeria ciliata y Festuca summilusitana 5 15: com. de Armeria ciliata y Dianthus merinoi $\quad$ 16: com. de Arenaria querioides y Sesamoides minor 17 17: Teesdaliopsio confertae-Festucetum summilusitanae 18: com. de canchales $\$$ 19: com. pionera de roquedos 4 20: cervunales 21: com. de Silene acutifolia TI 22: herbazales de Sedo forsteriani-Agrostietum castellanae Th: herbazales de Phalacrocarpo oppositifoliae-Festucetum merinoi 24: herbazales de Omphalodo nitidae-Linarietum triomithophorae

25: comunidades de turberas

Figura 14.- Esquemas mostrando diversos aspectos de la cubierta vegetal de los Montes de Invernadeiro publicados por a: Rodríguez Bouzo (1929), b: Castroviejo (1977, modificado), c: Pulgar (2004, modificado); y d: diagrama mostrando la distribución idealizada de las comunidades vegetales descritas en este trabajo 


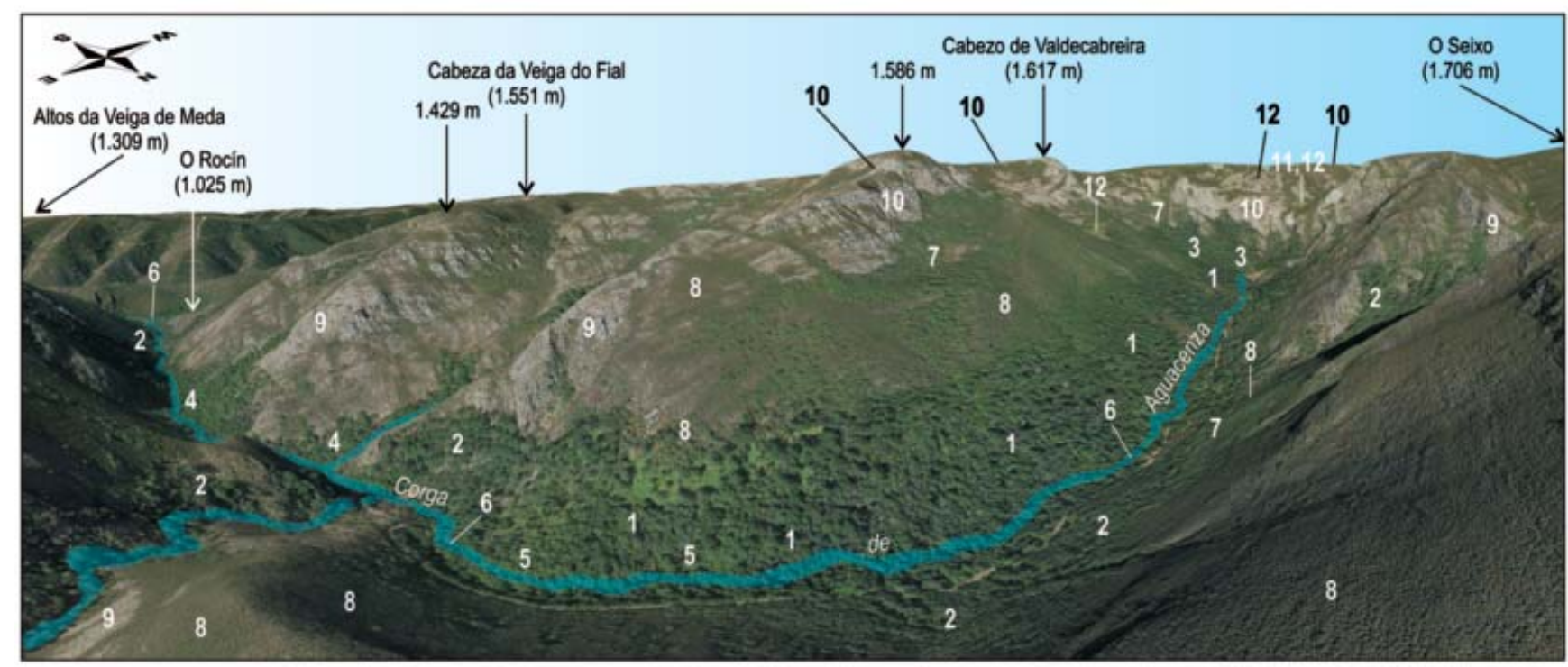

Figura 15.- Distribución de las principales comunidades vegetales reconocidas a lo largo del valle de la Corga de Augacenza, representativo del sector altitudinal superior del Parque Natural do Invernadeiro. 1: robledales umbrófilos de Quercus robur (Vaccinio myrtilli-Quercetum roboris), 2: robledales helio-xerófilos de Quercus pyrenaica (Holco mollis-Quercetum pyrenaicae), 3: acebedas, 4: bosques mixtos silicícolas sobre coluviones, 5: abedulares higro-turfófilos, 6: abedulares riparios (Valeriano officinalis-Betuletum pubescentis), 7: piornales de Genista polygaliphylla (Cytiso scoparii-Genistetum polygaliphyllae), 8: brezales secos (Pterosparto lasianthiEricetum aragonensis), 9: comunidades de roquedos y litosuelos, 10: comunidades de suelos crioturbados, 11: cervunales, 12: turberas. Figura elaborada a partir de imágenes obtenidas de GoogleEarth (https://www.google.com/earth/)

En relación a las comunidades arbóreas, el PNI parece mostrar una mayor proximidad a los macizos montañosos del área limítrofe ourensano-zamorano-leonesa, al compartir con aquellos los bosques de rebolo (Holco mollisQuercetum pyrenaicae), las acebedas y la comunidad de abedulares riparios (Valeriano officinalis-Betuletum pubescentis); sin embargo, la existencia de robledales dominados por Quercus robur (Vaccinio myrtilli-Quercetum roboris), ausentes de los macizos orientales de TrevincaSanabria, Cabrera, Teleno y Montezinho-Nogueira, establece un vínculo biogeográfico con las montañas "raianas" galaico-portuguesas, de carácter más oceánico.

Dentro del apartado de matorrales puede reconocerse una tendencia parecida a la descrita para las comunidades arbóreas, con presencia en el PNI de ciertas comunidades, como la de los brezales mayoritarios en este espacio, que no se presentan en las montañas del límite galaicoportugués centro-occidental (Peneda-Laboreiro y GerêsXurés), y que se comparten con montañas más orientales.

Por último, en lo relativo a la vegetación herbácea, y aunque el conjunto de comunidades aquí tratadas es una muestra parcial de las que podrían estudiarse, se refuerza la mayor vinculación biogeográfica de $\mathrm{O}$ Invernadeiro con varios macizos montañosos del oriente ourensano y $\mathrm{NE}$ de Portugal, particularmente los primeros.

La conclusión que se extrae de la revisión de la cubierta vegetal del PNI realizada en este estudio, es que el conjunto montañoso dentro del que se incluye (Macizo Central Ourensano) muestra una conexión biogeográfica más acentuada con las montañas del límite galaico-zamorano- leonés que con las situadas hacia el SSW del área de estudio. Este fenómeno estaría relacionado con el carácter más continental de estas montañas, inherente a su situación geográfica más interior, y con la mayor superficie que presentan dentro del horizonte superior del termotipo supratemplado en relación a lo que ocurre en los conjuntos montañosos del límite galaico-portugués centro-occidental. Estos dos factores justificarían, además, la existencia de determinadas comunidades en el PNI a las que se atribuye un óptimo orotemplado, y que no han sido reconocidas en las sierras luso-galaicas comentadas. Las condiciones bioclimáticas de atlanticidad que se registran en el PNI son congruentes con el carácter florístico que presentan los bosques de más amplia representación en este espacio y tienen continuidad con el resto de la fachada occidental del Macizo de Queixa (Morla 1985, Costa-Tenorio et al. 1990, Morla et al. 1990) y con las elevaciones montañosas situadas más hacia el oriente (Rodríguez Guitián \& RamilRego op. cit., González de Paz 2012).

Estas evidencias vienen a apoyar la propuesta de sectorización biogeográfica de Galicia realizada por Rodríguez Guitián \& Ramil Rego (2008), en la que las montañas del PNI, junto al resto del Macizo de Queixa, aparecen reunidas en una unidad (subsector Queixense) que constituye el extremo occidental del gran arco montañoso que establece la divisoria de augas Sil/Duero (Sector Galaico-Duriense), integrada en la subprovincia Orocantábrica. Por ello, defendemos que debe rechazarse su consideración como territorios de carácter mediterráneo, tal y como propugnan Rivas-Martínez et al. (2017). 


\begin{tabular}{|c|c|c|c|c|c|c|c|c|c|}
\hline \multirow{2}{*}{ Comunidades } & \multirow{2}{*}{$\begin{array}{c}\text { Castroviejo } \\
\text { (1977) }\end{array}$} & \multicolumn{8}{|c|}{ Territorios } \\
\hline & & P-L & G-X & PNI & MQ & T-S & PNM & C & $T$ \\
\hline \multicolumn{10}{|l|}{ Bosques } \\
\hline Robledales supratemplados (Vaccinio myrtilli-Quercetum roboris) & $S$ & ++ & + & + & ++ & - & - & - & - \\
\hline Melojares supratemplados (Holco mollis-Quercetum pyrenaicae) & $S$ & - & ++ & + & ++ & ++ & ++ & ++ & ++ \\
\hline Bosques mixtos de barrancos & $\mathrm{N}$ & - & - & + & - & - & - & - & - \\
\hline Acebedas & $S$ & $?$ & $?$ & + & ++ & ++ & - & - & - \\
\hline Abedulares riparios xuresianos (Carici reuterianae-Betuletum celtibericae) & $\mathrm{N}$ & ++ & ++ & - & - & - & - & - & - \\
\hline Abedulares riparios galaico-durienses (Valeriano officinalis-Betuletum pubescentis) & $\mathrm{N}$ & - & - & ++ & ++ & ++ & + & + & - \\
\hline Alisedas riparias supramediterráneas (Galio broterianae-Alnetum glutinosae) & S & + & ++ & + & + & + & ++ & ++ & ++ \\
\hline Abedulares higro-turfófilos & $\mathrm{N}$ & - & - & + & + & + & - & $?$ & - \\
\hline \multicolumn{10}{|l|}{ Matorrales } \\
\hline Brezales secos (Pterosparto lasianthi-Ericetum aragonensis) & S & - & - & +++ & +++ & +++ & +++ & +++ & +++ \\
\hline Brezales de Erica arborea & $S$ & + & + & + & + & + & + & + & + \\
\hline Brezales higro-turfófilos (Genisto anglicae-Ericetum tetralicis) & S & + & + & + & + & + & + & + & + \\
\hline Cambrionales (Festuco graniticolae-Echinospartetum pulviniformis) & $\mathrm{N}$ & + & + & + & + & + & + & + & + \\
\hline Piornales supratemplados de Genista obtusiramea & $S$ & - & + & $?$ & ++ & + & - & + & + \\
\hline Piornales supratemplados de (Cytiso scoparii-Genistetum polygaliphyllae) & S & + & ++ & ++ & ++ & ++ & + & ++ & ++ \\
\hline Escobonales de Cytisus multiflorus & S & + & ++ & ++ & ++ & ++ & ++ & ++ & ++ \\
\hline \multicolumn{10}{|l|}{ Comunidades herbáceas } \\
\hline Comunidad de suelos Ilanos crioturbados (Com. de Sesamoides minor) & $\mathrm{N}$ & - & - & + & $?$ & - & - & - & - \\
\hline Com. de laderas crioturbadas (Teesdaliopsio confertae-Festucetum isummilusitanae) & $\mathrm{N}$ & - & - & $?$ & + & ++ & - & ++ & ++ \\
\hline Com. de gleras finas (Sesamoido pygmeae-Silenetum gayanae) & $\mathrm{N}$ & - & - & - & - & + & - & + & - \\
\hline Com. de canchales (Dryopteridion oreadis) & $\mathrm{N}$ & - & - & $?$ & $?$ & + & - & + & + \\
\hline Com. rupicola (Armerio ciliatae-Festucetum summilusitanae) & $\mathrm{N}$ & - & - & + & + & + & - & - & - \\
\hline Com. casmofítica (Holco gayani-Silenetum acutifoliae) & $\mathrm{N}$ & - & - & $?$ & + & - & - & - & - \\
\hline Com. casmofitica (Minuartio recurvae-Silenetum acutifoliae) & $\mathrm{N}$ & + & + & - & - & - & - & - & - \\
\hline Herbazales pioneros supra-orotemplados (Agrostio durieui-Sedetum pyrenaici) & $\mathrm{N}$ & - & - & + & $?$ & + & - & + & - \\
\hline Herbazales pioneros meso-supratemplados (Sedo forsteriani-Agrostietum castellanae) & S & - & - & + & $?$ & - & - & - & - \\
\hline Herbazales vivaces (Phalacrocarpo oppositifolii -Festucetum merinoi) & $\mathrm{N}$ & - & - & + & - & - & + & - & - \\
\hline Herbazales de linde de bosque (Omphalodo-Linarietum triornithophorae) & $\mathrm{N}$ & + & + & + & + & + & - & - & - \\
\hline
\end{tabular}

Acrónimos de territorios: P-L: Peneda-Laboreiro; G-X: Gerês-Xurés; PNI: Parque Natural do Invernadeiro; MQ: resto del Macizo de Queixa; T-S: S Macizo de Trevinca-Sanabria; PNM: Parque Natural de Montezinho (Portugal); C: Sierra de La Cabrera; T: Sierra del Teleno. -: comunidad ausente; +: comunidad poco frecuente; ++: comunidad frecuente; +++: comunidad muy frecuente; ?: comunidad de presencia no confirmada.

Tabla 1.- Distribución de diferentes comunidades vegetales a lo largo de los macizos montañosos galaico-durienses y nor-portugueses y correspondencia con los tipos de hábitats del Anexo I de la DC 92/43/CEE

Los tipos de hábitats de la DC 92/43/CEE en el Parque Natural do Invernadeiro

La casi totalidad del territorio comprendido dentro del Parque se encuentra dentro de los límites de la Zona de Especial Conservación "ES1130002 Macizo Central", espacio natural protegido perteneciente a la Red Natura 2000 europea, establecida en virtud de la DC 92/43/CEE. Según el formulario estandarizado de datos proporcionado por la Agencia Ambiental Europea (AAE 2019), este espacio incluiría 28 tipos de hábitats del Anexo I de la DC 92/43/CEE tipificados como de interés comunitario, de los que 5 serían de tipo prioritario (Tabla 2). Según el Decreto 102/2019, de 11 de julio, publicado en el Diario Oficial de Galicia Núm. 170 de lunes, 9 de septiembre de 2019 (XUNTA 2019), estarían presentes dentro de los límites del Parque Natural do Invernadeiro un total de 16 tipos de hábitats del Anexo I de la DC 92/43/CEE tipificados como de interés comunitario (3 de ellos, prioritarios).

La información fitosociológica aportada en este trabajo puede utilizarse para valorar la variabilidad local de las comunidades vegetales que se integran en diversos tipos de hábitats incluídos en el Anexo I de la DC 92/43/CEE, constituyendo, en casos como el de las comunidades de suelos crioturbados, ambientes rupícolas o diversos tipos de bosques, la primera información fitosociológica disponible a este respecto dentro de este espacio. A este respecto (Tabla 2), los trabajos de campo realizados confirman la existencia dentro de los límites del Parque Natural estudiado de 22 de los 28 tipos de hábitats que figuran en la documentación proporcionada por la AAE (2019) como presentes dentro de la ZEC Macizo Central. Sin embargo, estos resultados no 


\begin{tabular}{|c|c|c|c|c|}
\hline $\begin{array}{l}\text { Código } \\
\text { Nat } 2000\end{array}$ & Denominación & $\begin{array}{c}\text { ZEC } \\
\text { Macizo Central } \\
\text { (AAE 2019) }\end{array}$ & $\begin{array}{c}\text { P. Nat. do } \\
\text { Invernadeiro } \\
\text { (XUNTA 2019) }\end{array}$ & $\begin{array}{l}\text { Este } \\
\text { trabajo }\end{array}$ \\
\hline 3160 & Lagos y estanques distróficos naturales. & - & - & 0 \\
\hline 3260 & Rios, de pisos de planicie a montano con vegetación de Ranunculion fluitantis y de Callitricho-Batrachion. & - & $\bullet$ & - \\
\hline $4020^{*}$ & Brezales húmedos atlánticos de zonas templadas de Erica cillaris y Erica tetralix. & $\bullet$ & - & $\bullet$ \\
\hline 4030 & Brezales secos europeos. & - & - & - \\
\hline 4060 & Brezales alpinos y boreales. & $\bullet$ & $\cdot$ & $\cdot$ \\
\hline 4090 & Brezales oromediterráneos endémicos con aliaga. & $\bullet$ & $\bullet$ & - \\
\hline $5230^{*}$ & Matorrales arborescentes de Laurus nobilis & $\bullet$ & $\cdot$ & - \\
\hline 6160 & Prados ibéricos siliceos de Festuca indigesta & $\bullet$ & - & - \\
\hline $6220^{*}$ & Zonas subestépicas de gramineas y anuales del Thero-Brachypodietea & $\bullet$ & $\bullet$ & 0 \\
\hline $6230^{*}$ & $\begin{array}{l}\text { Formaciones herbosas con Nardus, con numerosas especies, sobre sustratos siliceos de zonas montañosas } \\
\text { (y de zonas submontañosas de la Europa continental). }\end{array}$ & $\bullet$ & $\bullet$ & $\bullet$ \\
\hline 6410 & Prados con molinias sobre sustratos calcáreos, turbosos o arcillo-limónicos (Molinion caeruleae). & - & - & 0 \\
\hline 6430 & Megaforbios eutrofos hidrófilos de las orlas de llanura y de los pisos montano a alpino. & - & - & 0 \\
\hline 6510 & Prados pobres de siega de baja altitud (Alopecurus pratensis, Sanguisorba officinalis). & $\bullet$ & - & - \\
\hline 6520 & Prados de siega de montaña. & $\cdot$ & $\bullet$ & 0 \\
\hline $7110^{*}$ & Turberas altas activas. & $\bullet$ & - & - \\
\hline 7140 & «Mires» de transición. & $\bullet$ & - & 0 \\
\hline 7150 & Depresiones sobre sustratos turbosos del Rhynchosporion. & $\bullet$ & - & - \\
\hline 8130 & Desprendimientos mediterráneos occidentales y termófilos. & $\bullet$ & $\bullet$ & $\bullet$ \\
\hline 8220 & Pendientes rocosas siliceas con vegetación casmofitica. & $\bullet$ & $\bullet$ & $\bullet$ \\
\hline 8230 & Roquedos siliceos con vegetación pionera del Sedo-Scleranthion o del Sedo albi-Veronicion dillenii & $\bullet$ & $\bullet$ & $\bullet$ \\
\hline 8310 & Cuevas no explotadas por el turismo. & $\bullet$ & $\bullet$ & 0 \\
\hline 9180 & Bosques de laderas, desprendimientos o barrancos del Thlio-Acerion. & $\bullet$ & - & - \\
\hline $910^{*}$ & Turberas boscosas. & - & - & $?$ \\
\hline 91E0* & Bosques aluviales de Alnus giutinosa y Fraxinus excelsior (Almo-Padion, Alnion incanae, Salicion albae). & $\bullet$ & • & - \\
\hline 9230 & Robledales galaico-portugueses con Quercus robur y Quercus pyrenaica. & $\bullet$ & - & $\bullet$ \\
\hline 9260 & Bosques de Castanea sativa. & $\bullet$ & - & - \\
\hline $92 \mathrm{AO}$ & Bosques galeria de Salix alba y Populus alba. & $\bullet$ & - & - \\
\hline 9330 & Alcornocales de Quercus suber. & $\bullet$ & - & - \\
\hline 9340 & Encinares de Quercus ilex y Quercus rotundifolia. & $\bullet$ & - & - \\
\hline 9380 & Bosques de llex aquifolium. & $\bullet$ & $\bullet$ & $\bullet$ \\
\hline TOTAL & & 28 & 16 & 22 (23?) \\
\hline
\end{tabular}

- : tipo de hábitat presente en el territorio; - : tipo de hábitat ausente en el territorio; ?: tipo de hábitat que necesita confirmación; O: tipo de hábitat presente en el territorio pero no estudiado en el presente trabajo. Fuente: AAE (2019): Standard Data Form ZEC “ Macizo Central" (http://natura2000.eea.europa.eu/Natura2000/ SDF.aspx?site=ES1130002)

Tabla 2.- Comparación entre los tipos del Hábitats del Anexo I de la DC 92/43/CEE reconocidos en la ZEC Macizo Central, el Parque Natural do Invernadeiro y el presente trabajo

coinciden con el listado de tipos de hábitats que incluye el Decreto de aprobación del PRUG de este espacio natural protegido (XUNTA 2019), cuya metodología de elaboración y fuentes documentales empleadas nos son desconocidas. Dicho listado tampoco guarda relación con la información contenida en el documento técnico que ha servido de base (Ramil-Rego \& Crecente Maseda 2008) para la aprobación del Plan Director de la Red Natura 2000 de Galicia (XUNTA 2014). Entre los tipos de hábitats reconocidos por nosotros que no figuran en dicho PRUG destacan los brezales húmedos $\left(4020^{*}\right)$, dos tipos de hábitats turbosos $\left(7110^{*}\right.$, 7150) y los bosques de barrancos $\left(9180^{*}\right)$, tres de los cuales son de tipo prioritario. Además, a la vista de la información aquí presentada, consideramos necesaria la realización de estudios específicos para documentar más ampliamente y, en su caso, confirmar de manera definitiva, la presencia del tipo de hábitat prioritario "91D0* Turberas boscosas".

\section{Conclusiones}

Como resumen final de este trabajo y, aún reconociendo la necesidad de ahondar en el estudio de las condiciones y funcionamento ecológico de este espacio, particularmente en el campo de la botánica, puede afirmarse que los resultados obtenidos contribuyen a tener un mejor conocimento de la flora y vegetación del Parque Natural do Invernadeiro. Este incremento de información permite establecer que las relaciones biogeográficas de este territorio montañoso son más intensas con el conjunto de sierras del límite ourensano-zamorano-leonés que con las situadas más a occidente, a lo largo de la parte centrooccidental de la frontera galaico-portuguesa. Dado que este espacio natural protegido, al igual que el resto del conjunto montañoso galaico-duriense se encuentra bajo condiciones bioclimáticas de carácter templado, y que los bosques que ocupan mayor extensión presentan una componente 
florística de evidente afinidad atlántica, debe de admitirse su pertenencia a unidades biogeográficas de carácter eurosiberianas y no mediterráneas, como de manera reiterada se ha venido proponiendo. Por otra parte, en términos de tipos hábitats de la DC 92/43/CEE, el Parque Natural do Invernadeiro se revela como un territorio particularmente diverso dentro del ámbito de la ZEC Macizo Central y, por ende, en el conjunto de los espacios de montaña que forman parte de la Red Natura 2000 en el territorio de Galicia.

Más allá del esfuerzo invertido a título particular por los autores de la presente publicación, sería deseable que la administración responsable de la conservación del Patrimonio Natural en Galicia, dentro de un marco general de profundización en el conocimiento de los valores naturales que albergan los territorios que integran la red autonómica de espacios naturales protegidos, asumiera la financiación del estudio, catalogación y valoración de las comunidades vegetales presentes dentro dichos espacios, cuestiones que son básicas para garantizar una adecuada gestión de dichos valores.

Agradecimientos Los autores agradecen a D. Victor Gil (Servizo de Patrimonio Natural de Ourense, Consellería de Medio Ambiente, Territorio e Vivenda, Xunta de Galicia) la información proporcionda y su acompañamiento durante la realización de parte de los trabajos de campo, y a la guardería del Parque Natural do Invernadeiro su afabilidad y colaboración en los aspectos logísticos. Igualmente, agradecen las sugerencias aportadas por los revisores para mejorar el manuscrito original.

\section{Bibliografía}

AAE (Agencia Ambiental Europea)(2019). Natura 2000 Standard Dataform "ES1130002 Macizo Central). Accesible en: http://natura2000.eea.europa.eu/Natura2000/SDF.aspx?si te $=$ ES1130002 [acceso: 15 de octubre de 2019].

Aguiar, C. (2000). Flora e Vegetaçao da Serra da Nogueira e do Parque Natural de Montesinho. Tesis doctoral (inédita). Instituto Superior de Agronomía, Universidade Técnica de Lisboa. 659 pp.

Aguiar, C. \& Vila-Viçosa, C. (2017). Tras-os Montes and Beira Alta. En: J. Loidi (Ed.). The Vegetation of the Iberian Peninsula, Vol. 1: 367-394. Springer.

Amigo, J. (1984). Estudio de los matorrales y bosques de la Sierra del Caurel (Lugo). Tesis Doctoral (inéd.). Facultad de Farmacia. Universidade de Santiago de Compostela. $248 \mathrm{pp}$.

Amigo, J. Pulgar, Í \& Izco, J. (2009). Evidence of riverside ash tree forest in south of Galicia (Northwestern Spain). Lazaroa 30: 181-189.

Bayer, E. (1996). Erica L. En: S. Castroviejo \& al. (Eds.). Flora Iberica, Vol IV. Cruciferae-Monotropaceae: 485-506. Publ. Real Jardín Botánico. CSIC. Madrid.

Bellot, F. (1951). Novedades fitosociológicas gallegas. Trab. Jard. Bot. Santiago de Compostela 4: 1-18.
Braun-Blanquet, J. (1979). Fitosociología. Bases para el estudio de las comunidades vegetales. H. Blume Ediciones. Barcelona. 820 pp.

Castroviejo, S. (1977). Estudio sobre la vegetación de la Sierra del Invernadeiro (Orense). Publicaciones del I.C.O.N.A. Ministerio de Agricultura. Madrid. 102 pp.

Castroviejo, S. (1982). Sobre la flora gallega, IV. Anales Jard. Bot. Madrid 39(1):157-165.

Castroviejo, S. (Coord.) (1986-2018). Flora Iberica. Publ. Real Jardín Botánico. CSIC. Madrid.

Costa, J.C., Neto, C., Aguiar, C., Capelo, J., Espírito-Santo, M.D., Honrado, J., Pinto-Gomes, C., Monteiro-Henriques, T., Sequeira, M., Lousâ, M. (2012). Vascular plant communities in Portugal (continental, the Azores and Madeira). Global Geobotany 2: 1-180.

Costa-Tenorio, M., Higueras, J. \& Morla, C. (1990). Abedulares de la Sierra de San Mamede (Orense, España). Acta Bot. Malacitana 15: 253-265.

Costa-Tenorio, M., Morla, C. \& Sainz-Ollero, H. (1993). Datos sobre las comunidades de caméfitos espinosos en los macizos meridionales galaicos (NW España). Lazaroa 13:139-147.

Devesa, J.A., Catalán, P., Müller, J., Cebolla, C. \& Ortúñez, E. (2013). Checklist de Festuca L. (Poaceae) en la Península Ibérica. Lagascalia 33: 183-274.

Díaz, T.E. (2014). Mapas de vegetación de las series, geoseries y geopermaseries de España. 1:250.000. Asturias. Global Geobotany 3: 1-34.

Díaz, T.E. \& Fernández Prieto, J.A. (1994). La Vegetación de Asturias. Itinera Geobot. 8: 243-528.

Díaz, T.E. \& Vázquez, V. (2004). Guía de los bosques de Asturias. Ed. Trea. Gijón. 287 pp.

Díaz, T.E. \& Penas, A. (2017). The High Mountain Area of Northwestern Spain: The Cantabrian Range, the GalicianLeonese Mountains and the Bierzo Trench. En: J. Loidi (Ed.), The Vegetation of the Iberian Peninsula, Vol. 1: 251321. Springer.

Díaz, T.E., Andrés, J., Llamas, F., Herrero, L. \& Fernández, D. (1987). Datos sobre las olmedas y alisedas mediterráneas de la provincia de León (NW de España). Publ. Univ. La Laguna. Ser. Informes 22: 177-198.

Domingues de Almeida, J. (2000). Tres arbustos portugueses olvidados. An. Jard. Bot. Madrid 58(1): 194195.

Fernández-Prieto, J.A. \& Bueno, A. (1996). La Reserva Integral de Muniellos: flora y vegetación. Cuadernos de Medio Ambiente, Naturaleza 1. Principado de Asturias. 206 pp.

García-Baquero, G. (2005). Flora y vegetación del alto Oja (Sierra de La Demanda, La Rioja, España). Guineana 11: 5-250. 
González de Paz, L. (2012). Flora y vegetación de La Cabrera Baja (León): valoración del estado de conservación. Dpto. de Biodiversidad y Gestión Ambiental, Universidad de León. 556 pp.

Guitián, J. (1984). Estudio de la vegetación herbácea de la Sierra de Caurel (Lugo). Tesis doctoral (inéd.). Facultad de Farmacia, Universidade de Santiago de Compostela. 330 pp.

Guitián, J. (1996). Silene acutifolia Link ex Rohrb. en El Bierzo (León). Lazaroa 16: 191.

Honrado, J. (2003). Flora e Vegetação do Parque Nacional da Peneda-Gerês. Tésis Doctoral (Inéd.). Faculdade de Ciências, Universidade do Porto. 539 pp.

Honrado, J., Alves, P., Nepomuceno, H. \& Barreto Caldas, F. (2002). XXXIII: Ten new syntaxa from the Miniensean biogeographic subsector (northwestern Portugal). Notas do Herbário da Estação Florestal Nacional (LISFA): Fasc. XVI. Silva Lusit. 10(2): 247-259.

Honrado, J., Alves, P., Aguiar, C., Ortiz, S. \& Barreto Caldas, F. (2003). Juresian riparian birch woodlands: Carici reuterianae-Betuletum celtibericae ass. nova. Silva Lusit. 11(2): 237-241.

Horjales, M., Pérez Prego, J.M. \& Redondo, N. (2008). El género Dryopteris Adanson (Dryopteridaceae) en el noroeste de la Península Ibérica. Nova Acta Científica Compostelana (Bioloxía) 17: 39-63.

Iglesias, L. (1929). Impresiones de la excursión científica a la Sierra de los Ancares, Invernadero y Queija, en el mes de julio de 1927. Arquivos do Seminario de Estudos Galegos, iii, 137-150.

IGME (2019): Mapa Geológico continuo de España. Accesible en: http://info.igme.es/visor/ [acceso: 15 de diciembre de 2019].

Izco, J. \& Sánchez, J.M. (1996). Los medios halófilos de la ría de Ortigueira (A Coruña, España). Vegetación de dunas y marismas. Thalassas 12: 63-100.

Izco, J. \& Sánchez, J.M. (2002). Vegetation analysis and mapping of dunes and saltmarshes of the Betanzos ria ( $A$ Coruña, Spain). Thalassas 18(2): 17-42

Izco, J., Amigo, J. \& García-San León, D. (1999). Análisis y clasificación de la vegetación leñosa de Galicia (España). Lazaroa 20: 29-47.

Izco, J., Amigo, J. \& García-San León, D. (2001). Análisis y clasificación de la vegetación de Galicia (España), II. La vegetación herbácea. Lazaroa 21: 25-50.

Izco, J., Amigo, J. \& Pulgar, I. (2006): Southwest cantabroatlantic expression of coastal thorny woodland-fringe communities. Acta Bot. Gallica 153 (3): 325-334.

Izco, J. \& Ortiz, S. (1987). La vegetación glerícola del macizo de Peña Trevinca. Lazaroa 7: 55-65.

Jansen, J. (2011). Managing Natura 2000 in a changing world: The case of the Serra da Estrela (Portugal); Tesis doctoral (Inédita). Radboud University. Nijmegen. 281 pp.
Kerguélen, M. \& Morla, C. (1985). Festuca graniticola, nueva especie del noroeste de la Península Ibérica. Anal. Jard. Bot. Madrid 42 (1): 155-158.

Maldonado, F.J. (1994). Evolución Tardiglaciar y Holocena de la Vegetación en los Macizos del Noroeste Peninsular. Tesis doctoral (inédita). Universidad Politécnica de Madrid. $171 \mathrm{pp}$.

Merino, B. (1902): Viajes de Herborización por Galicia. Vol. IV. Razón y Fé, Tomo I: 88.

Morla, C. (1983). Estudio ecológico de la cubierta vegetal leñosa y análisis florístico en el macizo Manzaneda-Queija (Orense). Tesis doctoral (inéd.). Universidad Politécnica de Madrid. 408 pp.

Morla, C. (1985). Consideraciones acerca del paisaje vegetal y su evolución en la comarca de Trives (Orense, España). Anales de Geografía de la Universidad Complutense 5: 189-212.

Mucina, L., Bültmann, H., Dierßen, K., Theurillat, J.P., Raus, T., Čarni, A., Šumberová, K.,Willner, W., Dengler, J., Gavilán, R.G., Chytrý, M., Hájek, M., Di Pietro, R., lakushenko, D., Pallas, J., Daniëls, F.J.A., Bergmeier, E., Santos Guerra, A., Ermakov, N., Valachovič, M., Schaminée, J.H.J., Lysenko, T., Didukh, Y.P., Pignatti, S., Rodwell, J.S., Capelo, J., Weber, H.E., Solomeshch, A., Dimopoulos, P., Aguiar, C., Hennekens, S.M. \& Tichý, L. (2016). Vegetation of Europe: hierarchical floristic classification system of vascular plant, bryophyte, lichen, and algal communities. Appl. Veg. Sci. 19 (Suppl. 1): 3264.

Navarro Andrés, F., González Zapatero, M.A., Gallego Martín, F., Elena Roselló, J.A. Sánchez Anta, M.A. \& López Blanco, L. (1986). Alisedas salmantinas y zamoranas. Studia Bot. 5: 39-52.

Ortega-Olivencia, A., Devesa J.A. \& Rodríguez-Riaño, T. (2004). A new Galium species from NW Portugal. Bot. Helv. 114(1): 1-6.

Ortiz, S. (1986). Series de vegetación y su zonación altitudinal en el macizo de Pena Trevinca y Serra do Eixo. Tesis doctoral (inéd.). Facultad de Biología, Universidade de Santiago de Compostela. 509 pp.

Ortiz, S., Izco, J. \& Rodríguez-Oubiña, J. (1997). Complejos de vegetación del Macizo de Pena Trevinca y Serra do Eixo (NO de la Península Ibérica). Phytocoenologia 27(1): 25-52.

Paül Carril, V. (2011). 3. O Invernadeiro: de monte de pinos de repoblación forestal a parque natural. En: F. Molinero, J.F. Ojeda \& J. Tort (Coords.). Los paisajes agrarios de España. Caracterización, evolución y tipificación: 458-470. Ministerio de Medio Ambiente y Medio Rural y Marino. Madrid.

Penas, A. \& Díaz, T.E. (1985). Datos sobre la alianza Corynephoro-Plantaginion radicatae Rivas Goday \& RivasMartínez 1963 nom. invers. Rivas-Martínez 1975 en el sector Orensano-sanabriense. Acta Bot. Malacitana 10: 155-166. 
Pinto da Silva, A.R., Rozeira, A. \& Fontes, F. (1950). Os carvalhais da Serra do Gerês. Esboço fitosociológico. Agron. Lusit. 12: 433-447.

Pulgar, I. (1999). La vegetación de la Baixa Limia y Sierras del entorno. Tesis doctoral (inéd.). Fac. Farmacia, Univ. Santiago de Compostela. 369 pp.

Pulgar, I. (2004). Guía de la flora del Parque Natural Montes de Invernadeiro. Xunta de Galicia, Santiago de Compostela. $84 \mathrm{pp}$.

Pulgar, I. (2006). Aportaciones a la flora del sur de Galicia (NO España). Bot. Compl. 30: 113-116.

Pulgar, I. \& Izco, J. (2007). Characterization and classification of caespitose acidophilous pastures of South-west Europe (Festucetea indigestae class). Plant Biosystems 141 (3): 363-383

Pulgar, I., Ortiz, S. \& Rodríguez-Oubiña, J. (1996). Minuartio recurvae-Silenetum acutifoliae, un nuevo pastizal vivaz de las cumbres del macizo montañoso Xurés-Gerês. Lazaroa 17: 129-135.

Pulgar, I., Ortiz, S. \& Rodríguez Oubiña, J. (2001). Flora vascular de la Baixa Limia (SO Ourense, Galicia), I. Antecedentes históricos, Nova Acta Científica Compostelana (Bioloxía) 11: 153-166.

Ramil-Rego, P. \& Crecente Maseda, R. (Coords.). (2012). Plan Director da Rede Natura 2000 de Galicia. Documento Técnico. 8 Vols. Dirección Xreal de Conservación da Natureza, Conselleria do Medio Rural (Xunta de Galicia) Instituto de Biodiversidade Agraria e Desenvolvemento Rural (IBADER-USC). Santiago de Compostela.

Redondo, N. \& Horjales, M. 1984. Equisetum hyemale L. y otras aportaciones sobre flora vascular gallega. Anales Jard. Bot. Madrid 40(2): 379-384.

Rivas-Martínez, S. (1979). Brezales y jarales de Europa occidental (Revisión fitosociológica de las clases CallunoUlicetea y Cisto-Lavanduletea). Lazaroa 1: 5-119.

Rivas-Martínez, S. (1981). Sobre la vegetación de la Serra da Estrela (Portugal). An. Real Acad. Farm. 47: 435-480.

Rivas-Martínez, S. (2007): Mapa de series, geoseries y geopermaseries de vegetación de España (Memoria del Mapa de Vegetación Potencial de España. Parte I). Itinera Geobot. (Nueva Serie) 17. 436 pp.

Rivas-Martínez, S. (2011). Mapa de series, geoseries y geopermaseries de vegetación de España (Memoria del mapa de vegetación potencial de España. Parte II). Itinera Geobot. 18(1-2): 5-800.

Rivas-Martínez, S., Díaz, T.E., Fernández-Prieto, J.A., Loidi, J. \& Penas, A. (1984). La vegetación de la alta montaña cantábrica: los Picos de Europa. Ediciones Leonesas. León. 295 pp.
Rivas-Martınez, S., Penas, A., Dıaz-Gonzalez, T.E., Cantó, P., del Río, S., Costa, J.C., Herrero, L. \& Molero, J. (2017). Biogeographic Units of the Iberian Peninsula and Balearic Islands to district level. A concise synopsis. En: J. Loidi (Ed.): The Vegetation of the Iberian Península, Vol. I: 131188. Springer.

Rodríguez Bouzo, J. (1929). Datos botánico-agrícolas de las Sierras del Invernadero y de Queija (Orense). Memorias de la Real Sociedad Española de Historia Natural XV: 725728.

Rodríguez-Guitián, M.A. (2004). Aplicación de criterios botánicos para a proposta de modelos de xestión sustentable das masas arborizadas autóctonas do Subsector Galaico-Asturiano Septentrional. Tesis doctoral (inéd.). Escola Politécnica Superior de Lugo, Universidade de Santiago de Compostela. 620 pp.

Rodríguez Guitián, M.A. (2005). Avaliación da diversidade sílvica do subsector galaico-asturiano septentrional: tipos de bosques, valor para a conservación e principais ameazas. Recursos Rurais. Cursos e Monografias, 2: 2344.

Rodríguez-Guitián, M.A. (2011). Fitosocioloxía dos faiais e outras comunidades con Fagus sylvatica. En: M.A. Rodríguez Guitián \& A. Rigueiro Rodríguez (Coords.): Os faiais de Galicia: ecoloxía e valor ambiental: 281-346. Horreum-lbader. Lugo.

Rodríguez-Guitián, M.A. \& Bariego, P. (2009). Afinidades florísticas de los abedulares de las Sierras Segundera y Cabrera (Sanabria, NW Ibérico). En: F. Llamas \& C. Acedo (Coords.): Botánica Pirenaico-Cantábrica en el siglo XXI: 561-578. Servicio de Publicaciones. Universidad de León.

Rodríguez-Guitián, M.A. \& Ramil-Rego, P. (2007). Clasificaciones climáticas aplicadas a Galicia: revisión desde una perspectiva biogeográfica. Recursos Rurais, 3: 31-53.

Rodríguez-Guitián, M.A. \& Ramil-Rego, P. (2008). Fitogeografía de Galicia (NW Ibérico): análisis histórico y nueva propuesta corológica. Recursos Rurais, 4: 19-50.

Rodríguez-Guitián, M.A. \& Rigueiro, A. (Coords.)(2011). Os faiais de Galicia: Ecoloxía e valor ambiental. HorreumIbader. Lugo. $666 \mathrm{pp}$.

Rodríguez-Guitián, M., Amigo, J., Romero-Franco, R. (2001). Aportaciones sobre la interpretación, ecología y distribución de los bosques supratemplados navianoancarenses. Lazaroa, 21: 51-71.

Rodríguez-Guitián, M., Real, C., Amigo, J. \& RomeroFranco, R. (2003). The Galician-Asturian beechwoods (Saxifrago spathularidis-Fagetum sylvaticae): description, ecology and differentiation from other Cantabrian woodland types. Acta Bot. Gallica, 150 (3): 285-320. 
Rodríguez Guitián, M.A., Real, C., Blanco López, J.M. \& Ferreiro da Costa, J. (2005). Caracterización fitosociológica de la orla forestal de los hayedos silicícolas naviano-ancarenses (Sorbo aucupariae-Salicetum capreae ass. nova). Bull. Soc. Hist. Nat., Toulouse, 141(2): 69-74.

Rodríguez-Guitián, M.A., Romero-Franco, R. \& Ramil-Rego, P. (2007). Caracterización ecológica y florística de las comunidades lauroides del occidente de la Cornisa Cantábrica (Noroeste ibérico). Lazaroa, 28: 35-65.

Rodríguez Guitián, M.A., Amigo Vázquez, J., Real, C. \& Romero Franco, R. (2009). Revisión de la sintaxonomía de los hayedos del occidente de la Cordillera Cantábrica (NO Ibérico) mediante análisis multivariante. Lazaroa 30: 193221.

Rodríguez-Guitián, M.A., Ramil-Rego, P. \& Ferreiro da Costa, J. (2012). Propuesta de clasificación multicriterio para los bosques de Galicia (NW iberico). Recursos Rurais, Serie Cursos, 6: 63-106.

Rodríguez-Guitián, M.A., Romero-Franco, R., Real, C. \& Ferreiro da Costa, J. (2013). Descrición, cartografía e valor de conservación dos bosques da Devesa da Rogueira (Serra do Courel, NW Península Ibérica). Recursos Rurais, 9: 5-34.

Rodríguez Guitián, M.A., Romero-Franco, R., Ferreiro da Costa, J., Díaz-Varela, R.A. \& Real, C. (2014). Tipoloxía e valor de conservación dos bosques da Reserva de Biosfera "Os Ancares Lucenses e Montes de Cervantes, Navia e Becerreá" (Lugo, Galicia, España). Recursos Rurais, Serie Cursos, 7: 53-111.

Rodríguez-Guitián, M.A., Real, C., Romero-Franco, R. \& Alvarez-Hurtado, A. (2017). Phytosociological framework and conservation value of supratemperate riparian birch forest of the Northwestern Iberian Peninsula. Lazaroa, 38(2): 87-126.

Romero Zarco, C. (2015). Las gramíneas de la Península Ibérica e Islas Baleares. Claves ilustradas para la determinación de los géneros y catálogo preliminar de las especies. Colección Monografías de Botánica Ibérica 15. 172 pp. Jolube Consultor Botánico y Editor. Jaca (Huesca).

Santos, L. (2004). Late Holocene Forest History and Deforestation Dynamics in the Queixa Sierra, Galicia, Northwestern Iberian Peninsula. Mountain Research and Development, 24(3): 251-257.
Santos, L., Vidal Romaní, J.R. \& Jalut, G. (2000). History of vegetation during the Holocene in the Courel and Queixa Sierras, Galicia, northwest Iberian Peninsula. Journal of Quaternary Science 15(6): 621-632.

Silva-Pando, F.J. (1990). La flora y vegetación de la Sierra de Ancares: base para la planificación y ordenación forestal. Tesis doctoral (inédita). Facultad de Biología. Universidad Complutense de Madrid. 532 pp.

Silva-Pando, F.J. (2009). Los abedulares y acebedas de la Sierra de Ancares (Lugo-León, España). Actas del V Congreso Forestal Español. SECF-Junta de Castilla y León. Ávila. Accesible en: https://www.congresoforestal.es/index.php?men=71.

Talavera, S. (1999). Echinospartum (Spach.) Fourr. En: S. Castroviejo \& al. (Eds.): Flora Iberica, Vol. VII (I). Leguminosae (partim): 119-127. Real Jardín Botánico. CSIC. Madrid.

Xunta (1997). Decreto 155/1997, de 5 de junio, por el que se declara el Parque Natural de O Invernadeiro. DOG Núm. 123 Viernes, 27 de junio de 1997. Consellería de Agricultura, Ganadería y Montes. Xunta de Galicia. Santiago de Compostela.

Xunta (2014). Decreto 37/2014, de 27 de marzo, por el que se declaran zonas especiales de conservación los lugares de importancia comunitaria de Galicia y se aprueba el Plan director de la Red Natura 2000 de Galicia. DOG Núm. 62 de Lunes, 31 de marzo de 2014. Consellería de Medio Ambiente, Territorio e Infraestructuras. Santiago de Compostela.

Xunta (2019). Decreto 102/2019, do 11 de xullo, polo que se modifica o Decreto 166/1999, do 27 de maio, polo que se aproba o Plan de ordenación dos recursos naturais do Parque Natural do Invernadeiro, e polo que se aproba o Plan reitor de uso e xestión do Parque Natural do Invernadeiro. DOG Núm. 170 de 9 de septiembre de 2019. Consellería de Medio Ambiente, Territorio e Vivenda. Xunta de Galicia. Santiago de Compostela. 


\section{ANEXO I}

\section{Tablas de inventarios florísticos}

Tabla 1.- Robledales y melojares

1-8: Vaccinio myrtilli-Quercetum roboris; 9-15: Holco mollis-Quercetum pyrenaicae

\begin{tabular}{|c|c|c|c|c|c|c|c|c|c|c|c|c|c|c|c|}
\hline $\mathrm{N}^{0}$ de orden & 1 & 2 & 3 & 4 & 5 & 6 & 7 & 8 & 9 & 10 & 11 & 12 & 13 & 14 & 15 \\
\hline Altitud (m) & 1.230 & 1.245 & 1.290 & 1.040 & 1.230 & 1.250 & 1.270 & --- & 1.260 & 1.275 & 1.345 & 1.083 & 1.220 & 1.294 & --- \\
\hline Pendiente $\left({ }^{\circ}\right)$ & 30 & 32 & 28 & 32 & 30 & 30 & 30 & --- & 30 & 28 & 28 & 45 & 15 & 0 & -- \\
\hline Orientación & ENE & ENE & NNE & WNW & ENE & $\mathrm{N}$ & $\mathrm{E}$ & --- & SW & $E$ & SSE & $E$ & NE & --- & --- \\
\hline Alt. sup. copas (m) & $22-27$ & $14-20$ & $15-24$ & $14-27$ & $16-25$ & --- & $7-16$ & 25 & $12-22$ & $15-22$ & $12-15$ & --- & --- & 15 & 15,5 \\
\hline Cob. $E_{1}(\%)$ & 90 & 90 & 100 & 90 & 95 & 90 & 70 & $50-80$ & 80 & 75 & 85 & --- & --- & --- & $70-90$ \\
\hline Cob. $E_{2}(\%)$ & 30 & 50 & 10 & 30 & 20 & --- & 20 & $60-80$ & 15 & 15 & 10 & --- & --- & --- & $50-100$ \\
\hline Cob. $E_{3}(\%)$ & 85 & 40 & 60 & 70 & 35 & --- & 50 & 60 & 35 & 95 & 90 & --- & --- & --- & $80-100$ \\
\hline Área $\left(m^{2}\right)$ & 450 & 300 & 400 & 300 & 1000 & 400 & 500 & --- & 600 & 500 & 400 & 300 & 400 & 400 & --- \\
\hline $\mathrm{N}^{0}$ de taxones & 35 & 18 & 24 & 32 & 26 & 35 & 24 & --- & 29 & 31 & 31 & 27 & 27 & 20 & -- \\
\hline \multicolumn{16}{|l|}{$E_{1}(>4,0 \mathrm{~m})+E_{2}(>1,5-4,0 \mathrm{~m}):$} \\
\hline Sorbus aucuparia & 1 & 2 & 1 & 2 & 2 & 2 & + & IV & 2 & 1 & & $\cdot$ & $\cdot$ & · & I \\
\hline Erica arborea & 3 & 2 & + & + & · & 1 & 1 & II & · & $\cdot$ & + & 2 & 2 & 2 & $\cdot$ \\
\hline Genista polygaliphylla & + & 1 & · & 1 & · & $\cdot$ & 2 & IV & 1 & 1 & + & r & 1 & 2 & $\cdot$ \\
\hline Quercus robur & 5 & 5 & 4 & 4 & 4 & 3 & 3 & V & 2 & 2 & . & . & . & . & . \\
\hline Ilex aquifolium & 1 & 2 & 5 & 1 & 3 & 1 & 1 & IV & 4 & 2 & . & · & $\cdot$ & $\cdot$ & · \\
\hline Quercus pyrenaica & $\cdot$ & · & . & · & · & $\cdot$ & 1 & $\cdot$ & 4 & 4 & 5 & 5 & 5 & 5 & V \\
\hline Frangula alnus & . & $\cdot$ & . & 2 & $\cdot$ & 2 & . & I & $\cdot$ & $\cdot$ & . & 2 & 2 & r & I \\
\hline Betula pubescens & . & · & 1 & 3 & 1 & 1 & · & I & . & $\cdot$ & · & · & · & . & $\cdot$ \\
\hline Corylus avellana & $\cdot$ & $\cdot$ & $\cdot$ & 1 & 1 & 2 & $\cdot$ & I & · & $\cdot$ & $\cdot$ & $\cdot$ & · & . & · \\
\hline Acer pseudoplatanus & . & $\cdot$ & $\cdot$ & 1 & 1 & 2 & $\cdot$ & I & · & · & $\cdot$ & · & · & $\cdot$ & · \\
\hline Quercus $\mathrm{x}$ andegavensis & 2 & $\cdot$ & · & $\cdot$ & $\cdot$ & $\cdot$ & 2 & $\cdot$ & . & $\cdot$ & $\cdot$ & $\cdot$ & . & $\cdot$ & $\cdot$ \\
\hline Pyrus cordata & $\cdot$ & $\cdot$ & . & . & · & $\cdot$ & . & · & . & · & · & $\cdot$ & 1 & 1 & · \\
\hline Cytisus multiflorus & $\cdot$ & $\cdot$ & $\cdot$ & · & $\cdot$ & $\cdot$ & · & $\cdot$ & · & $\cdot$ & $\cdot$ & 1 & $r$ & $\cdot$ & $\cdot$ \\
\hline Rosa sp. & $\cdot$ & $\cdot$ & $\cdot$ & $\cdot$ & · & $\cdot$ & $\cdot$ & $\cdot$ & $\cdot$ & $\cdot$ & $\cdot$ & $r$ & r & $\cdot$ & $\cdot$ \\
\hline \multicolumn{16}{|c|}{$\begin{array}{l}\mathrm{E}_{3}(<1,5 \mathrm{~m}) \text { : } \\
\text { Taxones característicos de asociación, alianza y orden }\end{array}$} \\
\hline Teucrium scorodonia & 1 & + & $\cdot$ & 1 & + & + & 1 & IV & 1 & 1 & 1 & + & 2 & $\cdot$ & V \\
\hline Lonicera hispanica & + & + & + & + & . & 1 & · & V & + & + & $\cdot$ & 2 & 1 & $\cdot$ & I \\
\hline Hedera hibernica & + & + & + & 1 & 1 & 1 & . & III & 1 & + & . & . & . & . & I \\
\hline Holcus mollis & 1 & $\cdot$ & + & . & $\cdot$ & r & . & $\cdot$ & 1 & 4 & 2 & 1 & 2 & 1 & IV \\
\hline Vaccinium myrtillus & 1 & 1 & 1 & 4 & 1 & 1 & + & V & · & $\cdot$ & · & $\cdot$ & 2 & $\cdot$ & $\cdot$ \\
\hline Galium rotundifolium & + & $\cdot$ & 1 & 1 & 2 & $\cdot$ & $\cdot$ & V & 2 & 1 & + & $\cdot$ & $\cdot$ & $\cdot$ & I \\
\hline Viola riviniana & + & · & $\cdot$ & . & + & . & . & III & $\cdot$ & 1 & 1 & 1 & + & r & I \\
\hline Melampyrum pratense & 1 & + & $\cdot$ & $r$ & · & $\cdot$ & + & II & . & $\cdot$ & $\cdot$ & $\cdot$ & 1 & 2 & I \\
\hline Luzula sylvatica & 1 & 1 & 3 & + & $\cdot$ & 1 & $\cdot$ & III & & $\cdot$ & $\cdot$ & $\cdot$ & $\cdot$ & $\cdot$ & $\cdot$ \\
\hline Physospermum cornubiense & + & $\cdot$ & $\cdot$ & + & · & $\cdot$ & $\cdot$ & $\cdot$ & + & . & 1 & $\cdot$ & 1 & . & V \\
\hline Avenella flexuosa & 4 & $\cdot$ & 1 & . & $\cdot$ & $\cdot$ & 3 & $\|$ & $\cdot$ & $\cdot$ & $\cdot$ & $\cdot$ & $\cdot$ & $\cdot$ & $\cdot$ \\
\hline Arenaria montana & $\cdot$ & $\cdot$ & $\cdot$ & + & $\cdot$ & · & $\cdot$ & $\cdot$ & · & $\cdot$ & $\cdot$ & + & · & $r$ & I \\
\hline Veronica officinalis & . & . & $\cdot$ & · & · & · & · & II & · & + & $\cdot$ & $\cdot$ & · & $r$ & I \\
\hline Blechnum spicant & $\cdot$ & . & + & + & · & · & · & III & · & · & $\cdot$ & $\cdot$ & . & $\cdot$ & · \\
\hline Oxalis acetosella & $\cdot$ & . & + & . & 1 & $\cdot$ & . & V & . & $\cdot$ & $\cdot$ & . & · & $\cdot$ & $\cdot$ \\
\hline Saxifraga spathularis & $\cdot$ & $\cdot$ & $\cdot$ & + & $\cdot$ & + & · & III & · & $\cdot$ & $\cdot$ & $\cdot$ & · & $\cdot$ & $\cdot$ \\
\hline Hypericum pulchrum & . & $\cdot$ & · & + & · & r & · & $\cdot$ & · & · & $\cdot$ & $\cdot$ & · & . & $\cdot$ \\
\hline Anemone albida & . & · & . & · & · & + & · & I & · & · & · & $\cdot$ & · & $\cdot$ & · \\
\hline Lathyrus linifolius & $\cdot$ & $\cdot$ & · & · & $\cdot$ & $\cdot$ & · & I & $\cdot$ & $\cdot$ & + & $\cdot$ & · & · & $\cdot$ \\
\hline \multicolumn{16}{|c|}{ Taxones característicos de Querco-Fagetea } \\
\hline Stellaria holostea & 1 & $\cdot$ & 1 & 1 & $\cdot$ & $r$ & 1 & V & 1 & 1 & 2 & $r$ & 1 & $\cdot$ & IV \\
\hline Polypodium vulgare & $\cdot$ & + & + & · & · & r & + & III & · & $\cdot$ & · & $\cdot$ & $\cdot$ & . & $\cdot$ \\
\hline Melittis melissophylum & $\cdot$ & $\cdot$ & $\cdot$ & + & . & + & . & III & 1 & + & · & $\cdot$ & · & . & · \\
\hline Hyacinthoides non-scripta & $\cdot$ & . & 1 & · & · & $\cdot$ & + & $\cdot$ & + & 1 & 1 & · & · & $\cdot$ & $\cdot$ \\
\hline Crepis lampsanoides & + & $\cdot$ & $\cdot$ & · & $\cdot$ & + & $\cdot$ & $\cdot$ & $\cdot$ & + & 1 & $\cdot$ & · & · & I \\
\hline Melica uniflora & + & $\cdot$ & . & . & 1 & $\cdot$ & . & IV & $\cdot$ & 1 & . & $\cdot$ & · & $\cdot$ & $\cdot$ \\
\hline Anemone nemorosa & $\cdot$ & $\cdot$ & . & 1 & $\cdot$ & 1 & . & II & · & $\cdot$ & $\cdot$ & $\cdot$ & . & . & . \\
\hline Dyopteris filix-mas & $\cdot$ & $\cdot$ & · & 1 & $\cdot$ & + & $\cdot$ & II & $\cdot$ & $\cdot$ & $\cdot$ & $\cdot$ & $\cdot$ & $\cdot$ & $\cdot$ \\
\hline Sanicula europaea & $\cdot$ & $\cdot$ & $\cdot$ & $\cdot$ & 1 & $\cdot$ & $\cdot$ & III & 1 & $\cdot$ & $\cdot$ & $\cdot$ & $\cdot$ & $\cdot$ & $\cdot$ \\
\hline Conopodium bourgaei & + & . & + & . & . & $\cdot$ & $\cdot$ & $\cdot$ & $\cdot$ & 1 & $\cdot$ & . & $\cdot$ & $\cdot$ & $\cdot$ \\
\hline
\end{tabular}




\begin{tabular}{|c|c|c|c|c|c|c|c|c|c|c|c|c|c|c|c|}
\hline $\mathrm{N}^{0}$ de orden & 1 & 2 & 3 & 4 & 5 & 6 & 7 & 8 & 9 & 10 & 11 & 12 & 13 & 14 & 15 \\
\hline Poa nemoralis & . & . & . & · & . & . & · & III & $\cdot$ & $\cdot$ & 1 & $\cdot$ & $\cdot$ & $\cdot$ & . \\
\hline Polygonatum odoratum & + & . & + & . & . & . & . & . & . & . & . & . & . & . & . \\
\hline Dryopteris borreri & . & . & + & . & + & . & . & . & . & . & . & . & . & . & . \\
\hline Dryopteris dilatata & . & . & + & . & + & . & . & . & . & . & . & . & . & . & . \\
\hline Primula acaulis & . & . & · & . & . & . & . & . & + & . & + & . & . & . & . \\
\hline \multicolumn{16}{|l|}{ Otros taxones } \\
\hline Pteridium aquilinum & 1 & . & 1 & 1 & 1 & $r$ & + & IV & 2 & 4 & 3 & 2 & 3 & 1 & II \\
\hline Digitalis purpurea & 1 & . & r & + & . & . & + & $\cdot$ & + & 1 & . & $r$ & . & · & I \\
\hline Rubus lucensis & + & . & . & 2 & . & + & + & . & 1 & 1 & + & . & . & . & . \\
\hline Brachypodium rupestre & . & . & . & + & . & + & + & . & 1 & 3 & 4 & . & . & . & . \\
\hline Dactylis izcoi & . & . & . & . & . & . & . & . & 1 & + & 1 & + & + & . & V \\
\hline Anthoxanthum amarum & . & . & + & . & . & . & + & . & . & + & 1 & $\cdot$ & . & . & IV \\
\hline Anthoxanthum odoratum & 1 & + & · & . & . & + & · & IV & . & . & 2 & . & . & . & · \\
\hline Clinopodium vulgare & . & . & . & . & . & + & . & · & . & . & + & + & r & . & I \\
\hline Linaria triornithophora & . & . & . & . & . & $r$ & . & I & . & . & . & $r$ & $r$ & . & IV \\
\hline Arrhenatherum bulbosum & + & . & . & . & . & $r$ & . & . & . & . & . & . & + & . & IV \\
\hline Geranium robertianum & · & . & . & . & 1 & · & . & III & 2 & + & · & . & · & . & · \\
\hline Lamium maculatum & . & . & . & . & . & . & $r$ & $\cdot$ & 1 & 1 & + & . & r & . & . \\
\hline Polystichum setiferum & . & . & . & . & 2 & 1 & . & I & 1 & . & . & . & . & . & . \\
\hline Silene nutans & . & . & . & . & . & . & . & . & . & . & . & + & 1 & 1 & I \\
\hline Agrostis capillaris & . & . & . & . & . & . & . & . & + & 2 & 1 & . & . & . & . \\
\hline Agrostis sp. & $\cdot$ & . & . & . & . & . & + & . & . & . & . & . & 1 & 3 & . \\
\hline Omphalodes nitida & . & . & . & + & . & + & . & III & . & . & . & . & . & · & . \\
\hline Asphodelus macrocarpus & + & + & . & . & . & . & . & $\cdot$ & . & . & . & . & . & . & III \\
\hline Cruciata glabra & . & . & . & . & . & . & . & . & . & + & 1 & . & . & + & . \\
\hline Rumex acetosa & + & + & . & . & . & $r$ & . & . & . & . & . & . & . & . & . \\
\hline Narcissus triandrus & + & + & . & . & . & . & r & . & . & . & . & . & . & . & . \\
\hline Agrostis stolonifera & . & . & . & . & . & . & . & I & . & . & . & . & . & . & I \\
\hline Athyrium filix-femina & . & . & . & + & + & . & . & . & . & . & . & . & . & . & . \\
\hline Brachypodium sylvaticum & . & . & . & · & . & . & . & I & . & . & · & . & . & . & $\|$ \\
\hline Carex pairae & . & . & . & . & . & . & . & . & + & . & + & . & . & . & . \\
\hline Carex muricata & . & . & . & . & · & . & . & · & · & . & · & + & r & . & . \\
\hline Galeopsis tetrahit & $\cdot$ & . & . & . & $\cdot$ & . & . & I & + & . & . & . & . & . & . \\
\hline Galium papillosum & . & . & . & . & . & . & . & . & · & 1 & 1 & . & . & . & . \\
\hline Galium vivianum & . & + & . & . & . & . & . & I & . & . & . & . & . & $r$ & I \\
\hline Jasione montana & . & · & . & . & . & . & . & . & . & . & . & $r$ & . & $r$ & . \\
\hline Peucedanum gallicum & + & . & . & . & . & r & . & . & . & . & . & . & . & . & . \\
\hline Rubus sp. & . & . & . & . & . & . & . & . & . & . & . & 1 & + & . & . \\
\hline Urtica dioica & . & . & . & . & + & . & . & . & + & . & . & . & . & . & . \\
\hline
\end{tabular}

Taxones de baja frecuencia: $E_{1}+E_{2}$ : Cytisus scoparius: + en 13; Quercus x rosacea: III en 8; Quercus petraea: I en 8; Sambucus nigra: 1 en 5 ; Taxus baccata: I en 8. Taxones característicos de asociación, alianza y orden: Ceratocapnos claviculata: 2 en 7; Doronicum pubescens: + en 2. Taxones característicos de Querco-Fagetea: Aquilegia vulgaris: I en 8; Conopodium majus: I en 8; Dryopteris affinis: + en 6; Euphorbia amygdaloides: I en 8; Euphorbia dulcis: + en 4; Euphorbia hyberna: r en 13; Lilium martagon: I en 15; Polygonatum verticillatum: + en 5; Solidago virgaurea: + en 14; Veronica montana: + en 5; Otros taxones: Achillea millefolium: r en 12; Agrostis castellana: I en 15; Asplenium adiantum-nigrum: + en 12; Asplenium trichomanes: $r$ en 12; Helictochloa marginata: $r$ en 14; Campanula lusitanica: $r$ en 12; Centaurea micrantha: $r$ en 12; Eryngium juressianum: + en 1; Festuca gr. paniculata: + en 1; Festuca gr. rubra: 1 en 11; Festuca merinoi: 1 en 11; Galium aparine: + en 5; Galium broterianum: 1 en 10; Galium divaricatum: III en 15; Gentiana aurantiaca: 1 en 1; Geranium lucidum: + en 9; Geranium lusitanicum: + en 11; Halimium alyssoides: r en 14; Hypochaeris radicata: $r$ en 14 y II en 15; Lotus corniculatus: III en 15; Luzula campestris: I en 15; Luzula lactea: 2 en 1; Prunella grandiflora: + en 10; Ranunculus bulbosus: III en 15; Rubus cf. ulmifolius: I en 15; Sedum hirsutum: 1 en 7; Stellaria media: I en 15; Thesium pyrenaicum: I en 15; Thymus cf. pulegioides: r en 12; Umbilicus rupestris: + en 5; Veronica chamaedrys: + en 11; Vicia sepium: 1 en 11

Localidades (ETRS89, huso 29T, utm 1x1 km): 1: Ou: Vilariño de Conso, Pradoalbar, margen derecha del valle del Río de Casarello, aguas debajo de la Mallada dos Castiñeiros, ladera de Os Cirgos (635/4670); 2: Ou: Vilariño de Conso, Pradoalbar, margen derecho del Val do Figueiro (637/4671); 3: Ou: Vilariño de Conso, Pradoalbar, 0 Figueiro (636/4671); 4: Ou: Vilariño de Conso, Pradoalbar, margen izquierdo del Val do Figueiro (637/4668); 5: Ou: Vilariño de Conso, Pradoalbar, margen derecho del Val do Figueiro (637/4670); 6: Ou: Vilariño de Conso, Pradoalbar, margen izquierdo del Val do Figueiro (636/4671); 7: Ou: Vilariño de Conso, Pradoalbar, margen derecho del Val do Río de Casarello, aguas arriba de la Mallada dos Castiñeiros (634/4671); 8: columna sintética a partir de Castroviejo (1977); 9: Ou: Vilariño de Conso, Pradoalbar, margen izquierdo del Val do Río de Casarello, a la altura de la Mallada dos Castiñeiros (635/4670); 10: Ou: Vilariño de Conso, Pradoalbar, margen derecho del Val do Río de Casarello, a la altura de la Mallada dos Castiñeiros (634/4670); 11: Ou: Vilariño de Conso, Pradoalbar, Val do Río de Casarello, aguas arriba de la Mallada dos Castiñeiros (634/4671); 12: Ou: Vilariño de Conso, Castiñeira (649/4671); 13: Ou: Vilariño de Conso, entre Castiñeira y Chaguazoso (648/4672); 14: Ou: Vilariño de Conso, Chaguazoso (647/4672); 15: Columna sintética a partir de Castroviejo (1977) 
Tabla 2.- Bosques mixtos (inv. 1) y acebedas (inv. 2 y 3 )

\begin{tabular}{lccc}
\hline $\mathbf{N}^{0}$ de orden & $\mathbf{1}$ & $\mathbf{2}$ & $\mathbf{3}$ \\
\hline Altitud $(\mathbf{m})$ & 1.075 & 1.245 & 1.320 \\
Pendiente $\left({ }^{\circ}\right)$ & 32 & 38 & 36 \\
Orientación & $\mathrm{E}$ & $\mathrm{NE}$ & $\mathrm{S}$ \\
Alt. sup. copas $(\mathrm{m})$ & $15-25$ & $12-24$ & $15-20$ \\
Cob. $\mathrm{E}_{1}(\%)$ & 100 & 95 & 95 \\
Cob. $\mathrm{E}_{2}(\%)$ & 20 & 30 & 10 \\
Cob. $\mathrm{E}_{3}(\%)$ & 60 & 50 & 50 \\
Área $\left(\mathrm{m}^{2}\right):$ & 500 & 300 & 250 \\
$\mathrm{~N}^{0}$ taxones & 41 & $\mathbf{2 6}$ & $\mathbf{3 3}$ \\
\hline
\end{tabular}

\begin{tabular}{lccc}
\hline $\mathbf{N}^{0}$ de orden & $\mathbf{1}$ & $\mathbf{2}$ & $\mathbf{3}$ \\
\hline Luzula sylvatica & + & + & + \\
Vaccinium myrtillus & $\cdot$ & 3 & 2 \\
Blechnum spicant & $\cdot$ & 1 & + \\
Oxalis acetosella & $\cdot$ & + & 1 \\
Holcus mollis & + & $\cdot$ & $\cdot$ \\
Saxifraga spathularis & $\cdot$ & 1 & $\cdot$ \\
Arenaria montana & $\cdot$ & + & $\cdot$ \\
Avenella flexuosa & $\cdot$ & + & $\cdot$ \\
Ceratocapnos claviculata & $\cdot$ & + & $\cdot$ \\
Teucrium scorodonia & $\cdot$ & $\cdot$ & +
\end{tabular}

$\mathrm{E}_{1}(>4,0 \mathrm{~m})+\mathrm{E}_{2}(>1,5-4,0 \mathrm{~m})$

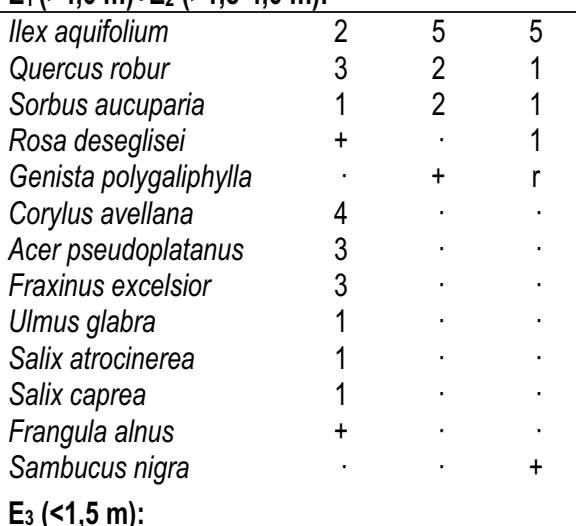

Taxones característicos de Fagetalia sylvaticae

Sanicula europaea $++\quad+\quad 1$

Melica uniflora

Primula acaulis

Poa nemoralis

Mycelis muralis

Veronica montana

Polystichum aculeatum

Moehringia trinervia

Taxones característicos de Quercetalia roboris

$\begin{array}{llll}\text { Galium rotundifolium } & 1 & + & 1 \\ \text { Hedera hibernica } & + & + & 1 \\ \text { Viola riviniana } & + & + & 1 \\ \text { Lonicera hispanica } & + & + & +\end{array}$

Taxones característicos de Querco-Fagetea

$\begin{array}{lccc}\text { Dryopteris dilatata } & + & 1 & + \\ \text { Polystichum setiferum } & 3 & . & 2 \\ \text { Hyacinthoides non-scripta } & 1 & 1 & . \\ \text { Stellaria holostea } & 1 & \cdot & + \\ \text { Dryopteris affinis } & + & + & . \\ \text { Dioscorea vulgaris } & 1 & . & . \\ \text { Anemone nemorosa } & 1 & . & . \\ \text { Melittis melissophylum } & 1 & . & . \\ \text { Crepis lampsanoides } & . & + & . \\ \text { Dryopteris borreri } & . & . & + \\ \text { Polypodium vulgare } & . & \text { r } & \text {. } \\ \text { Otros taxones } & & & \end{array}$

Polypodium vulgare

Otros taxones

Geranium robertianum $2+\infty$

Pteridium aquilinum $\quad+\quad 2 \quad 1$

Rubus lucensis $\quad+\quad+\quad 1$

Pentaglottis sempervirens $+\quad \cdot \quad 1$

Galium aparine $\quad+\quad \cdot \quad+$

Urtica dioica

Geranium lucidum

Lamium maculatum

Omphalodes nitida

Umbilicus rupestris

Vicia sepium

Carex asturica

Digitalis purpurea

Ranunculus repens

Scrophularia herminii

Localidades (ETRS89, huso 29T, utm 1x1 km): 1: Ou: Vilariño de Conso, Pradoalbar, margen derecha del Val do Figueiro (637/4669); 2: Ou: Vilariño de Conso, Pradoalbar, valle del Río de Casarello, margen derecha de la Corga dos Salgueiros, aguas arriba de la Mallada dos Castiñeiros (634/4671); 3: Ou: Vilariño de Conso, Pradoalbar, O Figueiro (636/4671) 
Tabla 3.- Bosques higrófilos

1-5: Valeriano officinalis-Betuletum pubescentis; 6-7: Galio broteriani-Alnetum glutinosae;

8: abedular higro-turfófilo

\begin{tabular}{|c|c|c|c|c|c|c|c|c|}
\hline $\mathrm{N}^{0}$ de orden & 1 & 2 & 3 & 4 & 5 & 6 & 7 & 8 \\
\hline Altitud (m) & 1225 & 1185 & 925 & 1060 & 1250 & 885 & 885 & 1230 \\
\hline Pendiente $\left({ }^{\circ}\right)$ & 6 & 8 & 10 & 6 & 30 & 4 & 6 & 18 \\
\hline Orientación & SSE & SSE & SE & SSW & $\mathrm{N}$ & SE & ESE & ESE \\
\hline Altura $E_{1}(m)$ & $10-18$ & $12-15$ & $10-20$ & $10-20$ & --- & 12 & $14-18$ & $12-20$ \\
\hline Cobertura $E_{1}^{\prime}(>4,0 \mathrm{~m})(\%)$ & 80 & 95 & 90 & 100 & 90 & 100 & 90 & 90 \\
\hline Cobertura $E_{2}(1,5-4,0 \mathrm{~m})(\%)$ & 30 & 10 & 15 & 10 & --- & 30 & 15 & 20 \\
\hline Cobertura $E_{3}(<1,5 \mathrm{~m})(\%)$ & 80 & 80 & 90 & 90 & --- & 95 & 95 & 75 \\
\hline Area $\left(m^{2}\right)$ & 320 & 200 & 300 & 600 & 400 & 400 & 300 & 300 \\
\hline $\mathrm{N}^{0}$ de táxones & 45 & 45 & 45 & 45 & 48 & 71 & 55 & 32 \\
\hline \multicolumn{9}{|l|}{$E_{1}(>4,0 \mathrm{~m})+E_{2}(>1,5-4,0 \mathrm{~m}):$} \\
\hline Betula pubescens & 3 & 3 & 3 & 3 & 4 & 1 & 2 & 4 \\
\hline Sorbus aucuparia & 3 & 3 & + & 1 & 2 & 1 & 1 & 2 \\
\hline Salix atrocinerea & 1 & 2 & 4 & 3 & . & 1 & . & 1 \\
\hline Ilex aquifolium & 3 & 2 & $\cdot$ & 1 & 3 & 1 & $\cdot$ & 2 \\
\hline Quercus robur & 1 & + & $\cdot$ & 1 & $\cdot$ & 1 & + & 1 \\
\hline Acer pseudoplatanus & $\cdot$ & 3 & 1 & 3 & $\cdot$ & 1 & + & $\cdot$ \\
\hline Genista polygaliphylla & $\cdot$ & . & 1 & + & 1 & 1 & 1 & $\cdot$ \\
\hline Erica arborea & + & . & 1 & . & 2 & 1 & . & . \\
\hline Corylus avellana & $\cdot$ & 2 & $\cdot$ & 3 & $\cdot$ & + & $\cdot$ & $\cdot$ \\
\hline Frangula alnus & $\cdot$ & 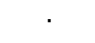 & 2 & $\cdot$ & $\cdot$ & 2 & 2 & $\cdot$ \\
\hline Alnus glutinosa & $\cdot$ & . & . & . & . & 5 & 5 & . \\
\hline \multicolumn{9}{|c|}{$\begin{array}{l}E_{3}(<1,5 \mathrm{~m}): \\
\text { Características de Salici-Populetea }\end{array}$} \\
\hline Athyrium filix-femina & 2 & 1 & 2 & 2 & + & 1 & 2 & 2 \\
\hline Carex reuteriana & 2 & . & 3 & . & . & 2 & 2 & . \\
\hline Galium broterianum & . & . & 2 & . & $r$ & 2 & 1 & . \\
\hline Polystichum setiferum & . & 2 & $\cdot$ & 1 & $\cdot$ & 1 & . & + \\
\hline Carex remota & + & & $\cdot$ & · & $\cdot$ & $\cdot$ & $\cdot$ & 2 \\
\hline \multicolumn{9}{|c|}{ Características de Querco-Fagetea } \\
\hline Luzula sylvatica & 4 & 3 & 3 & 4 & 2 & 2 & 4 & 2 \\
\hline Vaccinium myrtillus & 2 & + & 1 & + & 1 & + & 1 & 2 \\
\hline Blechnum spicant & 2 & 1 & + & . & 2 & + & + & 2 \\
\hline Euphorbia dulcis & 1 & $\cdot$ & 1 & + & + & 2 & 1 & + \\
\hline Primula acaulis & 1 & + & 1 & 1 & . & 2 & 1 & 1 \\
\hline Hedera hibernica & 1 & 1 & + & 1 & $\cdot$ & + & 1 & 1 \\
\hline Poa nemoralis & + & 1 & 1 & 1 & + & 1 & 1 & $\cdot$ \\
\hline Crepis lampsanoides & 1 & + & 1 & $\cdot$ & $r$ & 1 & 1 & $\cdot$ \\
\hline Anemone nemorosa & 2 & . & $\cdot$ & 1 & $r$ & 1 & 1 & 1 \\
\hline Viola riviniana & . & + & + & + & $r$ & + & + & . \\
\hline Aquilegia vulgaris & 1 & $\cdot$ & + & + & $\cdot$ & + & + & . \\
\hline Dryopteris affinis & $\cdot$ & 1 & $\cdot$ & + & $r$ & + & + & 2 \\
\hline Sanicula europaea & + & 1 & . & 1 & + & $\cdot$ & $\cdot$ & + \\
\hline Saxifraga spathularis & 1 & 1 & + & + & 1 & . & 1 & . \\
\hline Teucrium scorodonia & . & + & + & + & $\cdot$ & 1 & + & $\cdot$ \\
\hline Euphorbia amygdaloides & . & . & + & + & . & + & 1 & . \\
\hline Galium rotundifolium & + & 1 & . & + & r & . & . & . \\
\hline Hieracium cf. umbellatum & 1 & . & 1 & + & . & + & + & . \\
\hline Holcus mollis & . & 1 & . & + & 1 & . & + & + \\
\hline Lonicera hispanica & + & 1 & $\cdot$ & $\cdot$ & $r$ & $\cdot$ & . & + \\
\hline Oxalis acetosella & 1 & 2 & . & 1 & . & . & 1 & 2 \\
\hline Euphorbia hyberna & 1 & . & . & + & . & $\cdot$ & + & + \\
\hline Melittis melissophyllum & + & . & . & . & . & + & + & . \\
\hline Dryopteris dilatata & . & 1 & . & . & + & $\cdot$ & . & + \\
\hline Physospermum cornubiense & . & . & + & $\cdot$ & $\cdot$ & 1 & + & . \\
\hline Lathyrus linifolius & $\cdot$ & . & + & . & . & + & + & . \\
\hline Polypodium vulgare & + & + & . & + & . & $\cdot$ & . & . \\
\hline Veronica montana & $\cdot$ & + & . & + & $\cdot$ & $\cdot$ & $\cdot$ & + \\
\hline Milium effusum & . & 1 & . & 1 & . & . & . & . \\
\hline
\end{tabular}




\begin{tabular}{|c|c|c|c|c|c|c|c|c|}
\hline$N^{0}$ de orden & 1 & 2 & 3 & 4 & 5 & 6 & 7 & 8 \\
\hline Ajuga reptans & $\cdot$ & $\cdot$ & 1 & $\cdot$ & $\cdot$ & $\cdot$ & 1 & $\cdot$ \\
\hline Dryopteris borreri & + & . & $\cdot$ & . & . & + & . & . \\
\hline Stellaria holostea & $\cdot$ & + & · & · & $r$ & $\cdot$ & $\cdot$ & $\cdot$ \\
\hline \multicolumn{9}{|l|}{ Otros taxones } \\
\hline Omphalodes nitida & 1 & + & 1 & + & $r$ & 1 & 1 & + \\
\hline Ranunculus repens & + & 1 & + & + & $r$ & + & + & 1 \\
\hline Vicia sepium & 1 & + & 1 & 1 & . & . & + & . \\
\hline Dactylis izcoi & + & 1 & . & $\cdot$ & 1 & 1 & + & . \\
\hline Allium victorialis & 3 & $\cdot$ & . & . & 1 & 2 & 3 & . \\
\hline Viola palustris & 1 & . & 1 & . & . & 1 & 2 & . \\
\hline Rubus lucensis & 1 & + & + & + & . & . & $\cdot$ & . \\
\hline Prunella grandiflora & + & $\cdot$ & + & . & . & + & + & . \\
\hline Brachypodium rupestre & $\cdot$ & . & 1 & . & . & 2 & 1 & . \\
\hline Centaurea rivularis & . & $\cdot$ & 2 & $\cdot$ & . & 1 & 1 & . \\
\hline Heracleum sphondylium & $\cdot$ & 1 & . & + & . & 1 & . & . \\
\hline Festuca gr. rubra & + & $\cdot$ & . & . & 2 & + & . & . \\
\hline Galium papillosum & $\cdot$ & $\cdot$ & + & $\cdot$ & $\cdot$ & 1 & + & . \\
\hline Angelica laevis & . & + & . & + & . & + & $\cdot$ & . \\
\hline Silene dioica & . & + & . & + & . & + & . & . \\
\hline Festuca merinoi & . & $\cdot$ & + & . & . & + & + & . \\
\hline Potentilla erecta & . & $\cdot$ & + & . & . & $\cdot$ & + & + \\
\hline Linaria triornithophora & $\cdot$ & . & $\cdot$ & . & r & + & + & . \\
\hline Pteridium aquilinum & 1 & . & . & . & 2 & $\cdot$ & $\cdot$ & . \\
\hline Oenanthe crocata & . & . & 2 & . & . & . & 1 & . \\
\hline Deschampsia subtriflora & . & . & + & $\cdot$ & . & $\cdot$ & 2 & . \\
\hline Cruciata glabra & 1 & $\cdot$ & . & . & . & + & $\cdot$ & . \\
\hline Geranium robertianum & $\cdot$ & 1 & . & . & . & $\cdot$ & . & + \\
\hline Festuca gr. heterophylla & . & $\cdot$ & + & . & . & . & 1 & . \\
\hline Anemone albida & . & . & . & . & . & + & 1 & . \\
\hline Urtica dioica & . & + & . & + & . & . & . & . \\
\hline Pentaglotis sempervirens & $\cdot$ & $\cdot$ & + & + & $\cdot$ & $\cdot$ & $\cdot$ & . \\
\hline Prunella vulgaris & $\cdot$ & $\cdot$ & + & $\cdot$ & . & $\cdot$ & $\cdot$ & + \\
\hline Cirsium palustre & $\cdot$ & $\cdot$ & . & . & + & + & $\cdot$ & . \\
\hline Taraxacum sp. & $\cdot$ & . & r & . & . & + & $\cdot$ & . \\
\hline Anthoxanthum amarum & $\cdot$ & $\cdot$ & . & $\cdot$ & r & + & $\cdot$ & . \\
\hline Carex echinata & . & . & . & . & r & $\cdot$ & . & + \\
\hline Juncus effusus & . & . & . & . & $r$ & . & . & + \\
\hline
\end{tabular}

Taxones de baja frecuencia: $\mathrm{E}_{1}+\mathrm{E}_{2}$ : Fraxinus angustifolia: 1 en 6; Fraxinus excelsior: 2 en 4; Pyrus cordata: + en 7; Quercus pyrenaica: 1 en 5; Rosa corymbifera: 1 en 1; Rosa deseglissei: + en 7; Salix caprea: 1 en 4; Sambucus nigra: + en 4. Taxones característicos de Salici-Populetea: Allium scorzonerifolium: 1 en 6; Ranunculus ficaria: + en 2. Taxones característicos de Querco-Fagetea: Conopodium pyrenaeum: + en 6; Dyopteris filix-mas: + en 5; Eryngium juressianum: + en 6; Hieracium cf. murorum: 1 en 6; Hyacinthoides non-scripta: 1 en 1; Hypericum androsaemum: + en 7; Hypericum pulchrum: + en 6; Lilium martagon: + en 5; Melica uniflora: 1 en 2; Poa chaixii: 1 en 1; Polystichum aculeatum: + en 2; Veronica officinalis: r en 5. Otros taxones: Agrostis capillaris: 2 en 5; Anthoxanthum odoratum: + en 3; Arrhenatherum bulbosum: + en 6; Asphodelus macrocarpus: + en 6; Calamagrostis arundinacea: 2 en 6; Caltha palustris: + en 1; Cardamine flexuosa: + en 4; Carex laevigata: + en 8; Carex leporina: $r$ en 5; Chrysosplenium oppositifolium: 1 en 8; Clinopodium vulgare: + en 2; Dactylorhiza maculata: + en 1; Digitalis purpurea: + en 5; Epilobium sp.: + en 7; Galium helodes: r en 5; Luzula campestris: r en 5; Myosotis stolonifera: + en 7; Myosotis sp.: r en 5; Narcissus bulbocodium: 1 en 6; Picris hieraciodes: $r$ en 5; Polytrichum sp.: r en 5; Pyrola minor: + en 1; Ranunculus platanifolius: + en 6; Rumex acetosa: r en 7; Micranthes lepismigena: + en 6; Solidago virgaurea: + en 6; Sphagnum sp.: r en 5; Stellaria aff. graminea: + en 6; Stellaria alsine: r en 5; Umbilicus rupestris: r en 2; Vicia orobus: + en 6

Localidades (ETRS89, huso 29T, utm 1x1 km): 1: Ou: Vilariño de Conso, Pradoalbar, Río de Casarello, aguas debajo de la Mallada dos Castiñeiros (635/4670); 2: Ou: Vilariño de Conso, Pradoalbar, Val do Figueiro, Río de Augasenza (637/4670); 3: Ou: Vilariño de Conso, Edrada, Ribeira Pequena, aguas arriba de la confluencia con el Corgo das Rubias (637/4664); 4: Ou: Vilariño de Conso, Pradoalbar, Val do Figueiro, Río de Augasenza (637/4669); 5: Ou: Vilariño de Conso, Pradoalbar, Corga da Escada de Abaixo (636/4666); 6: Ou: Vilariño de Conso, Edrada, Ribeira Grande, aguas abajo del puente de las Casetas da Ribeira Grande (640/4664); 7: Ou: Vilariño de Conso, Edrada, Ribeira Pequena, aguas abajo de la confluencia con el Corgo das Rubias (639/4663); 8: Ou: Vilariño de Conso, Pradoalbar, ladera de la margen derecha del Río de Casarello, aguas abajo de la Mallada dos Castiñeiros (635/4670) 
Tabla 4.- Comunidad de cambrional

Festuco graniticolae-Echinospartetum pulviniformis

\begin{tabular}{lc}
\hline $\mathbf{N}^{0}$ de orden & $\mathbf{1}$ \\
\hline Altitud (m) & 1.360 \\
Pendiente ( $\left.{ }^{\circ}\right)$ & 0 \\
Cobertura (\%) & 20 \\
Área $\left(\mathbf{m}^{2}\right)$ & 9 \\
$\mathbf{N}^{0}$ de taxones & 12 \\
\hline Echinospartum ibericum & 3 \\
Polytrichum sp. & 3 \\
Cladonia sp. & 2 \\
Agrostis truncatula & 1 \\
Festuca summilusitana & 1 \\
Micropyrum tenellum & 1 \\
Sedum brevifolium & 1 \\
Spergula morisonii & + \\
Dianthus langeanus & $\mathrm{r}$ \\
Sedum hirsutum & $\mathrm{r}$ \\
Teesdalia nudicaulis & $\mathrm{r}$ \\
\hline
\end{tabular}

Localidad (ETRS89, huso 29T, utm 1x1 km): Ou: Vilariño de Conso, Chaguazoso, Embalse de Cenza. Plataforma superior de domo granítico con grietas $(641 / 4674)$

Tabla 5.- Comunidad de Arenaria querioides y Sesamoides minor sobre suelos llanos crioturbados

\begin{tabular}{|c|c|c|}
\hline $\mathrm{N}^{0}$ de orden & 1 & 2 \\
\hline Altitud (m) & 1.575 & 1.541 \\
\hline Pendiente $\left({ }^{\circ}\right)$ & $<5$ & $<5$ \\
\hline Cobertura (\%) & 50 & 30 \\
\hline Área $\left(m^{2}\right)$ & 5 & 6 \\
\hline $\mathrm{N}^{0}$ de taxones & 10 & 11 \\
\hline Arenaria querioides & 3 & 2 \\
\hline Sedum brevifolium & 1 & 2 \\
\hline Plantago radicata & 2 & + \\
\hline Helictochloa marginata & + & 1 \\
\hline Pterospartum lasianthum & + & + \\
\hline Rumex bucephalophorus & + & + \\
\hline Luzula lactea & 1 & \\
\hline Avenella iberica & 1 & \\
\hline Sesamoides minor & . & 1 \\
\hline Agrostis truncatula & . & 1 \\
\hline Filago minima & + & . \\
\hline Dianthus langeanus & + & . \\
\hline Ornithogalum concinnum & . & + \\
\hline Jurinea humilis & . & + \\
\hline Narcissus sp. & . & + \\
\hline \multicolumn{3}{|c|}{$\begin{array}{l}\text { Localidades: 1: Ou: Chandrexa de Queixa } \\
\text { Requeixo, Altos das Veigas Covas, cresta } \\
\text { pizarrosa (637/4671); 2: Ou: Laza. Camba, rellanc } \\
\text { crioturbado al lado de cresta de pizarras } \\
\text { verticales, entre los picos Cazcallal y Cabeza da } \\
\text { Veiga do Fial (633/4667) }\end{array}$} \\
\hline
\end{tabular}


Tabla 6.- Comunidad herbácea de laderas crioturbadas Teesdaliopsio confertae-Festucetum summilusitanae

\begin{tabular}{lc}
\hline $\mathbf{N}^{0}$ de orden & $\mathbf{1}$ \\
\hline Altitud (m) & 1.613 \\
Inclinación $\left(^{\circ}\right)$ & 60 \\
Orientación & $\mathrm{NE}$ \\
Cobertura (\%) & 40 \\
Area (m²) & 4 \\
$\mathbf{N}^{0}$ de taxones & 10 \\
\hline Agrostis truncatula & 2 \\
Sedum brevifolium & 2 \\
Helictochloa marginata & 1 \\
Dianthus langeanus & 1 \\
Festuca summilusitana & 1 \\
Teesdaliopsis conferta & 1 \\
Sedum anglicum & + \\
Phalacrocarpum oppossitifolium & $\mathrm{r}$ \\
\hline
\end{tabular}

Localidad: Ou: Chandrexa de Queixa, Requeixo, A Mallada Fría, rellano en roquedo de esquistos (636/4673)

Tabla 7.- Cervunales

\begin{tabular}{lcc}
\hline $\mathbf{N}^{0}$ de orden & $\mathbf{1}$ & $\mathbf{2}$ \\
\hline Altitud (m) & 1.540 & 1.550 \\
Inclinación ( $\left.{ }^{\circ}\right)$ & $<5$ & 0 \\
Cobertura (\%) & 98 & 100 \\
Area (m²) & 100 & 150 \\
$\mathbf{N}^{0}$ de taxones & 16 & 16 \\
\hline Nardus stricta & 4 & 4 \\
Juncus squarrosus & 4 & 3 \\
Carex pilulifera & 4 & 1 \\
Festuca nigrescens & 3 & 4 \\
Galium saxatile & 3 & 2 \\
Veronica gr. officinalis & 2 & 2 \\
Lotus aff. uliginosus & 2 & 2 \\
Pilosella capillata & 1 & 1 \\
Stellaria alsine & 1 & + \\
Calluna vulgaris & 1 & + \\
Narcissus sp. & 1 & + \\
Avenella flexuosa & 1 & + \\
Jasione laevis & + & + \\
Campanula herminii & $\cdot$ & 2 \\
Leontodon hispidus &. & 2 \\
Genista anglica & + & $\cdot$ \\
Polygala serpyllifolia & + & $\cdot$ \\
Viola lactea & + & $\cdot$ \\
Ranunculus bulbosus & $\cdot$ & + \\
\hline
\end{tabular}

Localidades: 1: Ou: Vilariño de Conso, Pradoalbar, Altos das Veigas Covas (638/4671). 2: Ou: Vilariño de Conso, Pradoalbar, depresión na divisoria entre Altos das Veigas Covas e o Corgo da Cenza de Val de Figuero (637/4671) 
Tabla 8.- Comunidad casmofítica de Silene acutifolia

\begin{tabular}{lc}
\hline $\mathbf{N}^{0}$ de orden & $\mathbf{1}$ \\
\hline Altitud $(\mathbf{m})$ & 1.055 \\
Pendiente $\left({ }^{\circ}\right)$ & 90 \\
Orientación & $\mathrm{N}$ \\
$\mathbf{N}^{0}$ de taxones & 110 \\
\hline Silene acutifolia & 2 \\
Sedum hirsutum & 1 \\
Sedum brevifolium & 1 \\
Ranunculus nigrescens & 1 \\
Umbilicus rupestris & 1 \\
Saxifraga spathularis & + \\
Phalacrocarpum oppositifolium & + \\
Rumex acetosella & $\mathrm{r}$ \\
Narcissus triandrus & $\mathrm{r}$ \\
Micranthes lepismigena & $\mathrm{r}$ \\
\hline
\end{tabular}

Localidad: Ou: Vilariño de Conso, Pradoalbar, valle de la Corga de Aguacenza (637/4669) 